\title{
Advances in hole transport materials engineering for stable and efficient perovskite solar cells
}

\author{
Zinab H. Bakr ${ }^{\mathrm{a}, \mathrm{b}, 1}$, Qamar Wali ${ }^{\mathrm{a}}$, Azhar Fakharuddin ${ }^{\mathrm{c}, \mathrm{d}, *}$, Lukas Schmidt-Mende ${ }^{\mathrm{c}}$, Thomas \\ M. Brown ${ }^{\mathrm{e}}$, Rajan Jose ${ }^{\mathrm{a}, *}$ \\ a Nanostructured Renewable Energy Materials Laboratory, Faculty of Industrial Science \& Technology, Universiti Malaysia Pahang, Kuantan, Malaysia \\ b Physics Department, Faculty of Science, Assiut University, Assiut, Egypt \\ ${ }^{c}$ Department of Physics, University of Konstanz, D-78457, Konstanz, Germany \\ a Nanosciences and Technology Department, National Center for Physics, Quaid-i-Azam University, Islamabad, Pakistan \\ e CHOSE (Centre for Hybrid and Organic Solar Energy), Department of Electronic Engineering, University of Rome Tor Vergata, via del Politecnico 1, Rome \\ 00133, Italy
}

\section{A R T I C L E I N F O}

Keywords:

Renewable energy

Charge transfer

Stability of perovskite solar cells

Open circuit voltage

\begin{abstract}
A B S T R A C T
This article reviews the various hole transporting materials (HTMs) used in perovskite solar cells (PSCs) in achieving high photo conversion efficiency (PCE) and operational stability. The PSCs are the latest development in solution processable solar cells offering PCE ( 22\%) on a par with that of practically deployed silicon and thin film solar cells. HTMs and electron transporting materials (ETMs) are important constituents in PSCs as they selectively transport charges within the device, influence photovoltaic parameters, determine device stability and also influence its cost. This article critically approaches role of structure, electrochemistry, and physical properties of varied of choice of HTMs categorized diversely as small and long polymers, organometallic, and inorganic on the photovoltaic parameters of PSCs conceived in various device configurations. Achievements in tailoring the properties of HTMs to best fit for PSCs are detailed; a well designed HTM suppresses carrier recombination by facilitating the passage of holes but blocking electrons at the HTM/perovskite interface. Moreover, in many PSCs the HTM acts as the first line of defense to external degrading factors such as humidity, oxygen and photon dose, the extent of which depends on its hydrophobicity, permeability, and density.
\end{abstract}

\section{Introduction}

Organic inorganic halide perovskites have attracted worldwide attention due to their impressive electrical and optical properties leading to remarkable performance in solar cells and light emitting devices [ 15$]$. These materials can be represented by a general formula $\mathrm{ABX}_{3}$, where $\mathrm{A}$ is an organic methylammonium $\left(\mathrm{CH}_{3} \mathrm{NH}_{3}\right)$ ion [6] or formamidinium $\left(\mathrm{NH}=\mathrm{CHNH}_{3}\right)$ ion [7 9], $\mathrm{B}$ is $\mathrm{Pb}, \mathrm{Sn}, \mathrm{Cs}$, or $\mathrm{Cd}$ ion, and $\mathrm{X}$ can be a halogen ion, $\mathrm{I}, \mathrm{Br}$, or $\mathrm{Cl}$ [10]. The remarkable performance of these perovskites in solar cells is attributed to their broad light absorption throughout the visible and near infrared spectrum, low exciton binding energy $(\sim 2 \mathrm{meV})$, and direct band gap [11]. In addition to high absorption coefficients, these materials demonstrated (i) long carrier lifetime $(\sim 270 \mathrm{~ns})$ resulting in diffusion lengths of few microns $(\sim 1 \mu \mathrm{m}$ in its thin films [12] and up to $\sim 175 \mu \mathrm{m}$ in single crystals [13]) so that the carriers can be transported safely across a $300 \mathrm{~nm}$ thick perovskite absorber without recombination
[12,14 17], (ii) high dielectric constant $\left(\begin{array}{ll}\sim 18 & 70\end{array}\right)$ [11,18], and (iii) high charge carrier mobility $\left(\sim 102320 \mathrm{~cm}^{2} \mathrm{~V}^{-1} \mathrm{~s}^{-1}\right)[16,19]$ thereby making them ideal photovoltaic materials $[16,18,20]$. Owing to these unique characteristics, a certified power conversion efficiency (PCE) of $22.1 \%$ is reported so far [21,22].

Fig. 1 gives a broad overview of the various configurations of PSCs. In a typical device, PSCs employ a thin perovskite absorber layer $(\sim 300 \mathrm{~nm})$ between an electron transport layer (ETL) and a HTM. Based on whether electrons or holes are collected at the bottom conducting substrate (usually a transparent conducting oxide, TCO), the PSCs are classified as $\mathrm{n}$ i p or $\mathrm{p}$ i $\mathrm{n}$ device, respectively. The former is also often termed as conventional and the latter as inverted architectures in the literature, depending on whether an ETL or HTM is deposited over the TCO (Fig. 1). The n i p architecture can be further divided into (i) mesoporous PSC, employing a metal oxide semiconductor (MOS) layer ( 200 $600 \mathrm{~nm}$ thick) as ETL with an additional $n$ type compact layer (CL) over it [4], (ii) meso super

\footnotetext{
* Corresponding author at: Department of Physics, University of Konstanz, D-78457 Konstanz, Germany.

E-mail addresses: azhar-fakharuddin@uni-konstanz.de (A. Fakharuddin), rjose@ump.edu.my (R. Jose).

${ }^{1}$ Currently on leave from Assiut University.
} 


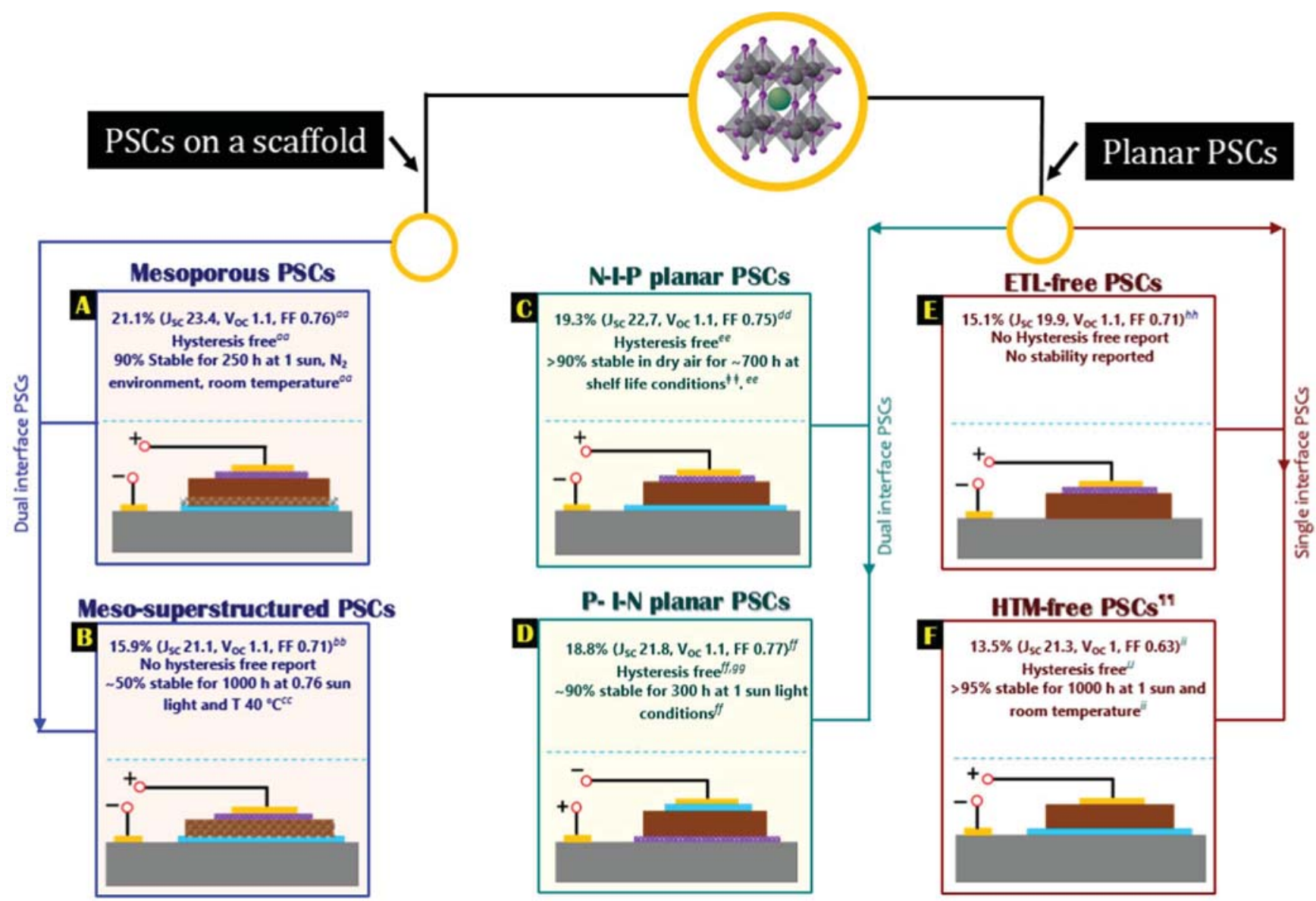

Fig. 1. The various common device designs employed for PSCs. The designs employ both ETL and HTM (a, c, and d), an insulating scaffold that replaces conducting ETL (b), and PSCs that employ only one of the two selective contacts, such as ETL-free (e) and HTM-free (f). Figures (c and d) refer to conventional (n-i-p) and inverted (p-i-n) architectures that represents if the electron or holes are to be collected at the conducting substrate, respectively. Figure adapted with permission from Ref. [32]. Copy right of AIP Publishing.

structured PSCs, employing an insulating scaffold $\left(\mathrm{Al}_{2} \mathrm{O}_{3}\right.$ or $\left.\mathrm{ZrO}_{2}\right)$ which does not take part in charge collection [23,24], (iii) planar devices without a mesoporous layer but employ only a CL (thickness < $50 \mathrm{~nm}$ ) [25], (iv) ETL free PSCs where the perovskite layer is deposited directly over the surface modified FTO [26,27], and (v) HTM free PSCs which do not employ an HTM [28]. In architectures (i) and (ii), the ETL may take part in charge collection, whereas in architectures (iii) and (iv), the perovskite works as an absorber as well as the only electron transporter. A particular type of $\mathrm{n} \mathrm{i} \mathrm{p}$ architecture without a back contact is the monolithic one consisting of a compact layer and a triple stack of screen printed mesoporous ETL, a mesoporous spacer and a $\sim 1015 \mu \mathrm{m}$ thick conductive carbon layer, all of which are subse quently infiltrated with the perovskite [29]. Alternatively, in p i n devices, holes are collected at the TCO and electrons at the metal back contact. This architecture could also be mesoporous (vi) or a planar (vii) depending on whether the $\mathrm{p}$ type layer is a mesoporous or compact only $[30,31]$.

The HTM serves various purposes in PSCs: (i) it is a physical/ energetic barrier between anode and perovskite layer that blocks the electron transfer to anode [33], (ii) it improves the hole transfer efficiency [34], (iii) influences the open voltage circuit $\left(\mathrm{V}_{\mathrm{OC}}\right)$ by determining the splitting of the quasi Fermi energy levels of the perovskite [35 38], as will be discussed in detail in Section 3.2 and (iv) avoids the degradation at the metal $(\mathrm{Au})$ perovskite interface which would take place in the absence of a HTM $[39,40]$. In fact, screening of suitable HTMs and a perovskite led to a $\mathrm{V}_{\mathrm{OC}}$ as high as $1.5 \quad 1.61 \mathrm{~V}$ in PSCs $[41,42]$. Similarly, the presence of an HTM layer has shown to improve surface coverage compared to that of a perovskite layer only
[43] (Fig. 2) and consequently suppress charge recombination by fully separating the top contact from the bottom transport or contact layers leading to improved performance. Apart from benefits on the PCE, the choice of HTM has shown to increase the stability of PSCs. For example, $\mathrm{NiO}_{\mathrm{x}}$ as an inorganic HTM layer in inverted PSCs not only showed a PCE $>16 \%$ but also $90 \%$ stable performance for over 60 days of storage in air [44]. Similarly, the champion HTM in inverted PSCs, 3,4 ethylenedioxythiophene): poly(styrene sulfonic) acid (PEDOT: PSS), is humidity sensitive and also known to cause degradation at conducting substrates due to its acidic nature. Removal of PEDOT: PSS with inorganic counterparts have shown remarkably stable perfor mance in PSCs. Furthermore, when it comes to commercialization of PSCs, their manufacturing cost will play a significant role [45]. Currently, HTM is arguably the most expensive material component in PSCs (see Table 1 for cost comparison of various common HTMs).

Inspired from the crucial role that the HTM plays in improving the device performance as well as in the stability of PSCs, this review aims to provide in depth analysis of various HTMs employed so far. We first define selection criteria to choose an efficient HTM (Section 2) and then explain its role towards charge extraction at the HTM perovskite interface and also in determining the photovoltaic (PV) parameters in PSCs (Section 3). We then detail the wide range of HTMs employed such as organic (small molecules and polymers) and inorganic HTMs in Section 4 and discuss their performance in PSCs. The influence of the HTM on the stability of PSCs is outlined in Section 5 of this manu script. Finally, we conclude our observations and provide an outlook to developing highly stable and efficient PSCs. 

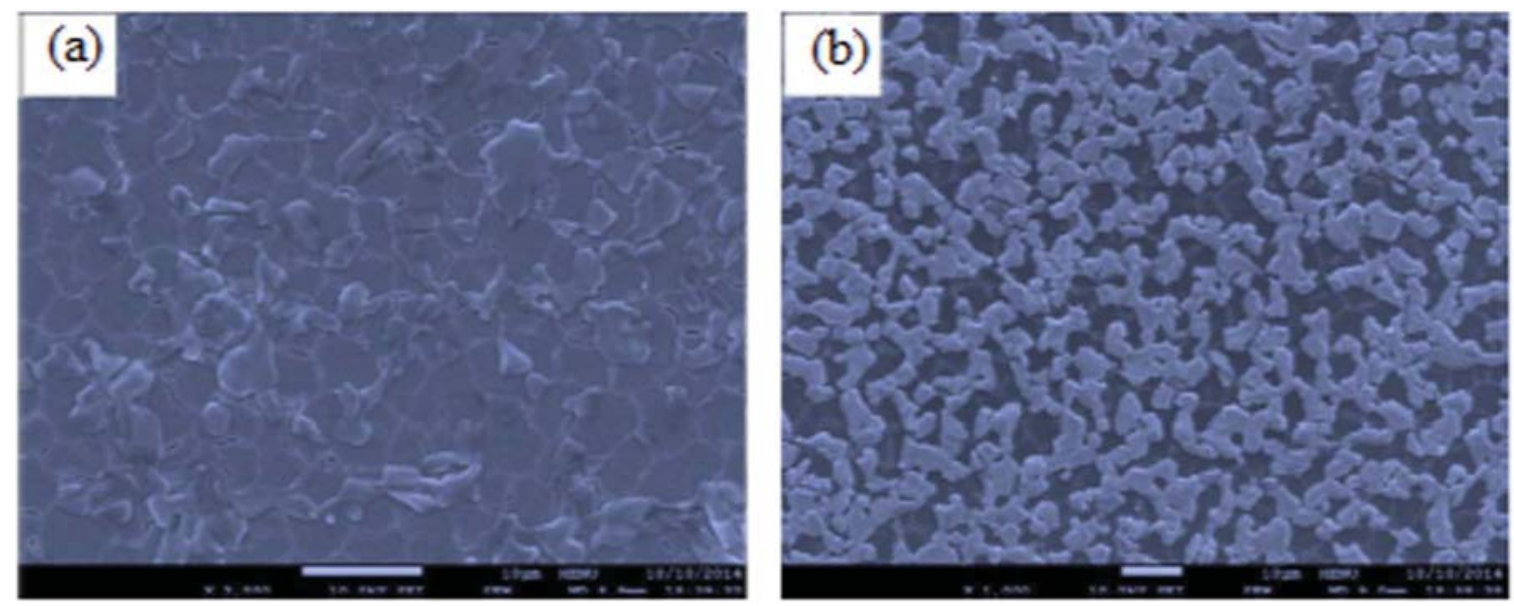

Fig. 2. Top view of $\mathrm{CH}_{3} \mathrm{NH}_{3} \mathrm{PbI}_{3}{ }_{x} \mathrm{Cl}_{x}$ film with (a) and without (b) poly(3-hexylthiophene) P3HT. Figure reproduced with permission from Ref. [43]. Copy right of Elsevier.

\section{Selection criteria for hole transport materials in PSCs}

The photovoltaic process in PSCs, similar to any other PV technol ogy, takes place in two steps: light absorption by an absorber material (the perovskite in PSCs) followed by selective charge collection at the respective contacts. Towards the latter, the HTM is one important active material in PSCs as it enables efficient hole extraction at the perovskite HTM interface. For efficient device operation, it should offer (i) high hole mobility to reduce losses during hole transport to the hole collecting contact, (ii) compatible ionization potential with that of the perovskite (i.e. highest occupied molecular orbital (HOMO) or valance band maximum (VB) almost matching that of the perovskite absorber so as to minimize injection losses), (iii) high thermal stability and resistance to external degradation factors such as moisture and oxygen for a long term durable PV operation, and (iv) low cost. Furthermore, a low electron affinity will also endow the HTM with beneficial electron blocking properties.

The mobility of the HTM has a significant bearing on the efficiency of the solar cell. Firstly, low mobilities lead to significant Ohmic losses across the HTM lowering the fill factor (FF). A recent computational study [46] shows that the FF improves by a wide margin (from $22 \%$ to $80 \%$ when the mobility changes from $10^{-6}$ to $10^{-4} \mathrm{~cm}^{2} / \mathrm{V} \mathrm{s}$ ). The short circuit photocurrent $\left(\mathrm{J}_{\mathrm{SC}}\right)$ is also strongly affected (improving two fold $\mathrm{w}$ an order of magnitude change in mobility). Thus it is important to utilize HTMs which are as thin as possible (guaranteeing uniform coverage) as well as with high mobilities.

HTMs employed in PSCs can be categorized as inorganic (NiO, $\mathrm{CuSCN}, \mathrm{CuI}, \mathrm{Cu}_{\mathrm{x}} \mathrm{O}$, and Graphene oxide (GO)) or organic (Table 1). The organic HTMs can further be divided into three types as (i) small molecules such as $\left(2,2^{\prime}, 7,7^{\prime}\right.$ tetrakis(N,N di $p$ methoxyphenyla mine) 9,9' spirobifluorene) Spiro OMeTAD, DOR3T TBDT, and Fused $\mathrm{F}$ etc. (Please refer to supplementary material for the chemical name of all HTM materials) or (ii) polymers such as P3HT, PEDOT: PSS and poly(triarylamine) PTAA $[47,48]$ or (iii) Oligomers such as S197 (full name not given). The Energy level diagram of common HTMs and their alignment with perovskite absorbers is shown in Fig. 3.

\section{Hole transporting materials and photovoltaic parameters in PSCs}

\subsection{Charge transport/transfer at HTM perouskite interface}

Although initially the role of perovskite was conceived to be only an absorber layer, the subsequent reports on its ambipolar charge trans

Table 1

An account of various common hole transporting materials in perovskite solar cells.

\begin{tabular}{|c|c|c|c|c|c|c|c|c|c|}
\hline HTM & $\begin{array}{l}\text { Hole mobility } \\
\left(\mathrm{cm}^{2} V^{1} s^{1}\right)\end{array}$ & $\begin{array}{l}\text { Cost } / g \\
(\$)\end{array}$ & Perovskite material & $\begin{array}{l}\text { Perovskite } \\
\text { deposition }\end{array}$ & Device structure & Dopants & PCE & $\mathbf{V}_{\mathbf{O C}}$ & Ref. \\
\hline $\begin{array}{l}\text { Spiro- } \\
\text { OMeTAD }\end{array}$ & $10^{3} 10^{4}[49,50]$, & $500[22]$ & $\mathrm{CH}_{3} \mathrm{NH}_{3} \mathrm{PbI}_{3}$ & OSSD & Mesoscopic & Li-TFSI, TBP & 19.71 & 1.08 & [51] \\
\hline FDT & & $60[22]$ & $\mathrm{FAPbI}_{3} / \mathrm{MAPbBr}_{3}$ & OSSD & Mesoscopic & $\begin{array}{l}\text { Li-TFSI, TBP, } \\
\text { FK209 }\end{array}$ & $20.2 \%$ & 1.14 & {$[22]$} \\
\hline P3HT & $<0.1$ [52], & $400 \quad 450^{*}$ & $\mathrm{CH}_{3} \mathrm{NH}_{3} \mathrm{PbI}_{3}$ & OSSD & $\begin{array}{l}\text { meso- } \\
\text { superstructured }\end{array}$ & $\begin{array}{l}\text { Li-TFSI, TBP, } \\
\text { PMMA }\end{array}$ & 15.3 & 1.02 & [53] \\
\hline PTAA & $10^{2} 10^{3}[2]$, & $\begin{array}{l}2500 \\
3000\end{array}$ & $\left(\mathrm{FAPbI}_{3}\right)_{1 \mathrm{x}}\left(\mathrm{MAPbBr}_{3}\right)_{\mathrm{x}}$ & TSSD & Mesoscopic & Li-TFSI, TBP, & 20.2 & 1.06 & [54] \\
\hline PEDOT: PSS & $10^{2} 10^{3}[55]$, & $200250^{*}$ & $\mathrm{CH}_{3} \mathrm{NH}_{3} \mathrm{PbI}_{3}$ & OSSD & Inverted planar & Li-TFSI, TBP & 18.1 & 1.1 & {$[56]$} \\
\hline CuI & $9.3[57]$, & $1015^{*}$ & $\mathrm{CH}_{3} \mathrm{NH}_{3} \mathrm{PbI}_{3}$ & GSC & Inverted planar & & 13.58 & 1.04 & {$[58]$} \\
\hline CuSCN & 25 [59], & $25^{*}$ & $\mathrm{CH}_{3} \mathrm{NH}_{3} \mathrm{PbI}_{3}$ & OSSD & Inverted planar & & 16.6 & 1.00 & [60] \\
\hline NiO & $0.141[61]$ & $1015^{*}$ & $\mathrm{CH}_{3} \mathrm{NH}_{3} \mathrm{PbI}_{3}$ & SET & Inverted planar & & 17.3 & 1.06 & [62] \\
\hline $\mathrm{Cu}_{2} \mathrm{O}$ & $100[63]$, & $212.5^{*}$ & $\mathrm{CH}_{3} \mathrm{NH}_{3} \mathrm{PbI}_{3}$ & OSSD & Inverted planar & & 16.52 & 1.07 & [64] \\
\hline GO & & $150400^{*}$ & $\mathrm{CH}_{3} \mathrm{NH}_{3} \mathrm{PbI}_{3}$ & SD & Mesoscopic & & 15.1 & 1.04 & [65] \\
\hline
\end{tabular}

SD: Sequential deposition, OSSD: One step spin coating deposition, GSC: Gas solid crystallization process.

TSSD: Two step spin coating deposition, SET: solvent engineering technique, DSVD: Dual source vapor deposition.

FDT: 2,7-bis(4-methoxyphenyl)amino) spiro[cyclopenta [2,1-b:3,4-b]dithiophene-4,9-fluorene.

TBP: 4-tert-butylpyridine, Li-TFSI: lithium bis(trifluoromethylsulphonyl) imide.

FK209: Tris(2-(1H-pyrazol-1-yl)-4-tert-butylpyridine)-Tris(bis(trifluoromethylsulfonyl)imide).

PMMA: poly(methyl methacrylate).

" The price is taken from Sigma Aldrich website (https://www.sigmaaldrich.com/germany.html on September 2016). 


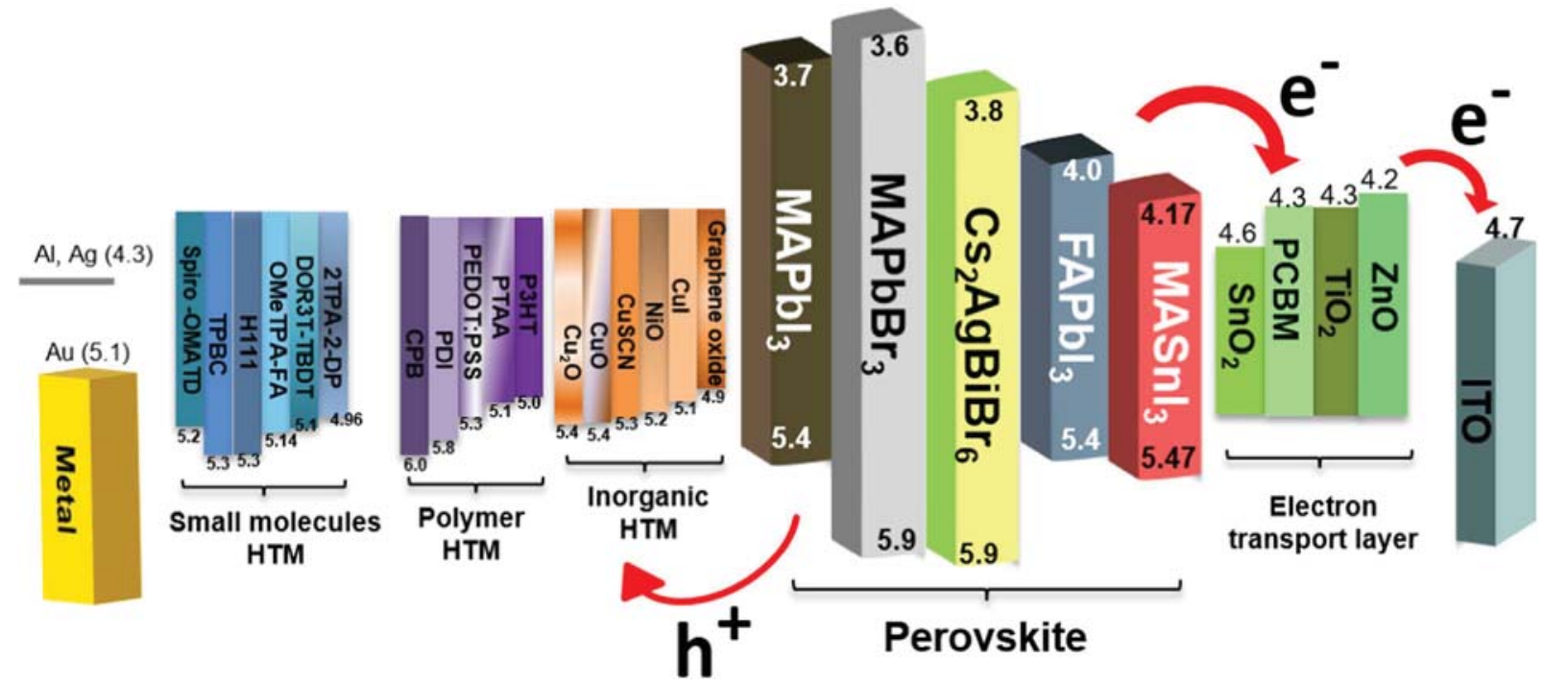

Fig. 3. Energy levels of various common HTMs together with iodide and bromide based halide-perovskites. It is important to note that the energy levels are those of isolated materials and that upon formation of the multilayer device, changes in the energy scheme and alignment may occur due to interfacial dipoles, band bending, trap states and impurities. The minus ( ) sign corresponding to the energy levels is omitted for simplicity. The Figure is drawn for free of scale for illustration only.

port characteristics showed that it carries both electrons and holes to their selective contacts [17]. An Electron Beam Induced Current (EBIC) analysis further showed $\mathrm{CH}_{3} \mathrm{NH}_{3} \mathrm{PbI}_{3}$ exhibiting a slightly more p type behaviour with a better hole extraction ability than electrons whereas the $\mathrm{CH}_{3} \mathrm{NH}_{3} \mathrm{PbI}_{3-\mathrm{x}} \mathrm{Cl}_{\mathrm{x}}$ shows characteristics similar to an intrinsic semiconductor [66]. This led to research in HTM free PSCs where a metal back contact was deposited directly on top of perovskite layer (PCE 10.85\%) [28,67]. It is important to note that the monilithic PSCs $[29,68,69]$ (employing a thick carbon layer as back contact with best PCE of 13.5\%) [70,71] although are often termed as HTM free PSCs are not in fact HTM free. This is due to the fact that carbon layer acts as a p type selective contact and has shown to improve charge extraction efficiency at the carbon perovskite interface $[72,73]$.

The crucial role of HTMs towards efficient charge extraction is also reported in literature $[74,75]$ where a notable difference in both charge recombination resistance $\left(R_{R E C}\right)$ and series resistance $\left(R_{S}\right)$ was ob served in devices with and without an HTM. Impedance spectroscopy investigations (Fig. 4a and b) of complete PSCs (in an EPH configura tion, employing both ETL and HTM, where E, P, and H represent ETL, perovskite and HTM layers, respectively) with those employing only one or no selective contact revealed that a device without HTM (labeled as EP) showed a larger $\mathrm{R}_{\mathrm{S}}$ compared to PSCs employing one (labeled as EPH). Similarly, a lower contact resistance $\left(\mathrm{R}_{\mathrm{CON}}\right)$ was also noted for EPH PSCs demonstrating that the presence of the HTM helps to form a smoother interface between the perovskite and the metal back contact. Furthermore, a lower $\mathrm{R}_{\mathrm{REC}}$ was observed in PSCs without an HTM (Fig. $4 c$ and d). As $R_{\text {REC }}$ is inversely proportional to recombination kinetics in the film $[76,77]$, it is evident that inclusion of HTM improves the charge collection characteristics of PSCs. However, one must note that a thicker HTM layer will also add to $R_{S}$ of the film which would reduce the fill factor (FF) of the device. For best performance, a compromise between the thickness and also compactness of HTM layer must be made. In general, the $\mathrm{R}_{\mathrm{REC}}$ for these devices showed the following trend: $\mathrm{EPH}>\mathrm{PH}>\mathrm{EP}>\mathrm{P}$. The lower recombination (or higher $\mathrm{R}_{\mathrm{REC}}$ ) in $\mathrm{PH}$ than $\mathrm{EP}$ can be understood from the better hole extraction ability of the perovskite film compared to its electron extraction ability [66].

Choice of selective contacts also affect the PV performance of the device. Whereas a device with both ETL and HTM selective contacts showed a PCE 9.1\%, PSCs employing either an ETL or HTM only showed a PCE of $1.8 \%$ and $5 \%$, respectively [75]. On the other hand, devices employing perovskite layer only (labeled as $\mathrm{P}$, without any selective contact) showed a PCE of only $0.1 \%$. This would also affirm that the PSCs require at least one of the selective contacts to be present to function. Also, interestingly, the $\mathrm{PH}$ devices showed a similar $\mathrm{V}_{\mathrm{OC}}$ $(0.95 \mathrm{~V})$ to that of EPH cells $(0.97 \mathrm{~V})$; however, the short circuit current density $\left(\mathrm{J}_{\mathrm{SC}}\right)$ and $\mathrm{FF}$ dropped significantly. The FF for $\mathrm{EPH}$, $\mathrm{PH}, \mathrm{EP}$ and P cells was $0.60,0.44,0.35$, and 0.25 , respectively, which can be correlated with the increasing $\mathrm{R}_{\mathrm{S}}$ upon removing the selective contacts.

An improved hole extraction efficiency at HTM/perovskite interface is directly reflected in improvement in PV performance, particularly, the $\mathrm{V}_{\mathrm{OC}}$ and the FF [78 81]. For example, Choi et al. [78] employed poly[2,6 (4,4 bis potassiumbutanylsulfonate $4 \mathrm{H}$ cyclopenta $[2,1 \mathrm{~b} ; 3$, $4 \mathrm{~b}^{\prime}$ ] dithiophene) alt 4,7 (2,1,3 benzothiadiazole)] (CPE K) in in verted planar PSCs and compared its performance with PEDOT: PSS. Whereas the steady state photoluminescence (PL) experiments showed that $71 \%$ and $99 \%$ of the photogenerated charges are quenched for PEDOT: PSS and CPE K, respectively, time resolved PL showed a carrier extraction time of 91 ns for glass/PEDOT: PSS/perovskite and $1.41 \mathrm{~ns}$ for glass/CPE K/perovskite. The improved charge extraction resulted in $\mathrm{FF} \sim 0.77$ (PCE 10.8\%) for CPE K, higher than a PEDOT: PSS alternative ( $\mathrm{FF} \sim 0.66, \mathrm{PCE} \sim 10.8 \%$ ), which is attributed to superior hole selectivity of the former.

\subsection{Hole transport materials and open circuit voltage in PSCs}

One of the remarkable feature of PSCs is their high output voltage; the $\mathrm{V}_{\mathrm{OC}}$ is $\sim 1.1 \mathrm{~V}$ and $\sim 1.61 \mathrm{~V}$ for $\mathrm{CH}_{3} \mathrm{NH}_{3} \mathrm{PbI}_{3}$ and $\mathrm{CH}_{3} \mathrm{NH}_{3} \mathrm{PbBr}_{3}$, respectively, which accounts for $\mathbf{E}_{G} \boldsymbol{q} \mathbf{V}_{\mathrm{OC}} \sim 0.45 \mathrm{~V}$ and $\sim 0.7 \mathrm{~V}$ respec tively (Table 2). It has been recently predicted, using Shockley Queisser limits, that theoretical maximum $\mathrm{V}_{\mathrm{OC}}$ for a perovskite material with bandgap $\sim 1.6 \mathrm{~V}$ is $1.33 \pm 0.02 \mathrm{~V}$ [82]. However, one must consider the fact that the practically obtainable $\mathrm{V}_{\mathrm{OC}}$ is always lower than its theoretical maximum, considering the losses during charge transport and transfer/collection. This is where selective contacts, particularly, play an important role. In PSCs, the $\mathrm{V}_{\mathrm{OC}}$ is significantly influenced by non radiative recombination which can be quantified by the emission yield (EQE) of electroluminescence (EL) spectra. The external electro luminescence yield $\left(\mathrm{EQE}_{\mathrm{EL}}\right)$ is higher if the charge injection from perovskite to an interfacing material is higher. In a recent work, Tress et al. [82] compared the $\mathrm{EQE}_{\mathrm{EL}}$ for PSCs with and without an HTM. Whereas the PSCs with HTM showed $\mathrm{EQE}_{\mathrm{EL}} \sim 10^{-5} 10^{-6}$ (labeled as $\mathrm{TiO}_{2}$ and $\mathrm{Al}_{2} \mathrm{O}_{3}$ in Fig. 5), the HTM free device showed an order of 

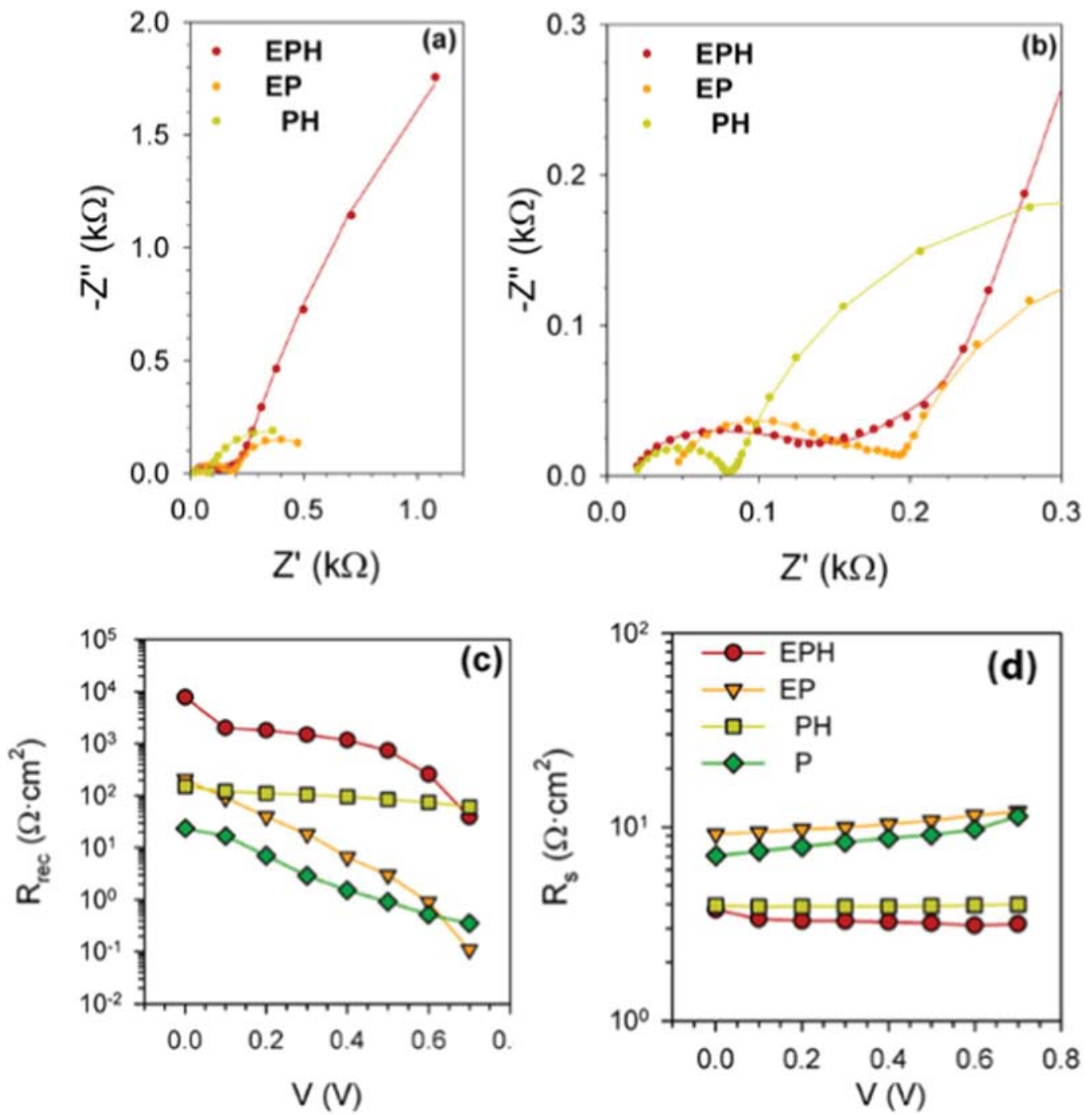

Fig. 4. (a and b): Nyquist plot of PSCs with and without selective contacts at DC bias of V=0.1 V under 1 sun illumination. Herein, EPH and EP show PSCs made with and with hole transport layer, PH shows PSCs with no electron-selective contact and P is a device without any selective contact (perovskite layer only). (a) Complete range and (b) zoom at highfrequency region, (c) Series resistance of the same devices and (d) recombination resistance, RREC obtained from impedance spectroscopy data. Figure are reproduced with permission from Ref. [75]. Copy right of American Chemical Society.

magnitude lower value. Although the authors of the study point out the intrinsic losses of perovskite film to be the primary limiting factor to the $\mathrm{V}_{\mathrm{OC}}$, a report by Chen et al. [35] suggest otherwise. They report that the $\mathrm{V}_{\mathrm{OC}}$ in PSCs is primarily limited by charge losses at the interfaces during extraction rather than the bulk losses within perovskite film. In their experiments employing $\mathrm{CH}_{3} \mathrm{NH}_{3} \mathrm{PbBr}_{3}$ as perovskite absorber, $\mathrm{V}_{\mathrm{OC}} \sim 1.5 \mathrm{~V}$ is obtained which is lower than the limiting $\mathrm{V}_{\mathrm{OC}}\left(\mathrm{V}_{\mathrm{OC}}, \operatorname{rad} \sim 1.95 \mathrm{~V}\right)$, i.e., $\Delta \mathrm{V}_{\mathrm{OC}} \sim 0.45 \mathrm{~V}$.

The above experiments make it hard to fully understand the origin of $\mathrm{V}_{\mathrm{OC}}$ in PSCs, however, the selective contacts, particularly HTMs, contribute significantly to it. For example, in an early report on PSCs that compares two different polymers HTMs, viz, P3HT and poly[N 9 hepta decanyl 2,7 carbazole alt 3,6 bis (thiophen 5 yl) 2,5 dioctyl 2,5 di hydropyrrolo[3,4 ]pyrrole 1,4 dione] (PCBTDPP) a difference of $\sim 0.66 \mathrm{~V}$ is observed in their $\mathrm{V}_{\mathrm{OC}}$ [83]. Whereas the P3HT based PSCs resulted in $\mathrm{V}_{\mathrm{OC}} \sim 0.5 \mathrm{~V}$, the latter resulted in $\sim 1.16 \mathrm{~V}$, in a similar device design. Various factors accounted for the observed large difference in the $\mathrm{V}_{\mathrm{OC}}$ : (i) the HOMO of PCBTDPP ( $5.4 \mathrm{eV}$ ) is deeper than P3HT ( $5.2 \mathrm{eV}$ ). This also makes the former have a smaller energy offset with the valance band maximum of the perovskite employed $\mathrm{CH}_{3} \mathrm{NH}_{3} \mathrm{PbBr}_{3}$ ( $5.38 \mathrm{eV}$ ) and a higher obtainable voltage. However, the HOMO level difference between the two polymers is only $\sim 0.2 \mathrm{eV}$ which is only one third of the difference in their $\mathrm{V}_{\mathrm{OC}}$. This brings into account other factors such as (ii) the different chemical structures of the two polymers, (iii) their different charge mobility (and conductivity of the polymer which would otherwise result in voltage drop), and (iv) light filtering effect. As shown in Fig. 6b, the PCBTDPP has carbazole groups that would interact different with perovskite. Also, the hole mobility of PCBTDPP is $\sim 0.02 \mathrm{~cm}^{2} \mathrm{~V}^{-1} \mathrm{~s}^{-1}$ which is $\sim 70$ times higher [84] than that of P3HT. Towards (iv), the P3HT overlaps absorbance of perovskite thereby creating a light filtering effect which could limit the PV parameters.

Table 2 list few examples where the HOMO level of HTM and the hole mobility made significant effect on the $\mathrm{V}_{\mathrm{OC}}$. A systematic increase in $\mathrm{V}_{\mathrm{OC}}$ is observed when HTMs with deeper HOMO levels are employed. For example, $\sim 0.45 \mathrm{~V}$ increase in $\mathrm{V}_{\mathrm{OC}}$ is observed when P3HT is replaced with PIF8 TAA (poly indenofl uoren 8 triarylamine). It is noteworthy that this increase is nearly equal to the energy level difference of the two HTMs. Interestingly, the energy level difference is not solely the vital factor. For example, in a comparative study, PSCs made using Phenyl $\mathrm{C}_{61}$ butyric acid methyl ester (PCBM) (HOMO $6.1 \mathrm{eV}$ ) showed $\sim 0.24 \mathrm{~V}$ lesser $\mathrm{V}_{\mathrm{OC}}$ than $\mathrm{N}, \mathrm{N}^{\prime}$ dialkyl perylenediimide (PDI) (HOMO $5.8 \mathrm{eV}$ ). This is because of the two orders of magnitude lower mobility of PCBM $\left(10^{-2} 10^{-3} \mathrm{~cm}^{2} \mathrm{~V}^{-1} \mathrm{~s}^{-1}\right)$ than PDI $\left(\sim 2.1 \mathrm{~cm}^{2} \mathrm{~V}^{-1} \mathrm{~s}^{-1}\right)$. Therefore, to obtain high $\mathrm{V}_{\mathrm{OC}}$ a high charge mobility as well as suitable energy level alignment are equally crucial. 
Table 2

A comparison of state-of-the-art open circuit voltage obtained using various halide perovskites in conjunction with a diverse range of electron and hole selective contacts. The Conduction band (CB) and $\mathrm{VB}$ edges for $\mathrm{MAPbI}_{3}$ and $\mathrm{MAPbBr}_{3}$ are ( $\left.3.9 / 5.4\right) \mathrm{eV}$ and ( 3.4/ 5.6) eV, respectively. Table is reproduced with permission from Ref. [32]. Copy right of AIP Publishing.

\begin{tabular}{|c|c|c|c|c|c|c|c|c|c|c|c|c|}
\hline $\mathrm{V}_{\mathrm{OC}}(\mathrm{V})$ & $\mathrm{J}_{\mathrm{SC}}\left(\mathrm{mA} \mathrm{cm}^{2}\right)$ & $\mathrm{FF}$ & PCE (\%) & ETL & Device architecture & HTM & $\begin{array}{l}\text { Band edges } \\
\text { (CB/ } \\
\text { HOMO) }\end{array}$ & $\begin{array}{l}\text { Hole mobility } \\
\left(\mathrm{cm}^{2} \mathrm{~V}^{1} \mathrm{~s}^{1}\right)\end{array}$ & Device & $\begin{array}{l}q \mathrm{~V}_{\mathrm{OC}} / \\
\mathrm{E}_{G}(\%)\end{array}$ & $\begin{array}{l}\mathrm{E}_{G^{-}} \\
q \mathrm{~V}_{\mathrm{OC}} \\
(\mathrm{eV})\end{array}$ & Reference \\
\hline 1.11 & 21.00 & 0.76 & 17.9 & $\mathrm{c}, \mathrm{m}-\mathrm{TiO}_{2}$ & $\begin{array}{l}\mathrm{Cs}_{\mathrm{x}}\left(\mathrm{MA}_{0.17}\right. \\
\left.\mathrm{FA}_{0.83}\right)_{(100 \mathrm{x})} \\
\mathrm{Pb}\left(\mathrm{I}_{0.83} \mathrm{Br}_{0.17}\right)_{3}\end{array}$ & $\begin{array}{l}\text { Spiro- } \\
\text { OMeTAD }\end{array}$ & $\begin{array}{l}4.4 \boldsymbol{m} /- \\
5.11 \Delta\end{array}$ & $10^{3} 10^{4}$ [49], & Mesoporous PSC & 72 & 0.44 & $\begin{array}{l}\text { Saliba et al } \\
{[85]}\end{array}$ \\
\hline 1.29 & 6.60 & 0.70 & 5.9 & $\mathrm{TiO}_{2}$ & $\mathrm{MAPbBr}_{3}$ & P-TAA & $5.14^{\wedge}$ & $>0.1[86]$ & Mesoporous PSC & 56 & 1.01 & $\begin{array}{l}\text { Ryu et al. } \\
{[87]}\end{array}$ \\
\hline 1.36 & 6.30 & 0.70 & 6.0 & $\mathrm{TiO}_{2}$ & $\mathrm{MAPbBr}_{3}$ & PF8-TAA & $5.44 \boldsymbol{\wedge}$ & $4 \times 10^{3}$ & & 59 & 0.94 & \\
\hline 1.40 & 6.10 & 0.79 & 6.7 & $\mathrm{TiO}_{2}$ & $\mathrm{MAPbBr}_{3}$ & PIF8-TAA & $5.51<$ & $4 \times 10^{2}$ & & 61 & 0.90 & \\
\hline 1.04 & 21.3 & 0.73 & 16.2 & $\mathrm{TiO}_{2}$ & $\mathrm{MAPbI}_{3}$ & P-TAA & $5.14 \wedge$ & $>0.1$ & & 67 & 0.51 & \\
\hline 0.92 & 8.90 & 0.56 & 4.6 & $\mathrm{TiO}_{2}$ & $\mathrm{MAPbI}_{3}$ & PF8-TAA & $5.44 \boldsymbol{\wedge}$ & $4 \times 10^{3}$ & & 59 & 0.63 & \\
\hline 1.04 & 19.0 & 0.46 & 9.1 & $\mathrm{TiO}_{2}$ & $\mathrm{MAPbI}_{3}$ & PIF8-TAA & $5.51 \wedge$ & $4 \times 10^{2}$ & & 67 & 0.51 & \\
\hline 1.09 & 8.5 & 0.79 & 7.3 & $\mathrm{TiO}_{2}$ & $\mathrm{MAPbBr}_{3}$ & P3HT & $5.0^{\wedge}$ & $>0.1[86]$ & Mesoporous PSC & 47 & 1.21 & $\begin{array}{l}\text { Heo et al. } \\
{[88]}\end{array}$ \\
\hline 1.35 & 8.4 & 0.82 & 9.3 & $\mathrm{TiO}_{2}$ & $\mathrm{MAPbBr}_{3}$ & P-TAA & $5.14 \wedge$ & $4 \times 10^{3}$ & & 59 & 0.95 & \\
\hline 1.51 & 8.4 & 0.82 & 10.4 & $\mathrm{TiO}_{2}$ & $\mathrm{MAPbBr}_{3}$ & PIF8-TAA & $5.51 \wedge$ & $4 \times 10^{2}$ & & 67 & 0.65 & \\
\hline 1.38 & 5.2 & 0.78 & 5.6 & PCBM & $\mathrm{MAPbBr}_{3}$ & $\begin{array}{l}\text { PEDOT: } \\
\text { PSS }\end{array}$ & $\begin{array}{l}3.9 \text { 四/ } \\
5.3 \Delta \boldsymbol{\Delta}\end{array}$ & & p-i-n inverted & 60 & 0.92 & $\begin{array}{l}\text { Wu et al. } \\
{[42]}\end{array}$ \\
\hline 1.61 & 6.04 & 0.77 & 7.5 & $\operatorname{ICBA}^{* \mathrm{a}}$ & $\mathrm{MAPbBr}_{3}$ & $\begin{array}{l}\text { PEDOT: } \\
\text { PSS }\end{array}$ & $\begin{array}{l}3.7 \cdot / \\
5.3 /\end{array}$ & & & 70 & 0.69 & $\begin{array}{l}\text { Wu et al. } \\
\text { [42] }\end{array}$ \\
\hline
\end{tabular}

"a ICBA: $1^{\prime}, 1^{\prime \prime}, 4^{\prime}, 4^{\prime \prime}$-tetrahydro-di $[1,4]$ methanonaphthaleno[1,2:2',3',56,60:2",3"] [5,6] fullerene-C60.

- For CB/conduction band edge of ETM and for HUMO of HTM.

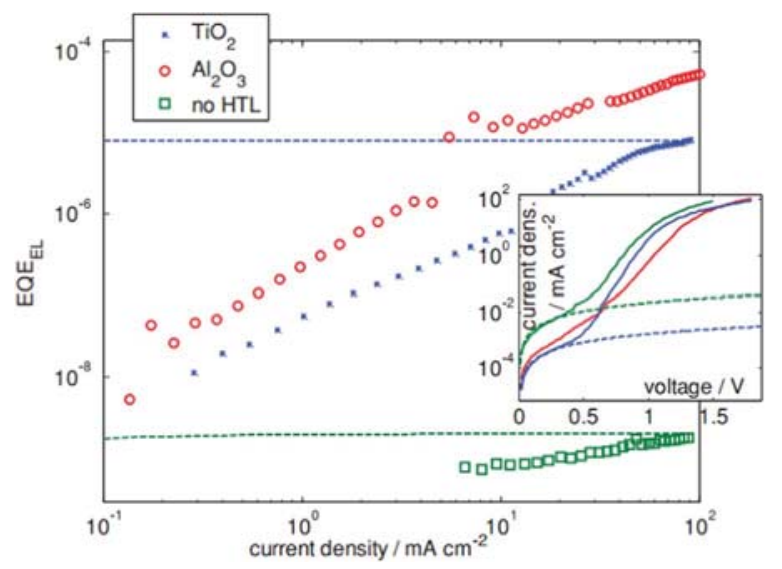

Fig. 5. External electroluminescence yield $\left(\boldsymbol{E} Q \boldsymbol{E}_{\boldsymbol{E L}}\right)$ as a function of the injection current. Dashed lines show the calculated EQE EL. The injection current as a function of applied voltage is shown in the inset (solid lines) including a fit to a shunt resistance (dashed), which is used to calculate the dashed lines in the main figure. Figure is reproduced with permission from Ref. [82]. Copyright of John Wiley and Sons.

\subsection{Buffer layers to reduce interfacial recombination at perovskite/ HTM interface}

The HTM/perovskite interface is one of the possible recombination centers within the device as the electrons photogenerated near the HTM layer, if not efficiently extracted, may recombine with holes in HTM. Furthermore, if the HTM layer is not compact, the electrons might reach the metal contact thereby creating short circuit in the device. This often results in low FF in the devices. Buffer layer (also called interfacial layer) of thickness of few nanometer are employed to reduce interfacial recombina tion $[89,90]$. For example, an ultrathin $\mathrm{Al}_{2} \mathrm{O}_{3}$ layer between perovskite and HTM improved the PCE from $15 \%\left(\mathrm{~J}_{\mathrm{SC}} 21.3 \mathrm{~mA} \mathrm{~cm}{ }^{-2}, \mathrm{~V}_{\mathrm{OC}} 1.03 \mathrm{~V}, \mathrm{FF}\right.$ $0.69)$ to $18 \%\left(\mathrm{~J}_{\mathrm{SC}} 21.7 \mathrm{~mA} \mathrm{~cm}^{-2}, \mathrm{~V}_{\mathrm{OC}} 1.08 \mathrm{~V}, \mathrm{FF} 0.77\right)$ [90]. The devices also showed significantly less hysteresis upon addition of the buffer layer. Herein, not only the $\mathrm{Al}_{2} \mathrm{O}_{3}$ layer reduced the back recombination at interface, but also passivated defects on perovskite surface, leading to an improved contact and eventually effective charge transfer. In another report, incorporation of graphene oxide thin layer between HTM and perovskite demonstrated PCE $18.2 \%\left(\mathrm{~J}_{\mathrm{SC}} 22.5 \mathrm{~mA} \mathrm{~cm}^{-2}, \mathrm{~V}_{\mathrm{OC}} 1.08 \mathrm{~V}, \mathrm{FF}\right.$
0.75), significantly higher than a reference device $\left(\mathrm{m} \mathrm{TiO}_{2} /\right.$ perovskite/ spiroOMeTAD) without buffer layer $\left(\mathrm{J}_{\mathrm{SC}} 20.9 \mathrm{~mA} \mathrm{~cm}^{-2}, \mathrm{~V}_{\mathrm{OC}} 1.03 \mathrm{~V}, \mathrm{FF}\right.$ 0.71 , PCE $15.3 \%$ ). The buffer layer passivated perovskite surface and facilitated more efficient hole extraction at perovskite/HTM interface. Other similar examples include Molybdenum isopropoxide resulting in better valance band alignment of spiroOMeTAD with perovksite and resulted in PCE enhancement from $10.8 \%$ to $12 \%$ [91].

\section{Hole Transporting materials in PSCs}

\subsection{Small molecules based hole transporting materials}

\subsubsection{Spiro OMeTAD}

Spiro OMeTAD (Fig. 6a) has been one of the most commonly used and successful HTMs in solid state dye sensitized solar cells ( $s$ DSSCs). However, the PCE in the state of the art s DSSCs employing Spiro OMeTAD as a HTM has been limited to $\sim 67.2 \%$ [92,93], which is far lower than the liquid electrolyte based counterparts $\sim 14.3 \%$ in DSSC [94]. This is primarily due to low hole mobility of pristine Spiro OMeTAD $\left(\sim 10^{-4} \mathrm{~cm}^{2} \mathrm{~V}^{-1} \mathrm{~s}^{-1}\right)$ and its incomplete pore filling in rela tively thick mesoporous $\mathrm{TiO}_{2}(\sim 13 \mu \mathrm{m}$ in s DSSCs which is much higher than the $\sim 300 \mathrm{~nm}$ thick $\mathrm{TiO}_{2}$ employed in PSCs) [95]. On the other hand, the first report of PSCs in 2009, that employed a device architecture similar to that of a liquid electrolyte DSSC, was marked by significant device degradation. The perovskite absorber $\left(\mathrm{CH}_{3} \mathrm{NH}_{3} \mathrm{PbI}_{3}\right)$ started to dissolve in the polar liquid electrolyte due to hygroscopic nature of the organic component (MAI) which led to rapid degradation of performance after $10 \mathrm{~min}$ at 1 sun illumination [3]. Park et al. replaced the liquid electrolyte with the solid state counterpart, spiroOMeTAD, which not only increased the stability of the device but remarkably increased the PCE up to $9.7 \%$ from the $\sim 3.9 \%$ of a liquid electrolyte analogue [4].

The low charge mobility and poor conductivity in pristine spiroOMeTAD arises from its inherent triangular pyramid configuration that leads to large intermolecular distances $[92,96]$. This results in inferior photovoltaic performance in PSCs due to high $\mathrm{R}_{\mathrm{S}}$ and low $\mathrm{R}_{\mathrm{REC}}$. Dopants such as lithium bis(trifluoromethylsulphonyl) imide (Li TFSI) and 4 tert butylpyridine (TBP) are added to suppress charge recombination as well as improve the contact between absorber and HTM [97]. These additives and Co (III) complexes have shown to enhance hole mobility of the 
spiroOMeTAD by an order of magnitude compared to the pure counterpart [98].

The spiroOMeTAD remains as one of the best performing HTMs in PSCs with PCEs as high as 19 20\% [51,99]. For example, Snaith and co workers reported PSCs employing a mixed halide perovskite $\left(\mathrm{CH}_{3} \mathrm{NH}_{3} \mathrm{PbI}_{3-\mathrm{x}} \mathrm{Cl}_{\mathrm{x}}\right)$ coated on a conducting scaffold of $\mathrm{Al}_{2} \mathrm{O}_{3}$ in conjunction with spiroOMeTAD and demonstrated a PCE of $\sim 10.9 \%$ [24]. Subsequent efforts to optimize the morphology of $\mathrm{CH}_{3} \mathrm{NH}_{3} \mathrm{PbI}_{3}$ on the $\mathrm{TiO}_{2}$ scaffold via a sequential deposition method coupled with spiroOMeTAD as HTM yielded a PCE 15\% [1]. The performance was further enhanced to $\sim 15.4 \%$ in a planar structure, employing a compact layer of $\mathrm{TiO}_{2}$ only, that allowed dense and pin hole free $\mathrm{CH}_{3} \mathrm{NH}_{3} \mathrm{PbI}_{3-x} \mathrm{Cl}_{x}$ deposition via dual source thermal evaporation [25]. A PCEs of $\sim 19.3 \%$ was obtained using $\mathrm{Li}$ and Co doped spiroOMeTAD as HTM in planar PSCs via interface optimizations to reduce energy offset at the various device interfaces [99]. A similar high performance (PCE of 1 19.7\%) was also reported for mesoporous PSCs where spiroOMeTAD was used in conjunction with the perovskite prepared via Lewis Base Adduct of Lead(II) Iodide [51]. Moreover, a

(a)<smiles>COc1ccc(N(c2ccc(OC)cc2)c2ccc3c4ccc(N(c5ccc(OC)cc5)c5ccc(OC)cc5)cc4c4cc(N(c5ccc(OC)cc5)c5ccc(OC)cc5)ccc4c3c2)cc1</smiles>

(b)<smiles>Brc1ccc(N(c2ccc(Br)cc2)c2ccc(Br)cc2)cc1</smiles><smiles>O=S(=O)(N([Al])S(=O)(=O)C(F)(F)F)C(F)(F)F</smiles>

(c)<smiles></smiles>

(e)

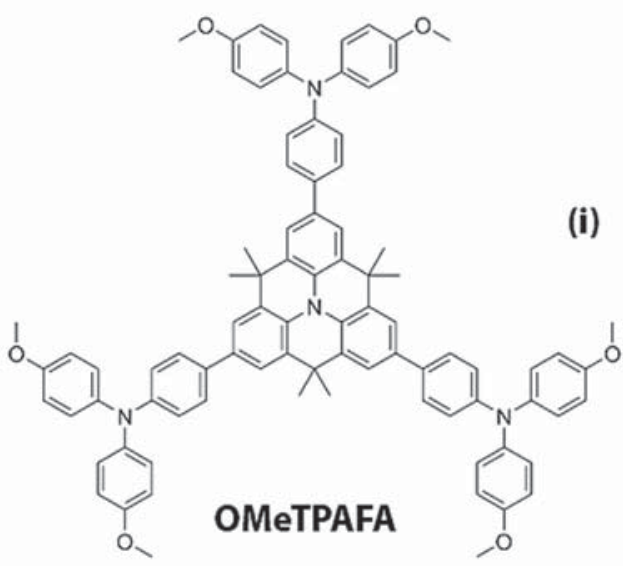

reproducible and hysteresis free PSC with PCE of $~ 20.5 \%$ (certified PCE 19.6\%) are also reported by Li et al. [100] prepared via vacuum flash solution processing method to obtain high electronic quality film over large area exceeding $\sim 1 \mathrm{~cm}^{2}$. This spiroOMeTAD based PSC also corresponds to one of the highest performing PSCs. Table 3 sum marizes high performing PSCs employing spiroOMeTAD as HTM.

\subsubsection{Role of dopants in spiroOMeTAD and its derivatives}

The role of OMe group in the spiroOMeTAD is to tune its electronic properties. Recently, Seok et al. [101] reported ortho substituted derivative in spiroOMeTAD and achieved a efficiency of $\sim 16.7 \%$ compared to $\sim 15.2 \%$ for conventional p OMe substituents. Similarly, Li et al. [102] employed three spiroacridine fluorene based HTMs and reported PCE $16.5 \%$ when tBP and Li TFSI are employed as dopant compared to $~ 14.3 \%$ for undoped spiroOMeTAD based device. A cost effective spiro type HTM 4,4', $4^{\prime \prime}, 4^{\prime \prime \prime}$ (2 H,2 H,4 H,4 H 3,3' spiro bi[thieno[3,4 b] [1,4]dioxepine] 6,6',8,8'te trayl)tetrakis(N, Nbis(4 methoxyphenyl)aniline) (PST1) was reported by Ganesan et al. [103] A PCE of $\sim 12.7 \%$ was achieved without Co as dopant ( $9.6 \%$ for Spiro OMeTAD based PSCs) which paves the way for develop

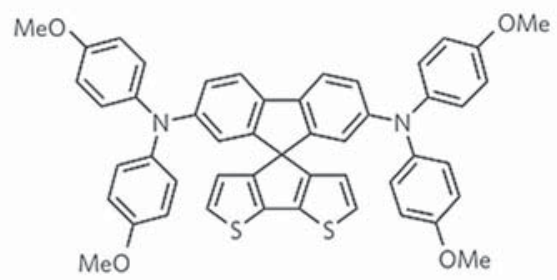

(g)<smiles>COc1ccc(N(c2ccc(OC)cc2)c2ccc(-c3sc(-c4ccc(N(c5ccc(OC)cc5)c5ccc(OC)cc5)cc4)c(-c4ccc(N(c5ccc(OC)cc5)c5ccc(OC)cc5)cc4)c3-c3ccc(N(c4ccc(OC)cc4)c4ccc(OC)cc4)cc3)cc2)cc1</smiles>

(h)

(d)<smiles>N#CC(C#N)=c1c(F)c(F)c(=C(C#N)C#N)c(F)c1F</smiles>

FK102

(f)

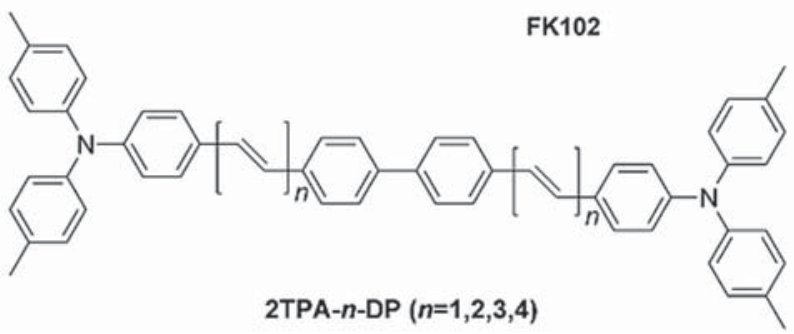

Fig. 6. (a): Chemical structures of most common small molecules based hole transport materials in perovskite solar cells. Chemical structures of the HTMs are reproduced with permission from references [47,48]. Copyright of John Wiley and Sons. (b): Chemical structures of most common polymers based hole transport materials in perovskite solar cells. Chemical structures of the HTMs are reproduced with permission from Refs. [47,48]. Copyright of John Wiley and Sons. 
(a)<smiles>CCCCCCc1cc(C)sc1-c1cc(CCCCCC)c(-c2cc(CCCCCC)c(-c3cc(CCCCCC)c(C(C)(C)C)s3)s2)s1</smiles>

(d)

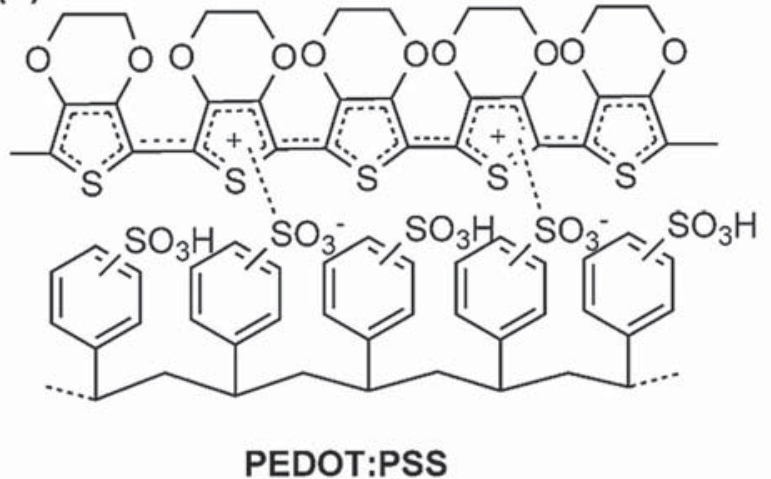<smiles>CN(C)c1ccc(Nc2ccc(Nc3ccc(N([14CH3])[14CH3])cc3)cc2)cc1</smiles>

(b)

PANI

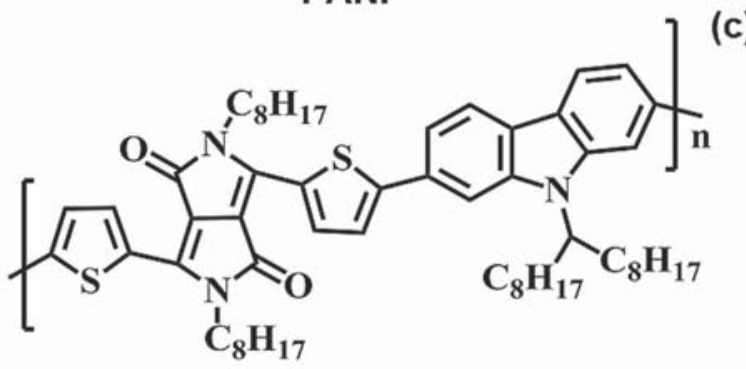

PCBTDPP<smiles>CCCCCCC1(CCCCC)c2cc(-c3ccc(N(c4ccc(C(C)(C)C)cc4)c4ccc(C(C)(C)C)cc4C)cc3)ccc2-c2ccc(C(C)(C)C)cc21</smiles>

(g) (f)

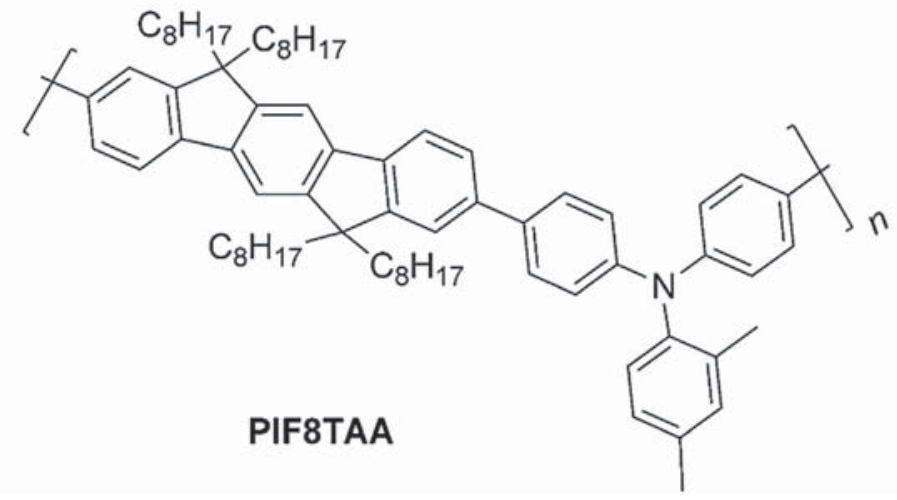

PF8TAA<smiles>Cc1ccc(N(c2ccc(C(C)(C)C)cc2)c2ccc(C(C)(C)C)cc2)c(C)c1</smiles>

PTAA

Fig. 6. (continued)

ing alternative hole transporting materials. The FDT is the most interesting deviation for Spiro OMeTAD which achieved the highest PCE 20.2\% whilst it can be prepared by one fifth of the costs of Spiro OMeTAD, and is environmentally friendly as it can be dissolved in toluene instead of chlorobenzene which is the typical solvent for spiroOMeTAD [22].

An important aspect while using Spiro OMeTAD as HTM is its interaction with atmosphere, particularly, when doped with Li TFSI dopant. Hwash et al. reported a [104] a decrease in conductivity in pristine Spiro MeOTAD films when exposed to humidity due to incorporation of gas molecules in the film films possibly leading to hole traps. The Sprio MeOTAD films were prepared by vacuum evaporation and do not contain the typically employed dopants (Li TFSI and tBP). A downward shift in Fermi energy level is also noted. A similar effect is noted for pentacene films when exposed to different gases $\left(\mathrm{N}_{2}, \mathrm{Ar}\right.$ and $\left.\mathrm{O}_{2}\right)$ demonstrating that gas molecules creep into the film via grain boundaries [105]. The authors reported a decrease in conductivity and downwards shift of Fermi level (closed to valance band) owing to a sharp rise in sub bandgap states density (from $\sim 10^{16}$ to $\sim 10^{18}$ states $\mathrm{eV}^{-1} \mathrm{~cm}^{-3}$ ). In the case of Li TFSI doped Spiro OMTAD, Zafer et al. [106] studied the redistribution of Li TFSI dopant across the spiroMeOTAD under controlled environmental conditions $\left(\mathrm{H}_{2} \mathrm{O}\right.$, $\mathrm{O}_{2}$ and ambient air) and demonstrated that the conductivity of spiroMeOTAD increased remarkably when exposed to humidity. However, an access humidity exposure leads to creation of pinholes in the film [107]. These pinholes could provide a channel to Li TFSI migration across the film (bottom to top) and facilitate diffusion of gas molecules from ambient air (e.g., $\mathrm{H}_{2} \mathrm{O}$ and $\mathrm{O}_{2}$ ) causing degradation. This would require incorporation of alternative dopants or dopant free HTM.

$\mathrm{Xu}$ et al. [108] introduced a silver based organic salt, silver bis(trifluoromethanesulfonyl) imide (Ag TFSI), as an effective dopant for Spiro OMeTAD and reported higher PV performance (PCE 12\% and $\mathrm{FF} \sim 0.62$ ) compared to a Li TFSI doped Spiro OMTAD rival (PCE 10.1\% and FF 0.55). Another interesting p dopant is a, tris[2 
Table 3

Photovoltaic parameters of several best performing PSCs using Spiro OMTAD as HTM and various dopants.

\begin{tabular}{|c|c|c|c|c|c|c|c|}
\hline \multirow[t]{2}{*}{ Device structure } & \multirow[t]{2}{*}{ Perovskite deposition method } & \multicolumn{4}{|c|}{ Photovoltaic parameters } & \multirow[t]{2}{*}{ Dopants } & \multirow[t]{2}{*}{ Ref. } \\
\hline & & $V_{\mathbf{O C}}(\mathrm{V})$ & $\mathrm{J}_{\mathrm{SC}}\left(\mathrm{mA} \mathrm{cm}^{2}\right)$ & $\mathbf{F F}$ & PCE (\%) & & \\
\hline \multicolumn{8}{|l|}{ Mesoporous PSCs } \\
\hline $\mathrm{CL} / \mathrm{mp} \mathrm{TiO}{ }_{2} / \mathrm{CH}_{3} \mathrm{NH}_{3} \mathrm{PbI}_{3} /$ Spiro/Au & OSSD & 0.88 & 17.6 & 0.62 & 9.7 & Li-TFSI, TBP & [4] \\
\hline $\mathrm{CL} / \mathrm{mp} \mathrm{TiO}{ }_{2} / \mathrm{CH}_{3} \mathrm{NH}_{3} \mathrm{PbI}_{3} /$ Spiro/Au & SD & 0.99 & 20 & 0.73 & 15 & Li-TFSI, FK209, TBP & [1] \\
\hline $\mathrm{CL}(\mathrm{ZnO}) / \mathrm{N}-\mathrm{ZnO} / \mathrm{CH}_{3} \mathrm{NH}_{3} \mathrm{PbI}_{3} / \mathrm{Spiro} / \mathrm{Ag}$ & SD & 0.96 & 21.3 & 0.7 & 16.05 & Not mention & {$[111]$} \\
\hline $\mathrm{CL} / \mathrm{mp} \mathrm{TiO} 2 / \mathrm{CH}_{3} \mathrm{NH}_{3} \mathrm{PbI}_{3} /$ Spiro/Au & TSSD & 1.05 & 21.64 & 0.74 & 17.01 & Li-TFSI, TBP & [112] \\
\hline $\mathrm{CL} / \mathrm{mp} \mathrm{TiO}{ }_{2} / \mathrm{CH}_{3} \mathrm{NH}_{3} \mathrm{PbI}_{3} /$ Spiro/Ag & OSSD & 1.08 & 23.83 & 0.76 & 19.71 & Li-TFSI, TBP & {$[51]$} \\
\hline $\mathrm{CL} / \mathrm{mp} \mathrm{TiO} 2 / \mathrm{FA}_{0.81} \mathrm{MA}_{0.15} \mathrm{PbI}_{2.51} \mathrm{Br}_{0.45} /$ Spiro/Au & VASP & 1.14 & 23.18 & 0.76 & 20.38 & Li-TFSI, TBP & {$[100]$} \\
\hline \multicolumn{8}{|l|}{ Planar PSCs } \\
\hline $\mathrm{CL} / \mathrm{CH}_{3} \mathrm{NH}_{3} \mathrm{PbI}_{3}{ }_{x} \mathrm{Cl}_{\mathrm{x}} /$ Spiro/Ag & DSVD & 1.07 & 21.5 & 0.67 & 15.4 & Li-TFSI, TBP & {$[25]$} \\
\hline $\mathrm{CL}-\mathrm{ZnO} / \mathrm{CH}_{3} \mathrm{NH}_{3} \mathrm{PbI}_{3} /$ Spiro/Ag & SD & 1.03 & 20.4 & 0.74 & 15.7 & Li-TFSI, TBP & {$[113]$} \\
\hline $\mathrm{CL}-\left(\mathrm{TiO}_{2} / \mathrm{ZnO}\right) / \mathrm{CH}_{3} \mathrm{NH}_{3} \mathrm{PbI}_{3} /$ Spiro $/ \mathrm{Au}^{*}$ & SET & 1.08 & 21.08 & 0.75 & 17.17 & not mention & {$[114]$} \\
\hline $\mathrm{SnO}_{2} / \mathrm{CH}_{3} \mathrm{NH}_{3} \mathrm{PbI}_{3} / \mathrm{Spiro} / \mathrm{Au}^{*}$ & SD & 1.11 & 23.27 & 0.67 & 17.21 & Li-TFSI, TBP & {$[115]$} \\
\hline $\mathrm{SnO}_{2} /(\mathrm{FAPbI} 3)_{0.85}\left(\mathrm{MAPbBr}_{3}\right)_{0.15} /$ Spiro/Au & SET & 1.13 & 21.2 & 0.75 & 18.1 & Li-TFSI, FK209, TBP & [116] \\
\hline $\mathrm{CL}\left(\mathrm{Y}-\mathrm{TiO}_{2}\right) / \mathrm{CH}_{3} \mathrm{NH}_{3} \mathrm{PbI}_{3}{ }_{x} \mathrm{Cl}_{x} /$ Spiro/Au & OSSD & 1.13 & 22.75 & 0.75 & 19.3 & Li-TFSI, FK209, TBP & [99] \\
\hline \multicolumn{8}{|l|}{ Meso-superstructured PSCs } \\
\hline $\mathrm{CL} / \mathrm{ZrO}_{2} / \mathrm{CH}_{3} \mathrm{NH}_{3} \mathrm{PbI}_{3} /$ Spiro/Ag & OSSD & 1.07 & 17.3 & 0.59 & 10.8 & Li-TFSI and TBP & {$[23]$} \\
\hline $\mathrm{CL} / \mathrm{SiO}_{2} / \mathrm{CH}_{3} \mathrm{NH}_{3} \mathrm{PbI}_{3} / \mathrm{Spiro} / \mathrm{Au}$ & OSSD & 1.05 & 16.4 & 0.66 & 11.45 & Li-TFSI and TBP & {$[117]$} \\
\hline $\mathrm{CL} / \mathrm{Al}_{2} \mathrm{O}_{3} / \mathrm{CH}_{3} \mathrm{NH}_{3} \mathrm{PbI}_{3}{ }_{x} \mathrm{Cl}_{x} /$ Spiro/Ag & OSSD & 1.02 & 21.5 & 0.71 & 15.9 & Li-TFSI and TBP & [118] \\
\hline
\end{tabular}

SVD: Sequential Vacuum Deposition.

Spiro=Spiro-OMeTAD.

${ }^{*} J-V$ data obtained at reverse bias, VASP: Vacuum flash solution processing.

(1H pyrazol yl)pyrimidine] cobalt(III) tris[bis (trifluoromethylsulfo nyl)imide] (MY11) which has the deepest redox potential among all cobalt based dopants used in solar cell applications [109]. In MY11, a pyrazolyl moiety is coupled with a pyrimidine moiety which is responsible to tune the redox potential of the dopant more positively. Koh et al. [109] reported MY11 as a new co dopant for Spiro OMTAD which increased the conductivity of pristine Spiro OMeTAD by two orders of magnitude, resulting in $\mathrm{PCE} \sim 11.9 \%, \mathrm{~V}_{\mathrm{OC}} \sim 1.0 \mathrm{~V}, \mathrm{FF} \sim 0.71$ compared to PCE 11\%, $\mathrm{V}_{\mathrm{OC}} \sim 0.96 \mathrm{~V}$ and $\mathrm{FF} \sim 0.68$ for FK102 doped Spiro OMTAD (FK102: Co dopant tris(2 (1H pyrazol 1 yl)pyridine) cobalt(III) tris(hexafluorophosphate)). Similarly, a new iridium com plex, where $\mathrm{Li}$ is replaced with $\operatorname{Ir}\left(\mathrm{IrCp}^{*} \mathrm{Cl}(\mathrm{PyPyz})[\mathrm{TFSI}]\right)$ by Badia et al. [110] demonstrated higher PCE and $\mathrm{V}_{\mathrm{OC}}(\sim 10.8 \%$ and $\sim 1.06 \mathrm{~V})$ than pristine Spiro OMeTAD (PCE $\left.\sim 9.2 \%, \mathrm{~V}_{\mathrm{OC}} \sim 1 \mathrm{~V}\right)$.

Despite the fact that Spiro OMeTAD demonstrated remarkable PCE 20\% in PSCs owing to a good pore filling of the $\mathrm{TiO}_{2}$ layer, it is characterized by low conductivity $\left(\sim 10^{-5} \mathrm{~S} \mathrm{~cm}^{-1}\right)$ [119] and a low hole mobility $\left(\sim 10^{-4} \mathrm{~cm}^{2} \mathrm{~V}^{-1} \mathrm{~s}^{-1}\right)$ in its pristine form. Although the dopants such as Li salt, TBP and Co (III) increased the transport properties of Spiro OMeTAD, they made Spiro OMeTAD sensitive to humidity, for example, Li TFSI which is extremely hygroscopic in nature acts as a humidity centre in HTM. This leads PSCs employing doped Spiro OMeTAD as HTM to degrade drastically when exposed to humid conditions. Moreover, currently, spiroOMeTAD is arguably one of the most expensive components in PSCs due to extensive synthetic processes involved in the preparation of the spirobifluorene core which might hamper the commercialization of PSCs. Alternative cost effective HTM materials are therefore extensively sought to overcome this issue.

\subsubsection{Alternative small molecule based hole transport materials to spiroOMeTAD}

In pursuit of cost effective and dopant free HTM materials, various research groups reported alternative small molecule based HTMs (listed in Table 4) which not only improved the PV parameters but also the stability of PSCs. Small molecules based HTMs can be mainly classified as: pyrenes derivatives [120], thiophenes derivatives [121], triazine derivatives [122] and porphyrins derivatives [123].

4.1.3.1. Pyrene derivatives. Pyrene core derivatives owing to its efficient charge transport capability are good candidate as HTM. Nam et al. [120] reported three HTMs based on pyrene core named as, 1 ( $N, N$ di $p$ methoxyphenylamine)pyrene (Py A), 1,3,6 tris $(N, N$ di $p$ methoxyphenylamine)pyrene (Py B), and 1,3,6,8 tetrakis (N,N di p methoxyphenylamine)pyrene (Py C), The HOMO levels of these HTMs were $5.41,5.25$, and $5.11 \mathrm{eV}$, respectively, close to that of spiroOMeTAD (5.22 eV). Py B, and Py C delivered efficiencies of $\sim 12.3$ and $\sim 12.4 \%$, respectively, comparable to that of spiroOMeTAD (12.7\%).

4.1.3.2. Thiophene derivatives. Typically, low glass transition temperature (Tg) and a small molecule size for HTM is preferred in PSCs as it facilitates easy processing of HTM (often at T $<100{ }^{\circ} \mathrm{C}$ ) and improved infiltration and pore filling. Hairong et al. [121] reported thiophene based HTM on 2,5 bis(4,4' bis(methoxyphenyl)aminophen 4" yl) 3,4 ethylenedioxythiophene (H101) for PSCs, which has $\mathrm{Tg}$ $\sim 73{ }^{\circ} \mathrm{C}$ which is lower than that of Spiro OMeTAD $\left(\mathrm{Tg} \sim 125^{\circ} \mathrm{C}\right)$. $\mathrm{H} 101$ also provides added features of low cost and easy processability than Spiro OMeTAD. A PCE $13.8 \%$ was reported for H101, which is slightly higher than Spiro OMeTAD based device ( 13.7\%). In another report, the same research group [124] developed two HTMs based on thiophene core, $\left(2,3,4,5\right.$ tetra[4,4' bis(methoxyphenyl)aminophen $4^{\prime \prime}$ yl] thiophene (H111) and 4,4',5,5' tetra[4,4' bis(methoxyphenyl) aminophen 4" yl] 2,2' bithiophene (H112). These HTMs showed superior air stability and higher solubility in common solvents compared to H101, and also deeper HOMO levels (H111 and H112 are 5.31 and $5.29 \mathrm{eV}$, respectively) than $\mathrm{H} 101(5.16 \mathrm{eV})$. This resulted improved PV performance, from $\sim 13.8 \%$ for $\mathrm{H} 101$ to $\sim 14.7 \%$ and 14.9\% for H112 and H111, respectively.

4.1.3.3. Triptycene derivatives. Triptycene core has similar twisted and bulky structure like Spiro OMeTAD which provides high thermal stability and a high solubility in common organic solvents [125]. Anurag et al. [126] reported HTMs employing triptycene derivatives such as 2,6,14 $\operatorname{Tri}(N, N$ bis(4 methoxyphenyl)amino) tripty cene (T101), 2,6,14 $\operatorname{Tri}(N, N$ bis(4 methoxyphenyl)amino phen 4 yl) triptycene (T102) and 2,6,14 $\operatorname{Tri}\left(5^{\prime}\right.$ ( $N, N$ bis(4 methoxyphenyl) 


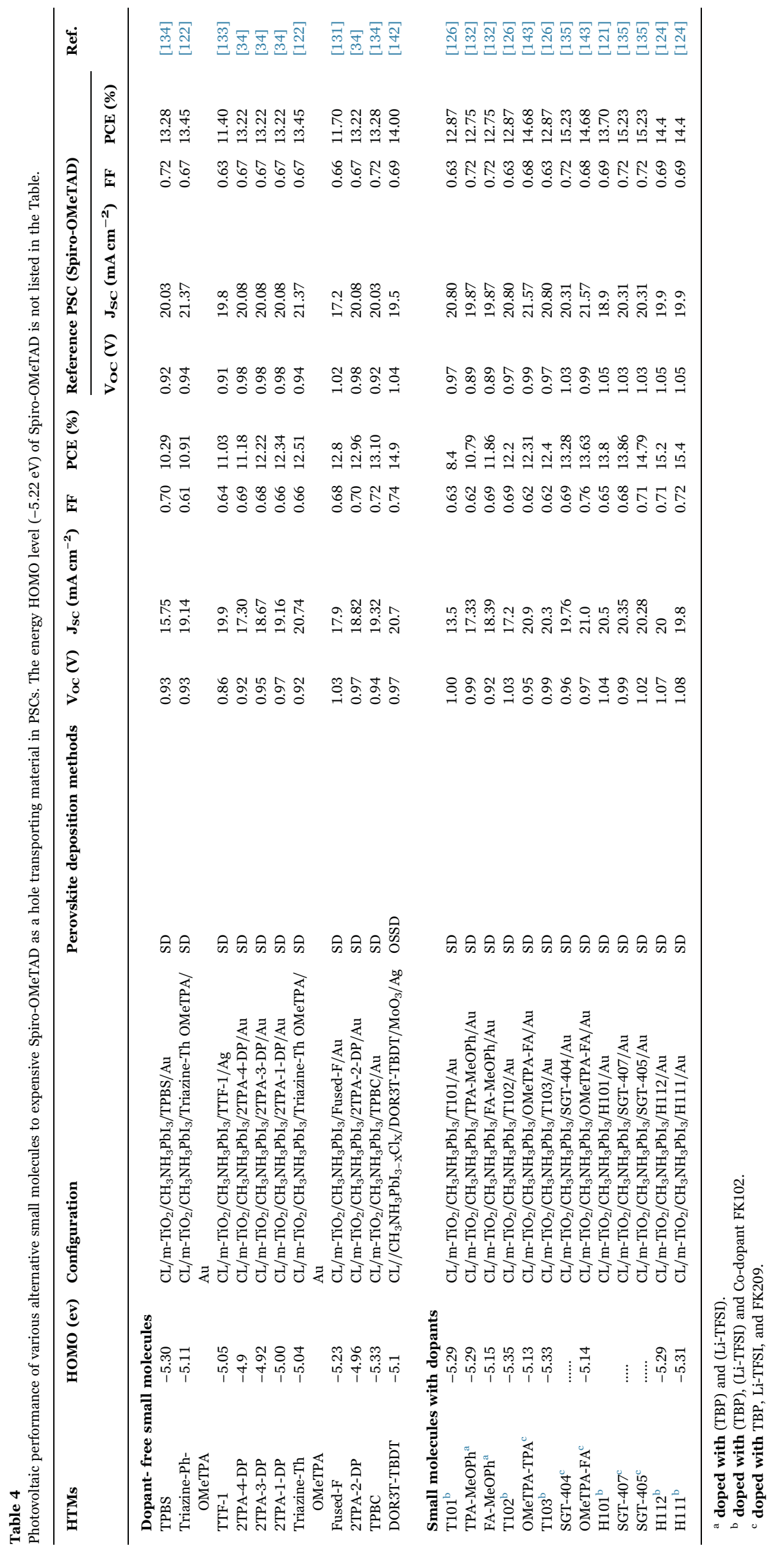


aminophen 4 yl)thiophene 2 yl) triptycene (T103) and demonstrated a superior $\mathrm{FF} \sim 0.69$ and $\mathrm{V}_{\mathrm{OC}} \sim 1.03 \mathrm{~V}$ than a Spiro OMeTAD based device $\left(\mathrm{FF} \sim 0.63, \mathrm{~V}_{\mathrm{OC}} \sim 0.97 \mathrm{~V}\right)$. The absorption peak of $\mathbf{T 1 0 2}$ and T103 showed a red shift compared to T101 due to greater л conjugation of the formers. The deeper HOMO level of these HTMs $\left(5.35,5.33\right.$ and $5.29 \mathrm{eV}$, respectively) explains the origin of the $\mathrm{V}_{\mathrm{OC}}$ enhancement (Table 4).

4.1.3.4. Triazine derivatives. HTMs based on star shaped triarylamine derivatives have been used in organic solar cells [127] Recently, Kwangseok et al. [122] synthesized two star shaped 2,4,6 tris[ $N, N$ bis (4 methoxyphenyl)amino $N$ phenylthiophen 2 yl] 1,3,5 triazine (Triazine-Th-OMeTPA) and 2,4,6 tris[ $N, N$ bis $(4$ methoxyphenyl) amino $N$ diphenyl] 1,3,5 triazine (Triazine-PhOMeTPA) and employed them as HTMs in PSCs. Triazine-ThOMeTPA, owing to its higher hole mobility $\left(1.74 \times 10^{-4} \mathrm{~cm}^{2} \mathrm{~V}^{-1} \mathrm{~s}^{-1}\right)$ than the latter $\left(1.5 \times 10^{-4} \mathrm{~cm}^{2} \mathrm{~V}^{-1} \mathrm{~s}^{-1}\right)$ resulted in a superior PV performance (PCE 12.51\% and FF 0.66) compared to Triazine-PhOMeTPA (PCE 10.90\% and FF 0.61). The performance of both these HTMs was, however, lower than a reference Spiro-OMeTAD PSC (PCE 13.45\% and FF 0.67).

4.1.3.5. Porphyrin derivatives. Zinc porphyrin dyes have demonstrated remarkable PV performance in dye sensitized solar cells $[128,129]$, and recently, as a potential alternative HTM to well known Spiro-OMeTAD in PSCs. Hsien Hsin et al. [123] designed zinc porphyrin HTMs, namely, $\mathbf{Y}_{\mathbf{2}}$ (Full name not available) and $\mathbf{Y}_{\mathbf{2}} \mathbf{A}_{\mathbf{2}}$ (Full name not available). A high PCE 16.6\% is achieved by $\mathbf{Y}_{\mathbf{2}}$ HTM which is comparable to that of Spiro-OMeTAD of $\sim 18.03 \%$. The PV performance of $\mathbf{Y}_{\mathbf{2}} \mathbf{A}_{\mathbf{2}}$ based PSCs was relatively poorer (PCE 10.55\%) due to large pinholes in its resultant film when deposited on perovskite and its an order of magnitude lower hole mobility $\left(1.53 \times 10^{-5} \mathrm{~cm}^{2} \mathrm{~V}^{-1} \mathrm{~s}^{-1}\right)$ than $\mathbf{Y}_{\mathbf{2}}\left(2.04 \times 10^{-4} \mathrm{~cm}^{2} \mathrm{~V}^{-1} \mathrm{~s}^{-1}\right)$. Sim ilarly, zinc(II) $5,10,15,20$-tetrakis [5-(p-acetylthiopentyloxy) phenyl]porphyrin [130] was employed as a buffer layer between PEDOT: PSS and perovskite films in inverted planar PSCs to modify the interfacial properties. A PCE 14.05\% is reported for PSCs employing PEDOT: PSS/porphyrin compared to $~ 11.35 \%$ for pristine PEDOT: PSS. The improvement in PV performance in former is attributed to a reduction in interfacial charge recombination and a better hole extraction owing to higher HOMO level of porphyrin.

4.1.3.6. Triphenylamines derivatives. Tris[[4 [3,3' dihexylsilylene $2,2^{\prime}$ bithiophene] 7 [ $5^{\prime} \mathrm{n}$ hexyl $\left(2,2^{\prime} ; 5^{\prime}, 2^{\prime}\right.$ terthiophene) $5 \mathrm{yl}$ benzo [c] [1,2,5]thiadiazole] 2,6,10 yl] 4,4,8,8,12,12 hexamethyl 4H,8H,12 Hbenzo [1,9] quinolizino[3,4,5,6,7, defg]acridine; (Fused-F)' is another dopant free small molecule with ability to adsorb in the UV region which significantly enhanced the absorption of Fused F/ perovskite film in the visible region [131]. Peng et al. employed mesoscopic PSCs $\left(\mathrm{CL} / \mathrm{TiO}_{2} / \mathrm{CH}_{3} \mathrm{NH}_{3} \mathrm{PbI}_{3} /\right.$ Fused F/Au $)$ with $\mathrm{PCE} \sim 12.8 \%$ and $\mathrm{V}_{\mathrm{OC}} \sim 1.03 \mathrm{~V}$, slightly higher than the rival doped Spiro OMeTAD (PCE 11.7\% and $\mathrm{V}_{\mathrm{OC}} \sim 1.02 \mathrm{~V}$ ) [131]. Similarly, planar amine of star shaped triphenylamine small molecules, e.g., $\operatorname{tris}\{\operatorname{bis}(4$ methoxyphenylethenyl) $N$ phenyl $\}$ amine (TPA-MeOPh) and tris $\{$ bis (4 methoxyphenylethenyl) $N$ phenyl amine quinolizinoacridine (FAMeOPh) demonstrated PCE and $\mathrm{V}_{\mathrm{OC}}$ of $\sim 11.86 \%$, and $\sim 0.92 \mathrm{~V}$ and $\sim 10.79 \%$, and $\sim 0.94 \mathrm{~V}$, respectively [132], which is comparable to that of a Spiro OMeTAD based reference device (PCE 12.75\%, $\left.\mathrm{V}_{\mathrm{OC}} \sim 0.89 \mathrm{~V}\right)$.
4.1.3.7. Tetrathiafulvalene derivatives. Liu et al. [133] reported a dopant free tetrathiafulvalene derivative (TTF-1) as HTM in architecture $\mathrm{CL} / \mathrm{mpTiO}_{2} / \mathrm{CH}_{3} \mathrm{NH}_{3} \mathrm{PbI}_{3} / \mathrm{TTF} 1 / \mathrm{Ag}$ yielding $\mathrm{PCE}$ of $\sim 11.03 \%$, and $\mathrm{V}_{\mathrm{OC}} \sim 0.86 \mathrm{~V}$ comparable to Spiro OMTAD based PSCs $\sim 11.4 \%$ and $\mathrm{V}_{\mathrm{OC}} \sim 0.91 \mathrm{~V}$, thereby evidencing that small molecules based HTM materials can deliver similar or even better performance than Spiro OMeTAD.

4.1.3.8. $N, N, N$, $N^{\prime}$ Tetra phenyl benzidine (TPB). Despite the advantages small molecule HTMs offer for efficient PSCs, the performance is primarily limited due to inferior $\mathrm{V}_{\mathrm{OC}}$ originating from (i) the energy offset between HOMO of HTM and HOMO of perovskite and (ii) the charge recombination owing to poor surface coverage of these HTMs. Towards the former, Yakun et al. [134] reduced the band offset of (TPB, $5.52 \mathrm{eV}$ ) by adding electron donating moieties which increased the electron density and shifted its HOMO level closer to that of HOMO level of $\mathrm{CH}_{3} \mathrm{NH}_{3} \mathrm{PbI}_{3}(5.15 \mathrm{eV})$. The new dopant free TPB derivatives N phenyl N' (4 (2 (3,4 ethylenedioxy)vinyl)phenyl) N,N' di p tolyl $\left[1,1^{\prime}\right.$ biphenyl $4,4^{\prime}$ diamine (TPBS) and $N(4$ (2 (9 ethyl $9 H$ carbazol 3 yl)vinyl)phenyl) $N^{\prime}$ phenyl $N, N^{\prime}$ di p tolyl $\left[1,1^{\prime}\right.$ biphenyl] 4,4' diamine (TPBC) when employed as HTM in mesoscopic PSCs demonstrated PCE 10.29\%, and $\sim 13.1 \%$, and $\mathrm{V}_{\mathrm{OC}} \sim 0.70 \mathrm{~V}$ and $\sim 0.72 \mathrm{~V}$, respectively, comparable to that obtained by a doped Spiro OMeTAD counterpart (PCE 13.3\% and $\left.\mathrm{V}_{\mathrm{OC}} \sim 0.72 \mathrm{~V}\right)$.

4.1.3.9. Carbazoles derivatives. One of the highest performance in PSCs employing small molecules based PSC (other than Spiro OMeTAD) was shown by employing Carbazole structures, SGT-405 (full name not available) and SGT-407(full name not available) belonging to the three arm type structure and SGT 404 for two type structure [135]. Among them, SGT-405 showed the ability to form a crystalline structure when coated as a film and exhibited the highest conductivity $\left(\sim 4.2 \times 10^{-8} \mathrm{~S} \mathrm{~cm}^{-1}\right)$ eventually leading to a remarkable PCE $\sim 14.79 \%$ and $\mathrm{V}_{\mathrm{OC}} \sim 1.02 \mathrm{~V}$ comparable to $\sim 15.23 \%$ and $\sim 1.03 \mathrm{~V}$ for a Spiro OMeTAD based device.

4.1.3.10. Phthalocyanine derivatives. Copper phthalocyanine (CuPc) is another alternative HTM due to its low cost, high hole mobility $\left(\sim 10^{-3}\right.$ to $\left.10^{-2} \mathrm{~cm}^{2} \mathrm{~V}^{-1} \mathrm{~S}{ }^{1}\right)$, stability and long exciton diffusion length $(\sim 868 \mathrm{~nm})[136,137]$. Kumar et al. [138] employed CuPc as HTM in a mesoporous PSCs that showed $\mathrm{J}_{\mathrm{SC}} \sim 16.3 \mathrm{~mA} \mathrm{~cm}{ }^{-2}$ and $\mathrm{V}_{\mathrm{OC}} \sim 0.75 \mathrm{~V}$; however, low $\mathrm{FF} \sim 0.4$ due to low shunt resistance which restricted the PCE to $\sim 5 \%$. To overcome this, Soek et al. [139] employed high LUMO (lowest unoccupied molecular orbital) level po-spiroOMeTAD doped $\mathrm{CuPc}$ to improve its electron blocking characteristics (Fig. 7a). The combination enhanced the PCE from 16.7\% (pristine po spiroOMeTAD) to $\sim 19.4 \%$ (average value) for the CuPc doped po spiroOMeTAD (Fig. 7b). In another report, Sun et al. [140] fabricated a low cost mesoscopic PSCs by incorporating CuPc nanorods as HTM together with the printable low temperature processed carbon as cathode material. A PCE $16.1 \%$ higher than a reference Spiro OMeTAD device (PCE 15\%) was demonstrated. Similarly, PCE $15.42 \%$ is shown by Yan et al. [141] in a fully vacuum processed device at room temperature using a CuPc.

\subsection{Polymer hole transport materials}

In pursuit of cost effective and stable HTMs, polymer materials 
(a)

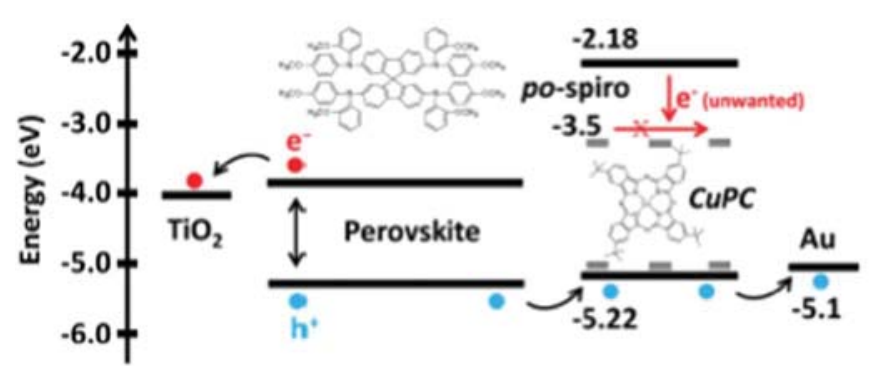

(b)

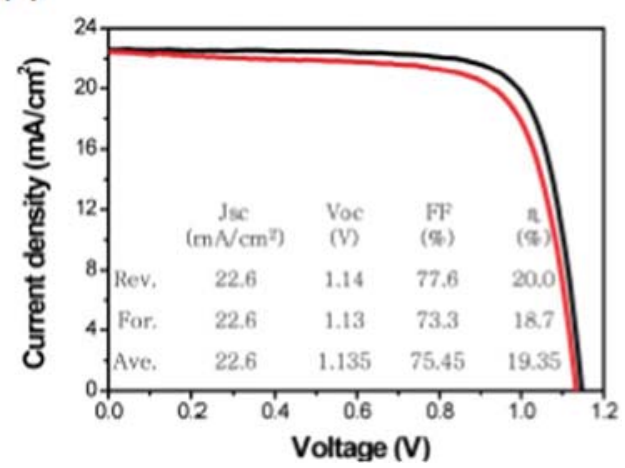

Fig. 7. (a) Energy level alignment of mesoscopic device (CL/mp $\mathrm{TiO}_{2} /\left(\mathrm{FAPbI}_{3}\right)_{0.85}\left(\mathrm{MAPbBr}_{3}\right)_{0.15} / \mathrm{CuPC}$ - po -Spiro-OMeTAD/Au) showing the working mechanism of CuPc, and (b) J$\mathrm{V}$ curve of the best performing device with a CuPc (4.8 wt\%)-doped po -spiro HTM at reverse (black) and forward (red) scans. The inset shows the average values of the photovoltaic parameters obtained from J-V curves under both scans. Figure are reproduced with permission from reference [139]. John Wiley and Sons.

with higher hole mobility than dopant free small molecules are also sought in s DSSC as well as in PSCs. Few common examples are P3HT, PTAA and PEDOT: PSS which achieved maximum PCE in PSCs, $\sim 15.3 \%, \sim 20.2 \%$ and $\sim 18.1 \%$, respectively.

\subsection{1. $P 3 H T$}

P3HT, owing to its relatively cheaper synthesis cost, is a widely employed conducting polymer in organic photovoltaic devices [144] as well as in PSCs [145]. In addition, contrary to Spiro OMeTAD, P3HT is a dopant free HTM and it does not require time consuming oxygen doping (which is required for Spiro OMeTAD based PSCs) for high efficiency thereby making it a material of choice. At an early stage, lower PCE values $(<7 \%)$ were reported in P3HT based PSCs $[43,146,147]$, due to the fact that the flat molecular structure of P3HT induced substantial charge recombination compared to a Spiro OMeTAD based devices [146]. However, recently comparable PCE to a Spiro OMeTAD device ( 13.7\% [148,149], 14.6\% [145], $\sim 15.3 \%$ [53]) has been reported in planar, mesoscopic and meso superstructured PSCs, respectively.

Zhang et al. reported a PCE of $\sim 6.1 \%$ in an architecture $\mathrm{CL} / \mathrm{mp}$ $\mathrm{TiO}_{2} / \mathrm{CH}_{3} \mathrm{NH}_{3} \mathrm{PbI}_{3-\mathrm{x}} \mathrm{Cl}_{\mathrm{x}} / \mathrm{P} 3 \mathrm{HT} / \mathrm{Au}$ compared with a HTM free device (PCE 3.5\%) and affirmed the role of P3HT as efficient hole extraction layer [43]. In another report, P3HT was shown to outperform Spiro OMeTAD in mesoscopic PSCs employing $\mathrm{CH}_{3} \mathrm{NH}_{3} \mathrm{PbI}_{2} \mathrm{Br}$ [147], yield ing PCE $\sim 6.6 \%$ compared to $\sim 5.7 \%$ for a rival Spiro OMeTAD device. This could be understood from the fact that, owing to the relatively inferior infiltration of P3HT, it might not reach conducting substrate which is the case for Spiro OMATAD. One would expect higher recombination at FTO interface for Spiro OMATAD if devices employ a poor hole blocking layer. A report by Di Giacomo et al. [150] demonstrated that doped P3HT excels Spiro OMeTAD in performance in a device architecture of $\mathrm{FTO} / \mathrm{m} \mathrm{TiO}_{2} / \mathrm{CH}_{3} \mathrm{NH}_{3} \mathrm{PbI}_{3}{ }_{\mathrm{x}} \mathrm{Cl}_{\mathrm{x}} / \mathrm{P} 3 \mathrm{HT} / \mathrm{Au}$. They achieved a PCE of $\sim 9.3 \%$ in P3HT devices compared to $\sim 8.6 \%$ in Spiro OMeTAD analogues. Despite the similar $\mathrm{J}_{\mathrm{SC}}$ and $\mathrm{FF}$, the en hancement in the PCE in PSCs employing P3HT was attributed to rise in the $\mathrm{V}_{\mathrm{OC}}$ (from $\sim 0.84$ to $\sim 0.93 \mathrm{~V}$ ) due to the difference in the ionization potential of the two HTMs. A remarkable performance (PCE 13.7\% and $\mathrm{V}_{\mathrm{OC}} \sim 0.96 \mathrm{~V}$ ) using P3HT was reported by Abbas et al. [148] for planar PSCs by optimizing the HTM thickness and using sequential vacuum deposition method for perovskite deposition which resulted in highly crystalline and continuous film as shown in Fig. 8. This hints that an optimization of HTM thickness and a pin hole free morphology is crucial to obtaining high PCEs. Zhang et al. [151] developed a smooth $\mathrm{CH}_{3} \mathrm{NH}_{3} \mathrm{PbI}_{2.4} \mathrm{Br}_{0.6}$ film using compressed air blow drying method. A high air flow speed resulted in better smooth ness and high surface coverage compared to a corresponding one step spin coated perovskite film. The PSCs fabricated using air blow drying method yielding a PCE of $\sim 10.2 \%$ with high $\mathrm{V}_{\mathrm{OC}}$ up to $\sim 1 \mathrm{~V}$ using pristine P3HT as HTM.

The PV performance of P3HT based PSCs is generally lower than doped Spiro OMeTAD based PSCs due to the low hole mobility of the former $\left(3 \times 10^{-4} \mathrm{~cm}^{2} \mathrm{~V}^{-1} \mathrm{~s}^{-1}\right)[43,147]$. Efforts have been dedicated to (a)

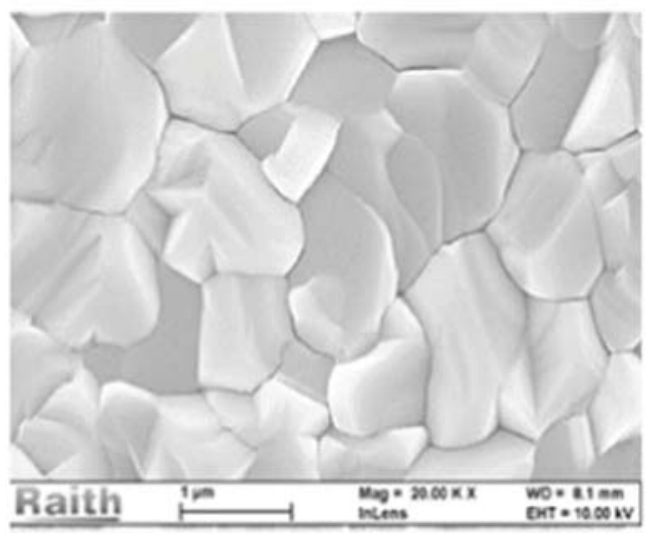

(b)

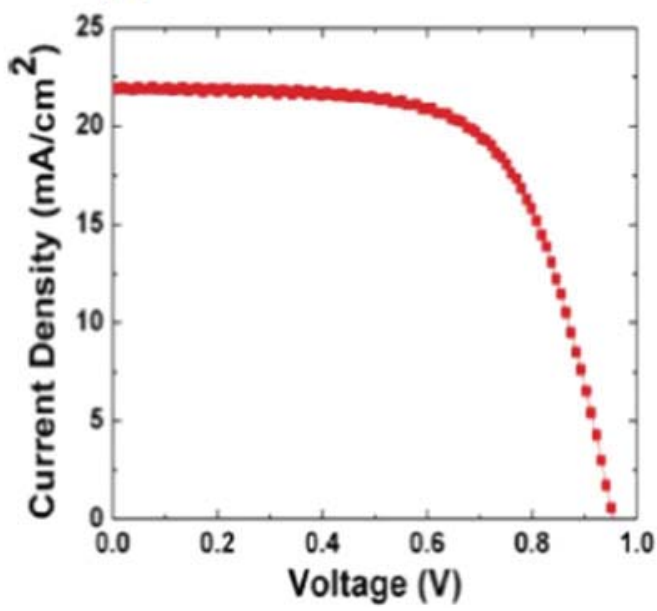

Fig. 8. (a) SEM image of highly crystalline and continues $\mathrm{CH}_{3} \mathrm{NH}_{3} \mathrm{PbI}_{3}$ thin film with grain size of $500 \mathrm{~nm}$ deposited by sequential vacuum deposition method, and (b) I-V curve of the best device with PCE 13.7\%. Figure are reproduced with permission from Ref. [148]. Copy right of AIP Publishing. 

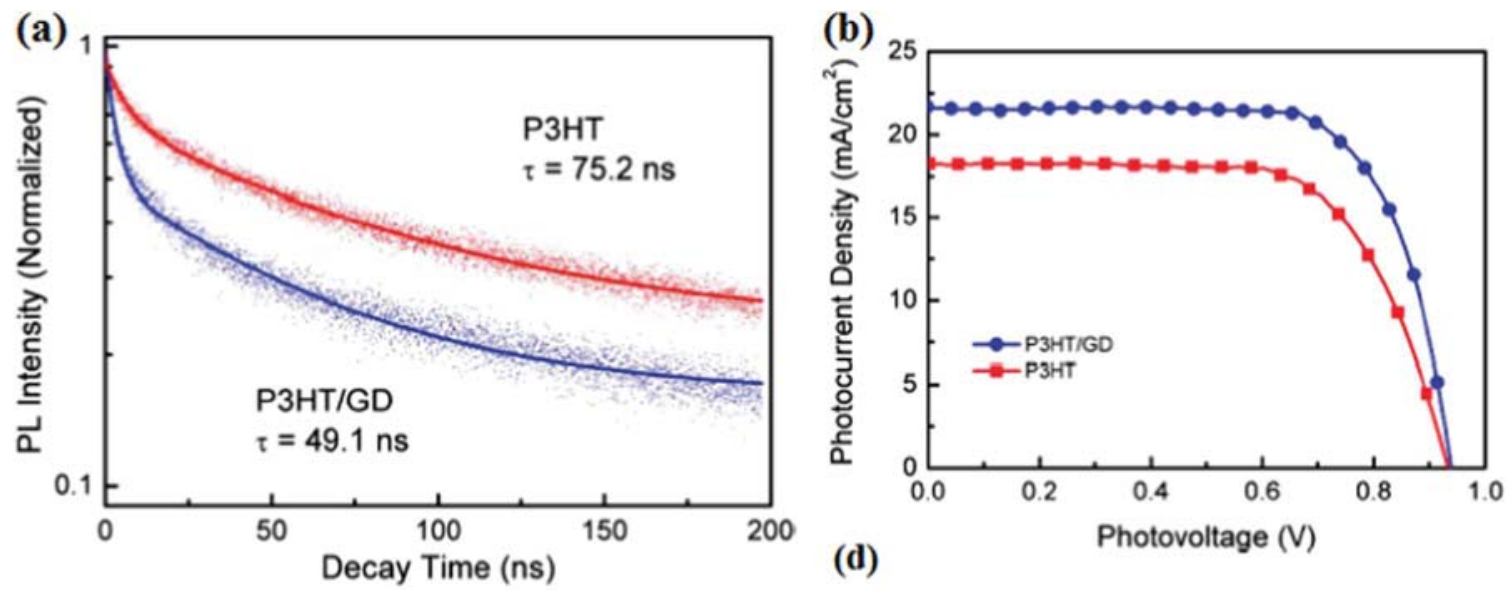

(c)
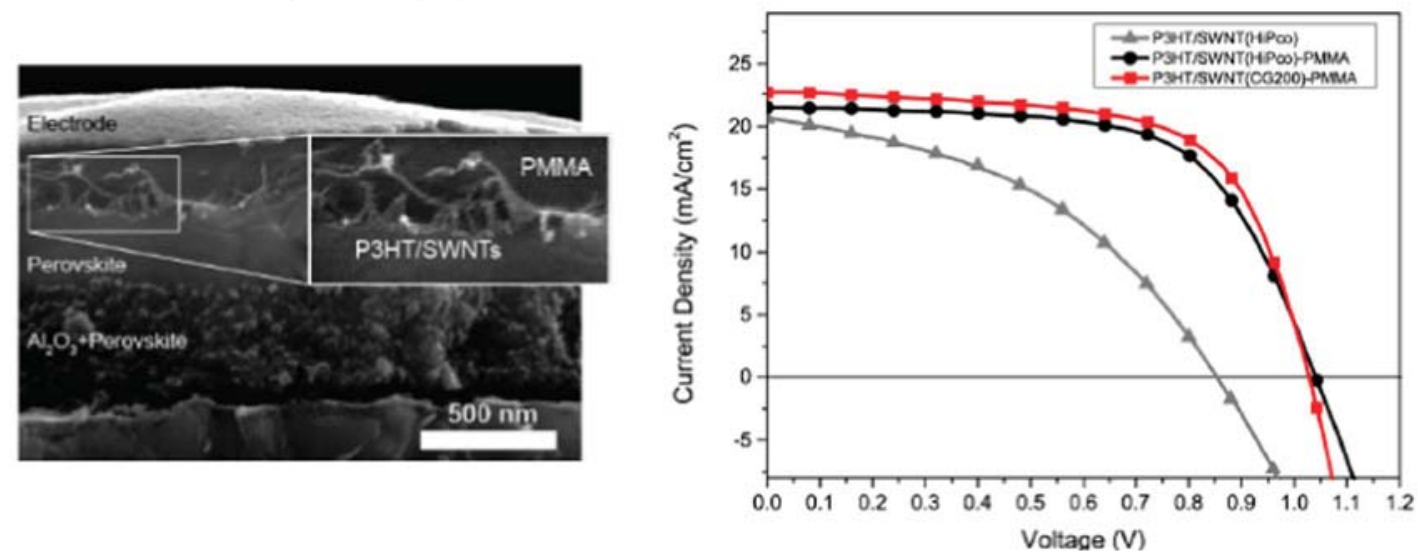

Fig. 9. (a) Normalized life time for P3HT and P3HT/GD HTL based PSCs, (b) J-V characteristic curve of the same. Figure are reproduced with permission from Ref. [145]. Copy right of Wiley (c) Cross-section of the complete device showing P3HT/SWNTs nanohybrid mesh in-filled with PMMA and (d) its current voltage curve of the complete device with (red curve) and without PMMA (grey curve). Figure are reproduced with permission from Ref. [53]. Copy right of American Chemical Society.

enhance hole mobility via carbon nano materials $[152,153]$ and Li salts $[154,155]$ as additives. Heo et al. [155] examined the effect of Li TFSI and TBP additives on the device performance. Li-TFSI and TBP increased the conductivity of $\mathrm{P} 3 \mathrm{HT}$ and resulted in $\mathrm{PCE} \sim 13.7 \%$, $\mathrm{V}_{\mathrm{OC}} \sim 0.92 \mathrm{~V}, \mathrm{FF} \sim 0.74$ for doped P3HT, significantly higher than a pristine counterpart (PCE 5.7\%, $\mathrm{V}_{\mathrm{OC}} \sim 0.55 \mathrm{~V}, \mathrm{FF} \sim 0.67$ ). Chen et al. [153] used multi walled carbon nanotubes (MWNTs) with P3HT which significantly enhanced the conductivity of P3HT an order of magnitude higher than their pristine counterparts and also demonstrated PCE 6.45\% compared to a P3HT based device (4.12\%). Similarly, Cai et al. [152] employed P3HT/bamboo structure carbon nanotubes (BCN) composite as HTL in mesoscopic PSCs. An optimized concen tration (1 wt\% of BCN in P3HT solution) increased the conductivity of the composite $\sim 50$ times and improved the charge transfer at the
$\mathrm{CH}_{3} \mathrm{NH}_{3} \mathrm{PbI}_{3} \quad \mathrm{HTM}$ interface two folds. The PCE drastically increased to $8.3 \%$ from an initial $3.6 \%$ for pristine $\mathrm{P} 3 \mathrm{HT}$, primarily due to increase in $\mathrm{V}_{\mathrm{OC}} \sim 0.86 \mathrm{~V}$ and $\mathrm{FF} \sim 0.52$. In another report, Xiao et al. [145] introduced graphdiyne (GD) as an additive to P3HT in meso scopic PSCs which resulted in a remarkable PCE 14.6\% and $\mathrm{V}_{\mathrm{OC}} \sim 0.94 \mathrm{~V}$. The high PCE is attributed to improved light absorption in PSCs and a shorter life time for P3HT/GD based device (49.1 ns) compared to a pristine P3HT (75.2 ns) as shown in Fig. 9a, which shows accelerated hole extraction at the $\mathrm{CH}_{3} \mathrm{NH}_{3} \mathrm{PbI}_{3} / \mathrm{P} 3 \mathrm{HT} / \mathrm{GD}$ inter face. Similarly, a P3HT/SWNTs (single walled carbon nanotubes) composite embedded in insulating polymer (PMMA) resulted in a remarkable PCE of $\sim 15.3 \%\left(\mathrm{~V}_{\mathrm{OC}} \sim 1.02 \mathrm{~V}\right.$ and $\left.\mathrm{FF} \sim 0.66\right)$ [53]. The PMMA was employed to prevent a direct contact between the per ovskite absorber and metal back contact (Ag) which could otherwise (a)

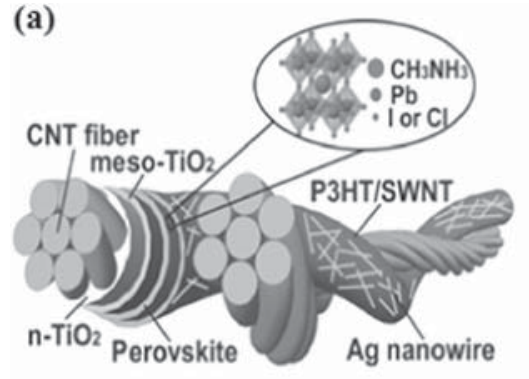

(b)

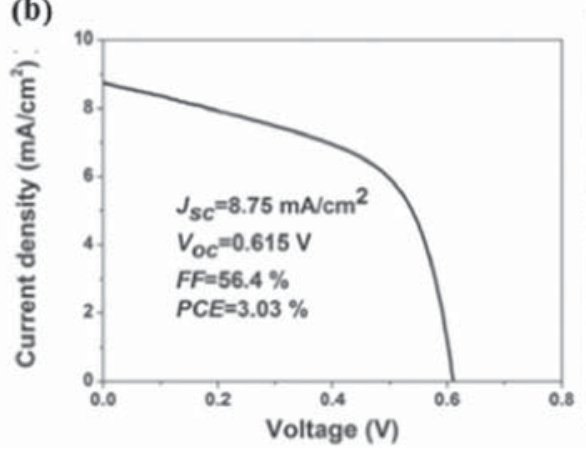

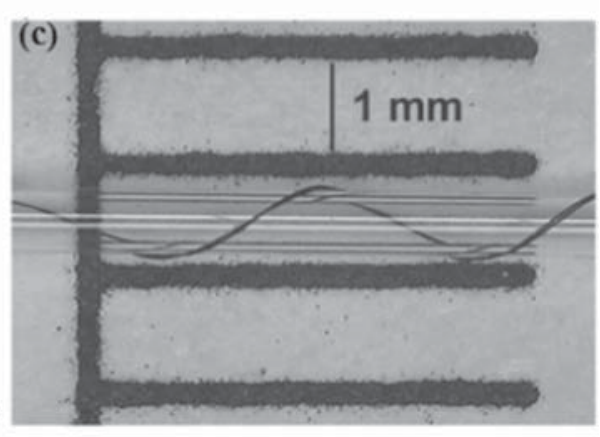

Fig. 10. (a) Double-twisted fibrous PSCs structure (PMMA layer not shown), (b) J-V curve of Double-twisted PSCs with best PCE 3.03\% and (c) The photograph of the double-twisted fibrous PSCs warped onto a capillary tube with curvature radius of $0.3 \mathrm{~mm}$. Figure are reproduced with permission from Ref. [156]. Copyright of John Wiley and Sons. 
(a)

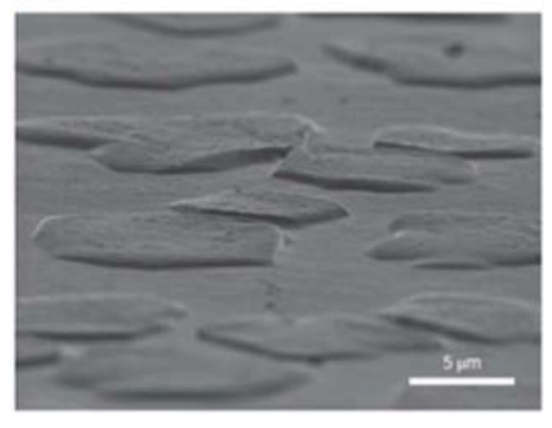

(b)

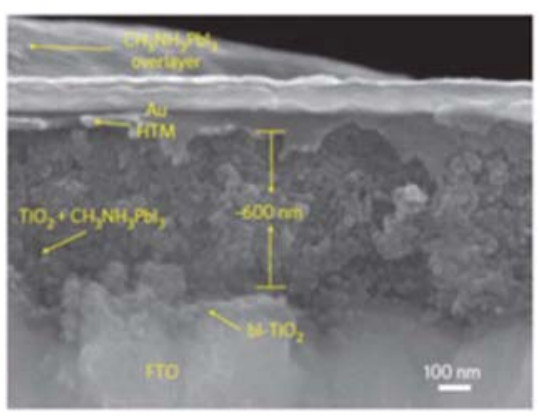

(c)

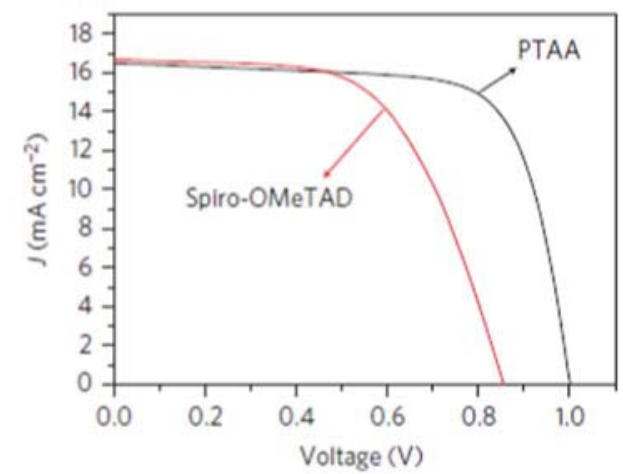

Fig. 11. (a) $\mathrm{SEM}$ image of $\mathrm{CH}_{3} \mathrm{NH}_{3} \mathrm{PbI}_{3}$-coated mp-TiO $\mathrm{O}_{2}$ film (top view), (b) a cross-sectional image of mp-TiO $\mathrm{O}_{2} / \mathrm{CH}_{3} \mathrm{NH}_{3} \mathrm{PbI} 3 / \mathrm{PTAA} / \mathrm{Au}$ device, and (c) $J-V$ curve for the best performing cells fabricated using PTAA and spiroOMeTAD as HTMs. Figure are reproduced with permission from Ref. [2]. Copy right of nature publishing group.

lead to corrosion of Ag.

P3HT is also used as HTM in fiber shaped PSCs, which is an interesting application area of PSCs as wearable electronics and textiles. Li et al. [156] reported highly twisted flexible CNT fiber used as anode in an architecture $\mathrm{CL} / \mathrm{mp} \mathrm{TiO}_{2} / \mathrm{CH}_{3} \mathrm{NH}_{3} \mathrm{PbI}_{3-\mathrm{x}} \mathrm{Cl} / \mathrm{P} 3 \mathrm{HT} /$ SWNTs)/Ag nanowire, as shown in Fig. 10. PMAA was used as protecting layer to provide a mechanical support and also to prevent moisture ingress [53]. Although a PCE $\sim 3 \%, \mathrm{~V}_{\mathrm{OC}} \sim 0.61 \mathrm{~V}$ was achieved, which is not on par with state of the art PSCs, the result is interesting enough to pave way for future self powering e textiles.

\subsubsection{PTAA}

PTAA is another successful polymer HTM employed in PSCs owing to its higher hole mobility $\left(1 \times 10^{-2} 1 \times 10^{-3} \mathrm{~cm}^{2} \mathrm{~V}^{-1} \mathrm{~s}^{-1}\right)$ compared to other polymers (P3HT $3 \times 10^{-4} \mathrm{~cm}^{2} \mathrm{~V}^{-1} \mathrm{~s}^{-1}$ ) [157]. Heo et al. first reported a PCE 12\%, $\mathrm{V}_{\mathrm{OC}} \sim 0.99 \mathrm{~V}, \mathrm{FF} \sim 0.72$ [2]. They introduced a capping layer of $\mathrm{CH}_{3} \mathrm{NH}_{3} \mathrm{PbI}_{3}$ overlaying the $3 \mathrm{D}$ composites of $\mathrm{TiO}_{2} /$ $\mathrm{CH}_{3} \mathrm{NH}_{3} \mathrm{PbI}_{3}$ as shown in Fig. 11. Moreover, owing to its high molecular weight, PTAA could only partially be infiltrated into the $\mathrm{TiO}_{2} / \mathrm{CH}_{3} \mathrm{NH}_{3} \mathrm{PbI}_{3}$ composite unlike the spiroOMeTAD which can be easily infiltrated into composites of $\mathrm{TiO}_{2} / \mathrm{CH}_{3} \mathrm{NH}_{3} \mathrm{PbI}_{3}$. This could explain the higher $\mathrm{R}_{\mathrm{S}}$ and a low $\mathrm{FF} \sim 0.58$ for spiroOMeTAD based PSCs. The same group subsequently used a mesoscopic architecture $\left.\left(\mathrm{CL} / \mathrm{mp} \mathrm{TiO}_{2} / \mathrm{FAPbI}_{3}\right)_{0.85}\left(\mathrm{MAPbBr}_{3}\right)_{0.15} / \mathrm{PTAA} / \mathrm{Au}\right)$ and showed a cer tified PCE 17.9\%, $\mathrm{V}_{\mathrm{OC}} \sim 1.11 \mathrm{~V}$ [158]. As $\mathrm{FAPbI}_{3}$ exhibits an irregular morphology with bumpy roughness, incorporating $\mathrm{MAPbBr}_{3}$ into $\mathrm{FAPbI}_{3}$ (with $\mathrm{x}=0.15$ ) led to uniform and crystalline phase which is reflected by their high performance. Bi et al. [159] grew $\mathrm{CH}_{3} \mathrm{NH}_{3} \mathrm{Pbl}_{3}$ film with large crystalline grains on a non wetting PTAA hole transport material which dramatically reduced charge trap density and boosts the PCE to $\sim 18.1 \%$ for planar PSCs. In fact, one of the highest reported PCE ( 20.2\%) also used PTAA and large grain size $\mathrm{FAPbI}_{3}$ micro structures as HTM [54].

\subsubsection{PEDOT:PSS}

PEDOT: PSS is one of the most successful HTMs owing to its good film forming properties, its transparency and its high work function $(\sim 5.2 \mathrm{eV})$ [160] which appropriately lies close to the ionization potential of $\mathrm{CH}_{3} \mathrm{NH}_{3} \mathrm{PbI}_{3}$ (see Fig. 3). It is mainly used in inverted planar PSCs (Table 5), an architecture that typically employ organic compact charge extraction layers on the substrates to collect holes whereas the electrons are collected from the metal back contact. PEDOT: PSS is particularly suitable for flexible or low temperature PSCs as it can be processed at low temperature $<100{ }^{\circ} \mathrm{C}$ making it compatible with flexible substrates. In inverted planar PSCs, a per ovskite layer is sandwiched between thin compact HTM on FTO and ETL on the metal contact, typically PEDOT: PSS and PCBM, respec tively [161]. This architecture might employ additional electron and hole buffer layers to improve interfacial charge transfer.

Docampo et al. compared PEDOT: PSS to $\mathrm{NiO}$ and $\mathrm{V}_{2} \mathrm{O}_{5}$ in device architecture FTO/HTM $/ \mathrm{CH}_{3} \mathrm{NH}_{3} \mathrm{PbI}_{3-\mathrm{x}} \mathrm{Cl}_{\mathrm{x}} / \mathrm{PCBM} / \mathrm{TiO} \mathrm{x}_{\mathrm{x}} / \mathrm{Al}$ resulting high surface coverage $\sim 95 \%$ of $\mathrm{CH}_{3} \mathrm{NH}_{3} \mathrm{Pbl}_{3}$ above PEDOT: PSS [162]. A PCE 9.8\% ( $\mathrm{V}_{\mathrm{OC}} \sim 0.9 \mathrm{~V}, \mathrm{~J}_{\mathrm{SC}} \sim 15.8 \mathrm{~mA} \mathrm{~cm}^{-2}$ and $\left.\mathrm{FF} \sim 0.66\right)$ is reported on FTO. Similarly, Malinkiewicz et al. [163] employed an evaporated $\mathrm{CH}_{3} \mathrm{NH}_{3} \mathrm{Pbl}_{3}$ layer between PEDOT: PSS and PCBM and reported PCE 12\%. The performance of these inverted PSCs is mostly influenced by the perovskite coverage and its absorption which depends, to some extent, on the morphology of HTM over which perovskite is to be deposited. Jeng et al. [164] reported inverted planar PSCs in architecture (ITO/PEDOT: PSS $/ \mathrm{CH}_{3} \mathrm{NH}_{3} \mathrm{Pbl}_{3} / \mathrm{PCBM} / \mathrm{BCP} / \mathrm{Al}$ ) that resulted in a low $\mathrm{V}_{\mathrm{OC}} \sim 0.6 \mathrm{~V}$ with maximum $\mathrm{PCE} \sim 3.9 \%$. The very low PCE in these device was due to un optimized absorber layer thickness $(<50 \mathrm{~nm})$ and poor surface interaction between $\mathrm{CH}_{3} \mathrm{NH}_{3} \mathrm{Pbl}_{3}$ film and PEDOT: PSS layer. Similarly, Sun et al. [165] reported a PCE of $\sim 5.2 \%$ (FF $\sim 0.7$ and $\mathrm{V}_{\mathrm{OC}} \sim 0.82 \mathrm{~V}$ ) in a ITO/PEDOT: $\mathrm{PSS} / \mathrm{CH}_{3} \mathrm{NH}_{3} \mathrm{PbI}_{3} / \mathrm{PCBM} / \mathrm{Al}$ architecture where $\mathrm{CH}_{3} \mathrm{NH}_{3} \mathrm{PbI}_{3}$ was deposited using single step solution processing. The PCE and $\mathrm{V}_{\mathrm{OC}}$ were further increased to $\sim 7.4 \%$ and $\sim 0.94 \mathrm{~V}$, respectively using a thicker $\mathrm{CH}_{3} \mathrm{NH}_{3} \mathrm{PbI}_{3}$ film developed via sequential deposition method thereby evidencing that optimization of perovskite layer thickness is crucial to obtain high performance.

Owing to the crucial role of the crystallinity, morphology and surface coverage of the perovskite layer on the photovoltaic perfor mance in PSCs, various research groups introduced additives in the perovskite absorber in inverted PSCs resulting in a high PCE of $\sim 8$ 11.8\% listed in Table 5 [166 168]. Another way to further increase the performance of PSCs is to engineer ITO/HTM interface to over come the energy mismatch. Towards this end, Lim et al. [169] modified the work function of PEDOT: PSS from 4.86 (pristine) to $5.4 \mathrm{eV}$ (PEDOT: PSS and PFI, (SOHEL) via surface treatment using a perfluorinated ionomer (PFI). They built ITO/SOHEL/ $\mathrm{CH}_{3} \mathrm{NH}_{3} \mathrm{PbI}_{3} /$ $\mathrm{PCBM} / \mathrm{Al}$ structure with $\mathrm{PCE}$ as high as $\sim 11.7 \%$ and $\mathrm{V}_{\mathrm{OC}} \sim 1 \mathrm{~V}$ (PCE 8.1\% and $\mathrm{V}_{\mathrm{OC}} \sim 0.8 \mathrm{~V}$ for pristine PEDOT: PSS). Higher PCE in inverted planar PSCs are achieved via optimization of ETL or HTM interface and also by controlling the characteristics of perovskite layer. For example, Chen et al. [170] employed a Sequential Vacuum Deposition method for perovskite deposition in an architecture ITO/ PEDOT: $\quad$ PSS $/ \mathrm{CH}_{3} \mathrm{NH}_{3} \mathrm{PbI}_{3} / \mathrm{C}_{60} /$ phen(Bathophenanthroline)/Ca/Ag and demonstrated a PCE of $\sim 15.4 \%$ ( $\left.\mathrm{V}_{\mathrm{OC}} \sim 1 \mathrm{~V}, \mathrm{FF} \sim 0.7\right)$. Similarly, an optimized PEDOT: PSS morphology yielded a PCE of $\sim 16.3 \%$ with $\mathrm{V}_{\mathrm{OC}} \sim 1.0 \mathrm{~V}, \mathrm{FF} \sim 0.7$ in conjunction with $\mathrm{PC}_{71} \mathrm{BM}$ and $\mathrm{CH}_{3} \mathrm{NH}_{3} \mathrm{PbI}_{3}$ as ETL and perovskite, respectively [171].

High efficiency $>17 \%$ in $\mathrm{p}$ i n PSCs was achieved by controlling the morphology of perovskite and HTM and also by overcoming the energy offset at the three interfaces (ETL/perovskite, HTM/perovskite, and HTM/ITO), which would result in higher $\mathrm{V}_{\mathrm{OC}}$ and higher PCE thereby 
Table 5

Perovskite solar cells employing the three common polymer hole transporting materials (P3HT, PTAA and PEDOT: PSS) along with their device architecture, and details perovskite deposition method.

\begin{tabular}{|c|c|c|c|c|c|c|}
\hline \multirow[t]{2}{*}{ Device structure } & \multirow[t]{2}{*}{ Perovskite deposition methods } & \multicolumn{4}{|c|}{ Photovoltaic parameters } & \multirow[t]{2}{*}{ Ref. } \\
\hline & & $V_{\text {oc }}(\mathrm{V})$ & $\mathrm{Jsc}\left(\mathrm{mA} \mathrm{cm}{ }^{2}\right)$ & FF & PCE (\%) & \\
\hline \multicolumn{7}{|l|}{ P3HT } \\
\hline $\mathrm{CL} /$ oriented rod $\mathrm{TiO}_{2} / \mathrm{CH}_{3} \mathrm{NH}_{3} \mathrm{PbI}_{3}{ }_{\mathrm{x}} \mathrm{Cl}_{\mathrm{x}} / \mathrm{P} 3 \mathrm{HT} / \mathrm{Au}$ & OSSD & 0.74 & 14.65 & 0.55 & 6.06 & [43] \\
\hline $\mathrm{CL} / \mathrm{mp} \mathrm{TiO} 2 / \mathrm{CH}_{3} \mathrm{NH}_{3} \mathrm{PbI}_{2} \mathrm{Br} / \mathrm{P} 3 \mathrm{HT} / \mathrm{Au}$ & OSSD & 0.82 & 12.93 & 0.62 & 6.64 & [147] \\
\hline $\mathrm{CL} / \mathrm{mp} \mathrm{TiO} 2 / \mathrm{CH}_{3} \mathrm{NH}_{3} \mathrm{PbI}_{3} / \mathrm{P} 3 \mathrm{HT}-1$ wt $\%$ BCN $/ \mathrm{Au}$ & SD & 0.86 & 18.75 & 0.52 & 8.30 & [152] \\
\hline $\mathrm{CL} / \mathrm{mp} \mathrm{TiO}{ }_{2} / \mathrm{CH}_{3} \mathrm{NH}_{3} \mathrm{PbI}_{3} \mathrm{Cl}_{\mathrm{x}} / \mathrm{P} 3 \mathrm{HT} / \mathrm{Au}$ & OSD & 0.93 & 12.00 & 0.6 & 9.3 & [150] \\
\hline $\mathrm{CL} / \mathrm{mp} \mathrm{TiO}_{2} / \mathrm{CH}_{3} \mathrm{NH}_{3} \mathrm{PbI}_{2.4} \mathrm{Br}_{0.6} / \mathrm{P} 3 \mathrm{HT} / \mathrm{Au}$ & Air blow-drying & 0.952 & 15.45 & 0.69 & 10.2 & [151] \\
\hline $\mathrm{CL} / \mathrm{mp} \mathrm{TiO} 2 / \mathrm{CH}_{3} \mathrm{NH}_{3} \mathrm{PbI}_{3} / \mathrm{P} 3 \mathrm{HT}-\mathrm{MWNTs} / \mathrm{Au}$ & OSSD & 0.76 & 14.8 & 0.57 & 6.45 & [153] \\
\hline $\mathrm{CL} / \mathrm{CH}_{3} \mathrm{NH}_{3} \mathrm{PbI}_{3 \times} \mathrm{Cl}_{\mathrm{x}} / \mathrm{P} 3 \mathrm{HT} / \mathrm{Ag}$ & OSSD & 0.98 & 19.1 & 0.66 & 12.4 & [154] \\
\hline $\mathrm{CL} / \mathrm{CH}_{3} \mathrm{NH}_{3} \mathrm{PbI}_{3} / \mathrm{P} 3 \mathrm{HT} / \mathrm{Au}$ & SVD & 0.96 & 21.76 & 0.65 & 13.7 & [148] \\
\hline $\mathrm{CL} / \mathrm{mp} \mathrm{TiO}{ }_{2} / \mathrm{CH}_{3} \mathrm{NH}_{3} \mathrm{PbI}_{3} / \mathrm{P} 3 \mathrm{HT} / \mathrm{Au}$ & OSSD & 0.92 & 20.1 & 0.74 & 13.7 & [155] \\
\hline $\mathrm{CL} / \mathrm{mp} \mathrm{TiO} 2 / \mathrm{CH}_{3} \mathrm{NH}_{3} \mathrm{PbI}_{3} / \mathrm{P} 3 \mathrm{HT}-\mathrm{GD} / \mathrm{Au}$ & SD & 0.94 & 21.7 & 0.71 & 14.58 & [145] \\
\hline $\mathrm{CL} / \mathrm{Al}_{2} \mathrm{O}_{3} / \mathrm{CH}_{3} \mathrm{NH}_{3} \mathrm{PbI}_{3} / \mathrm{P} 3 \mathrm{HT} / \mathrm{SWNTs} / \mathrm{PMAA} / \mathrm{Ag}$ & OSSD & 1.02 & 22.71 & 0.66 & 15.3 & [53] \\
\hline \multicolumn{7}{|l|}{ PTAA } \\
\hline $\mathrm{CL} / \mathrm{mp} \mathrm{TiO}{ }_{2} / \mathrm{CH}_{3} \mathrm{NH}_{3} \mathrm{PbI}_{3} / \mathrm{PTAA} / \mathrm{Au}$ & OSSD & 0.99 & 16.5 & 0.72 & 12.00 & {$[2]$} \\
\hline $\left.\mathrm{CL} / \mathrm{mp} \mathrm{TiO} 2 / \mathrm{FAPbI}_{3}\right)_{0.85}\left(\mathrm{MAPbBr}_{3}\right)_{0.15} / \mathrm{PTAA} / \mathrm{Au}$ & SET & 1.11 & 22.5 & 0.70 & 17.9 & [158] \\
\hline $\mathrm{PTAA} / \mathrm{CH}_{3} \mathrm{NH}_{3} \mathrm{PbI}_{3} / \mathrm{PCBM} / \mathrm{C}_{60} / \mathrm{BCP} / \mathrm{Al}$ & TSSD & 1.07 & 22.0 & 0.76 & 18.1 & [159] \\
\hline $\mathrm{CL} / \mathrm{mp} \mathrm{TiO} 2 /\left(\mathrm{FAPbI}_{3}\right)_{1}{ }_{\mathrm{x}}\left(\mathrm{MAPbBr}_{3}\right)_{\mathrm{x}} / \mathrm{PTAA} / \mathrm{Au}$ & TSSD & 1.06 & 24.7 & 0.77 & 20.2 & [54] \\
\hline \multicolumn{7}{|l|}{ PEDOT: PSS } \\
\hline ITO/PEDOT: PSS/ $\mathrm{CH}_{3} \mathrm{NH}_{3} \mathrm{Pbl}_{3} / \mathrm{PCBM} / \mathrm{BCP} / \mathrm{AL}$ & OSSD & 0.6 & 10.32 & 0.63 & 3.9 & [164] \\
\hline PET/ITO/PEDOT: PSS/C $\mathrm{CH}_{3} \mathrm{NH}_{3} \mathrm{PbI}_{3} / \mathrm{PCBM} / \mathrm{BCP} / \mathrm{Al}$ & OSSD & 0.92 & 7.93 & 0.62 & 4.54 & [183] \\
\hline ITO/PEDOT: PSS $/ \mathrm{CH}_{3} \mathrm{NH}_{3} \mathrm{Pbl}_{3} / \mathrm{PCBM} / \mathrm{AL}$ & OSSD & 0.90 & 10.82 & 0.75 & 7.41 & [165] \\
\hline ITO/PEDOT: PSS/Cs $0.1 \mathrm{MA}_{0.9} \mathrm{PbI}_{3} / \mathrm{C}_{60} / \mathrm{AL}$ & OSSD & 1.05 & 10.10 & 0.73 & 7.68 & [184] \\
\hline ITO/PEDOT: PSS/polyTPD/ $\mathrm{CH}_{3} \mathrm{NH}_{3} \mathrm{PbI}_{3} / \mathrm{C}_{60} / \mathrm{Au} / \mathrm{LiF}$ & DSVD & 1.05 & 15.88 & 0.46 & 7.73 & [185] \\
\hline ITO/PEDOT: $\mathrm{PSS} / \mathrm{CH}_{3} \mathrm{NH}_{3} \mathrm{PbI}_{3}-\mathrm{BmPyPhB} / \mathrm{PCBM} / \mathrm{Al}$ & OSSD & 0.88 & 14.7 & 0.63 & 8.14 & [166] \\
\hline FTO/PEDOT: PSS/CH $\left.\mathrm{CH}_{3} \mathrm{NH}_{3} \mathrm{PbI}_{3}{ }_{\mathrm{x}} \mathrm{Cl}_{\mathrm{x}} / \mathrm{C}_{60} / \mathrm{TiOx} / \mathrm{Al}\right)$ & OSSD & 0.94 & 15.8 & 0.66 & 9.8 & [162] \\
\hline ITO/PEDOT: $\mathrm{PSS} / \mathrm{CH}_{3} \mathrm{NH}_{3} \mathrm{PbI}_{3}-\mathrm{NH}_{4} \mathrm{Cl} / \mathrm{PCBM} / \mathrm{Al}$ & OSSD & 0.88 & 14.08 & 0.80 & 9.93 & [168] \\
\hline ITO/PEDOT: PSS/ $\mathrm{CH}_{3} \mathrm{NH}_{3} \mathrm{PbI}_{3}{ }_{\mathrm{x}} \mathrm{Cl}_{\mathrm{x}} / \mathrm{PCBM} / \mathrm{Al}$ & OSSD & 0.87 & 18.5 & 0.72 & 11.5 & [186] \\
\hline ITO/SOHEL $/ \mathrm{CH}_{3} \mathrm{NH}_{3} \mathrm{Pbl}_{3} / \mathrm{C}_{60} / \mathrm{AL}$ & OSSD & 0.99 & 16.7 & 0.70 & 11.7 & [169] \\
\hline FTO/PEDOT: PSS/ $\mathrm{CH}_{3} \mathrm{NH}_{3} \mathrm{PbI}_{3}{ }_{\mathrm{x}} \mathrm{Cl}_{\mathrm{x}} \quad 1 \% \mathrm{DIO} / \mathrm{PCBM} / \mathrm{Bis}-\mathrm{C}_{60} / \mathrm{Ag}$ & OSSD & 0.92 & 17.5 & 0.73 & 11.8 & [167] \\
\hline ITO/PEDOT: PSS/PolyTPD/ $\mathrm{CH}_{3} \mathrm{NH}_{3} \mathrm{Pbl}_{3} / \mathrm{PCBM} / \mathrm{Au}$ & DSVD & 1.05 & 16.12 & 0.67 & 12.04 & [163] \\
\hline ITO/ $1 \%$ wtMoO $3 /$ PEDOT: PSS $/ \mathrm{CH}_{3} \mathrm{NH}_{3} \mathrm{PbI}_{3} / \mathrm{C}_{60} / \mathrm{Bphen} / \mathrm{Ag}$ & TSSD & 0.96 & 20.06 & 0.67 & 12.78 & [187] \\
\hline ITO/PEDOT: PSS/ $\mathrm{CH}_{3} \mathrm{NH}_{3} \mathrm{PbI}_{3} / \mathrm{PCBM} / \mathrm{PN}_{4} \mathrm{~N} / \mathrm{Al}$ & OSSD & 1.00 & 20.61 & 0.72 & 15 & [188] \\
\hline ITO/PEDOT: PSS $/ \mathrm{CH}_{3} \mathrm{NH}_{3} \mathrm{PbI}_{3} / \mathrm{C}_{60} / \mathrm{phen} / \mathrm{Ca} / \mathrm{Ag}$ & SVD & 1.02 & 20.9 & 0.72 & 15.4 & {$[170]$} \\
\hline ITO/PEDOT: PSS $/ \mathrm{CH}_{3} \mathrm{NH}_{3} \mathrm{Pbl}_{3} / \mathrm{PCBM} / \mathrm{C}_{60} / \mathrm{BCP} / \mathrm{AL}$ & TSSD & 0.99 & 19.6 & 0.79 & 15.4 & [189] \\
\hline ITO/PEDOT: PSS/ $\mathrm{CH}_{3} \mathrm{NH}_{3} \mathrm{Pbl}_{3} / \mathrm{PC}_{71} \mathrm{BM} / \mathrm{Ca} / \mathrm{Al}$ & TSSD & 1.05 & 19.98 & 0.78 & 16.31 & [171] \\
\hline ITO/PEDOT: PSS/CH $\mathrm{CH}_{3} \mathrm{NH}_{3} \mathrm{PbI}_{3}{ }_{\mathrm{x}} \mathrm{Cl}_{\mathrm{x}} / \mathrm{PCBM} / \mathrm{PFN} / \mathrm{Al}$ & OSSD & 1.05 & 20.3 & 0.80 & 17.1 & [173] \\
\hline FTO/PEDOT: PSS/ $\mathrm{CH}_{3} \mathrm{NH}_{3} \mathrm{Pbl}_{3} / \mathrm{PCBM} / \mathrm{Al}$ & Hot-casting technique & 0.92 & 22.4 & 0.82 & 18 & [172] \\
\hline ITO/PEDOT: $\mathrm{PSS} / \mathrm{CH}_{3} \mathrm{NH}_{3} \mathrm{Pbl}_{3} / \mathrm{PCBM} / \mathrm{Au}$ & OSSD & 1.1 & 20.9 & 0.79 & 18.1 & [56] \\
\hline
\end{tabular}

SOHEL=perfluorinated ionomer (PFI)/PEDOT: PSS), BCP =2,9-dimethyl-4,7-diphenyl-1,10-phenanthroline.

$\mathrm{DIO}=1,8$-diiodooctane, $\mathrm{BmPyPhB}=1,3$-Bis[3,5-di(pyridin-3-yl)phenyl]benzen.

$[56,172,173]$. This also eliminated hysteresis, i.e., drop in power output under an electric bias or light. For example, a high performance PCE 17.1\% ( $\left.\mathrm{V}_{\mathrm{OC}} \sim 1.05 \mathrm{~V}, \mathrm{FF} \sim 0.80\right)$ was reported by You et al. [173] in a device consisting of ITO/PEDOT: PSS $/ \mathrm{CH}_{3} \mathrm{NH}_{3} \mathrm{PbI}_{3-\mathrm{x}} \mathrm{Cl}_{\mathrm{x}} / \mathrm{PCBM} /$ PFN/Al where polyelectrolyte poly[(9,9 bis(30 (N,N dimethylamino) propyl) 2,7 fluorene) alt 2,7 (9,9 dioctylfluorene)] (PFN) was used to form an ohmic contact to help electron extraction from the PCBM to Al. Recently, Heo et al. [56] got high quality perovskite using $\mathbf{H I}$ as an additive resulting in a PCE $18.1 \%$ without significant $J V$ hysteresis. $J$ $V$ hysteresis free is due to the fact that the thermally annealed PCBM layer on $\mathrm{MAPbI}_{3}$ could reduce the surface traps significantly. Also important to note that the work function of PEDOT: PSS (4.9 $5.2 \mathrm{eV}$ depending on the ratio of PEDOT to PSS) is lower than the valance band edge of perovskite (e.g., $5.4 \mathrm{eV}$ for $\mathrm{CH}_{3} \mathrm{NH}_{3} \mathrm{PbI}_{3}$ ), so the potential energy loss at the PEDOT: PSS/perovskite interface decreases the built in potential in PSCs and eventually their photovoltaic performance increases. Nevertheless, PEDOT: PSS based devices suffer from poor chemical stability due to its hygroscopic nature as well as inefficient electron blocking behaviour which require additional layer for efficient performance $[174,175]$. It is also noteworthy that PEDOT: PSS is acidic and it may leads to corrosion at substrates, especially in the case of flexible devices, where conducting polymer based plastic substrates are employed [176].

\subsection{Other polymer, organic and carbon based HTMs}

As the HTM contributes towards the $\mathrm{V}_{\mathrm{OC}}$ in PSCs (Section 3.2 of this article), i.e. the difference of quasi Fermi energy levels of electron and hole species at the two opposing contacts, screening HTMs with energy levels to favor high $\mathrm{V}_{\mathrm{OC}}$ is crucial. A mismatch in energy bands between HTM and perovskite will not only effect the $\mathrm{V}_{\mathrm{OC}}$ but also will reduce the charge transfer at the interface [177]. For example, Cai et al. [83] reported PCBTDPP as HTM with $\mathrm{CH}_{3} \mathrm{NH}_{3} \mathrm{PbBr}_{3}$ in mesoscopic PSCs. They obtained a $\mathrm{V}_{\mathrm{OC}} \sim 1.15 \mathrm{~V}$ with PCE 3.04\% which is signifi cantly higher than a P3HT device $\left(\mathrm{V}_{\mathrm{OC}} \sim 0.5 \mathrm{~V}\right.$, and PCE 0.76\%, respectively). Herein, the lower $\mathrm{J}_{\mathrm{SC}}$ is due to large bandgap $(\sim 2.4 \mathrm{eV})$ of the perovskite $\left(\mathrm{CH}_{3} \mathrm{NH}_{3} \mathrm{PbBr}_{3}\right)$ which limits the maximum obtain able $\mathrm{J}_{\mathrm{SC}}$ to be $\sim 9 \mathrm{~mA} \mathrm{~cm}^{-2}$ only $[42,86]$. Selecting perovskite absorbers with lower bandgap could help obtaining higher PV parameters. The larger difference in the $\mathrm{V}_{\mathrm{OC}}(\sim 0.66 \mathrm{~V})$ of the two device is due to weaker light filtering effect of the PCBTDPP polymer than P3HT, and also due to the fact that the carbazole groups in PCBTDPP have favorable effect on device performance owing to a higher hole mobility and deeper HOMO level of the former. Similarly, Nagarjuna et al. [178] employed D A conjugated copolymer (abbreviated as P) as HTM in mesoscopic PSCs $\left(\mathrm{CL} /\right.$ meso $\left.\mathrm{TiO}_{2} / \mathrm{CH}_{3} \mathrm{NH}_{3} \mathrm{PbI}_{3} / \mathrm{P} / \mathrm{Au}\right)$ which achieved PCE of $\sim 6.64 \%$ and a $\mathrm{V}_{\mathrm{OC}} \sim 0.84 \mathrm{~V}$, notably higher than a P3HT counterpart 
(PCE 4.24\%, and $\mathrm{V}_{\mathrm{OC}} \sim 0.64 \mathrm{~V}$ ). An impressive $\mathrm{V}_{\mathrm{OC}} \sim 1.3 \mathrm{~V}$ was obtained via PDI as $\mathrm{HTM}$ in meso superstructured PSCs $\left(\mathrm{CL} / \mathrm{Al}_{2} \mathrm{O}_{3} /\right.$ $\mathrm{CH}_{3} \mathrm{NH}_{3} \mathrm{PbBr}_{3} / \mathrm{PDI} / \mathrm{Au}$ ) due to a deeper HOMO level and wide energy gap of $\mathrm{CH}_{3} \mathrm{NH}_{3} \mathrm{PbBr}_{3}$ [86]. Later, the same group used larger band gap absorber (2.3 eV) $\mathrm{CH}_{3} \mathrm{NH}_{3} \mathrm{PbBr}_{3-\mathrm{x}} \mathrm{Cl}_{\mathrm{x}}$ and deeper HOMO level HTM, 4,4' bis( $\mathrm{N}$ carbazolyl) $1,1^{\prime}$ biphenyl (CBP) leading to high $\mathrm{V}_{\mathrm{OC}}$ $(\sim 1.5 \mathrm{~V})$ and $\mathrm{J}_{\mathrm{SC}} \sim 4 \mathrm{~mA} \mathrm{~cm}^{-2}$ compared to $\mathrm{V}_{\mathrm{OC}} \sim 1.38 \mathrm{~V}$, and $\mathrm{J}_{\mathrm{SC}}$ $\sim 0.7 \mathrm{~mA} \mathrm{~cm}^{-2}$ for $\mathrm{CH}_{3} \mathrm{NH}_{3} \mathrm{PbBr}_{3}$ based mesoscopic PSCs. The higher current in the former is because the use of $\mathrm{Cl}$ increased the surface coverage of perovskite layer and consequently resulted in a superior light absorption [41]. The highest $\mathrm{V}_{\mathrm{OC}} \sim 1.61 \mathrm{~V}$ to date in PSCs was obtained using $1^{\prime}, 1^{\prime \prime}, 4^{\prime}, 4^{\prime \prime}$ tetrahydro di [1,4]methanonaphthale no[1,2:2', $\left.3^{\prime}, 56,60: 2^{\prime \prime}, 3^{\prime \prime}\right][5,6]$ fullerene $\mathrm{C}_{60}$ as an ETL, $\mathrm{CH}_{3} \mathrm{NH}_{3} \mathrm{PbBr}_{3}$ as an absorber and PEDOT: PSS as HTM [42]. The devices showed a PCE $7.5 \%$ with a high $\mathrm{FF} \sim 0.77$ and a $\mathrm{J}_{\mathrm{SC}} \sim 6.04 \mathrm{~mA} \mathrm{~cm}^{-2}$. Although the $\mathrm{J}_{\mathrm{SC}}$ was close to its maximum theoretical limit for the material combination employed $\left(\sim 9 \mathrm{~mA} \mathrm{~cm}{ }^{-2}\right)$, the loss in potential, i.e., $\mathrm{E}_{G}$ $q \mathrm{~V}_{\mathrm{OC}}(\sim 0.7 \mathrm{eV})$ is still higher and further improvements are possible. Such PSCs are highly suitable as a top cell in tandem device config uration as they have already resulted in $\mathrm{V}_{\mathrm{OC}}$ as high as $\sim 2.25 \mathrm{~V}$ (PCE 10.4\%) [179].

A high open circuit voltage $\sim 1.4 \mathrm{~V}$ was also achieved when carbon nanotubes (CNTs) were used as a hole conductor in $\mathrm{MAPbBr}_{3} \mathrm{PSCs}$ [180] and was due to efficient charge extraction and low recombination of the CNT hole conductor. Tandem solar cells with all perovskite absorbers were demonstrated with a $\mathrm{MAPbBr}_{3} / \mathrm{CNT}$ top cell and a $\mathrm{MAPbI}_{3}$ bottom cell, achieving a $V_{\mathrm{OC}}$ of $\sim 2.24 \mathrm{~V}$ in series connection. Habisreutinger et al. [53] replaced the organic hole transport material with polymer functionalized (SWNTs) embedded in an insulating polymer matrix, i.e. PMMA. With this composite structure, PCEs of up to $\sim 15.3 \%$ were achieved, as well as reduced thermal degradation and improved resistance to water ingress as compared to cells employ ing state of the art organic hole transporting materials.

Biologically derived materials have also been employed as transport layers in solar cells. Whereas in OPV, deoxyribose nucleic acid (DNA) in its "natural" Na salt form was successfully integrated as an ETL between ITO and the bulk heterojunction polymer active layer [181], in perovskite solar cells a DNA hexadecyl trimethyl ammonium chloride (CTMA) complex was used as HTM in an inverted $\mathrm{p} i \mathrm{n}$ device configuration with PCBM as electron acceptor layer. The cells exhibited a PCE of $\sim 15.9 \%$ maintaining more than $85 \%$ of its initial value after 50 days in air [182].

\subsection{Oligomer HTMs}

Oligomer is a molecule of intermediate relative molecular mass which consist of a small plurality of units different than small molecules. Unlike Spiro OMeTAD and PTAA, Oligomer has strong absorption in the visible and near IR region, which contributes to the light harvesting in PSCs. Peng et al. [190] reported oligomer S197, a HTM with an order of magnitude higher hole mobility of $\sim 5.1 \times 10^{-4} \mathrm{~cm}^{2} \mathrm{~V}^{-1} \mathrm{~s}^{-1}$ than Spiro OMeTAD $\left(\sim 4 \times 10^{-5} \mathrm{~cm}^{2} \mathrm{~V}^{-1} \mathrm{~s}^{-1}\right)$ but lower than PTAA $\left(\sim 3 \times 10^{-3} \mathrm{~cm}^{2} \mathrm{~V}^{-1} \mathrm{~s}^{-1}\right)$. The lower molecular weight of $\mathbf{S 1 9 7}$ facilitates its infiltration into perovskite nanocrystals and capping layer is formed above perovskite which effectively block the electron reaching anode. The devices employing $\mathbf{S 1 9 7}$ demon strated a champion $\mathrm{PCE} \sim 12 \%$ and $\mathrm{V}_{\mathrm{OC}} \sim 0.96 \mathrm{~V}$.

\subsection{Inorganic HTMs}

Amongst the various HTM materials employed so far, Sipro OMeTAD and P3HT have shown the best performance typically resulting $\mathrm{PCE} \geq 15 \%$. Despite the efficient performance, these materials are (i) often characterized by inferior hole mobility in their pristine form, (ii) becomes sensitive to humidity upon addition of dopants (typically hygroscopic Li salts) and (iii) are expensive (1 g of Sipro
OMeTAD cost $\sim 500 \$$, see Table 1 ). The humidity sensitiveness often hinders stable performance of PSCs, as will be elaborated in the stability section of this article. This put stringent conditions on the choice of materials to be used as HTM, particularly when the commercial deployment of devices is considered which requires several years of device operation. This brings into play inorganic $p$ type materials that have already shown promising results in the DSSCs and quantum dot solar cells due to wider band gap and high conductivity [191 193]. Furthermore, numerous reports have demon strated that these inorganic hole conductors outperformed spiroOMeTAD based counterparts in solid state dye sensitized solar cells [194,195]. Employing such inorganic materials in PSCs will not only lead to high PCEs but also, more importantly, will result in long term operation and cost effective PSCs. Amongst such materials, CuI, $\mathrm{CuSCN}, \mathrm{NiO}, \mathrm{Cu}_{2} \mathrm{O}$, GO (graphene oxide), $\mathrm{MoO}_{3}$ and lead sulfide quantum dots (PbS QDs) and offer promising possibilities to be employed as HTM in PSCs as listed in Table 6.

\subsubsection{Copper iodide (CuI)}

The first inorganic hole transport material which has been used in PSCs is CuI that resulted in a moderate PCE 6\% [196] with PV parameters $\left(\mathrm{J}_{\mathrm{SC}} \sim 17.8 \mathrm{~mA} \mathrm{~cm}^{-2}, \mathrm{~V}_{\mathrm{OC}} \sim 0.55 \mathrm{~V}, \mathrm{FF} \sim 0.62\right)$ comparable to a spiroOMeTAD based PSC $\left(\mathrm{J}_{\mathrm{SC}} \sim 16.1 \mathrm{~mA} \mathrm{~cm}{ }^{-2}, \mathrm{~V}_{\mathrm{OC}} \sim 0.79 \mathrm{~V}\right.$, $\mathrm{FF} \sim 0.61 \%$ yielding a PCE 7.9\%). However, a lowering of $\sim 300 \mathrm{mV}$ in $\mathrm{V}_{\mathrm{OC}}$ in CuI based PSCs was attributed to the high recombination rate in $\mathrm{CuI}$ due to free iodine that could act as valence band trap and work as a recombination channel, as reported for s DSSC [197]. High hole mobility of CuI $\left(\sim 9.3 \mathrm{~cm}^{2} \mathrm{~V}^{-1} \mathrm{~s}^{-1}\right)$ which is five orders of magnitude greater than that of Spiro OMeTAD $\left(\sim 10^{-4} \mathrm{~cm}^{2} \mathrm{~V}^{-1} \mathrm{~s}^{-1}\right)$ still en courages its use in mesoscopic PSCs (Fig. 12b) [198]. A key obstacle was to deposit $\mathrm{CuI}$ from solution as solvents used to dissolve it can dissolve the perovskite layer also. Towards this end, an inexpensive gas solid reaction method was introduced to deposit a $\mathrm{CuI}$ thin film on $\mathrm{CH}_{3} \mathrm{NH}_{3} \mathrm{PbI}_{3}$ which yielding an exceptionally high $\mathrm{J}_{\mathrm{SC}} \sim 32 \mathrm{~mA} \mathrm{~cm}{ }^{-2}$. The remarkable $\mathrm{J}_{\mathrm{SC}}$ was due to interfacial species formed between the $\mathrm{CH}_{3} \mathrm{NH}_{3} \mathrm{PbI}_{3}$ and the CuI (Fig. 12a) resulting in photocurrent collec tion in NIR region $(\sim 1200 \mathrm{~nm}$, Fig. 12c). The devices showed a PCE 7.4\% with negligible hysteresis (Fig. 12d) compared to $\sim 9.3 \%$ for the spiroOMeTAD counterpart. Chen et al. [58] demonstrated that $\mathrm{CuI}$ as HTM in inverted planar PSCs showed PCE 13.6\%, $\mathrm{V}_{\mathrm{OC}} 1.04 \mathrm{~V}$ owing to its high transmittance and deep valance band $(\sim 5.1 \mathrm{eV})$, and $\mathrm{J}_{\mathrm{SC}} 21.06 \mathrm{~mA} \mathrm{~cm}^{-2}$.

\subsubsection{Copper thiocyanate (CuSCN)}

Marked by good transparency in the visible and infrared regions, high mobility of $\sim 0.010 .1 \mathrm{~cm}^{2} \mathrm{~V}^{-1} \mathrm{~s}^{-1}$, higher than Spiro OMeTAD $\left(4 \times 10^{-5} \mathrm{~cm}^{2} \mathrm{~V}^{-1} \mathrm{~s}^{-1}\right)$, and high chemical stability [199 201], CuSCN remains another compelling HTM of choice in PSCs. Chavhan et al. achieved PCE 6.4\% using CuSCN in planar architecture $\left(\mathrm{FTO} / \mathrm{TiO}_{2} /\right.$ $\mathrm{CH}_{3} \mathrm{NH}_{3} \mathrm{PbI}_{3-\mathrm{x}} \mathrm{Cl}_{\mathrm{x}} / \mathrm{CuSCN} / \mathrm{Au}$ ) with $\mathrm{V}_{\mathrm{OC}} \sim 0.72 \mathrm{~V}$ and $\mathrm{FF} \sim 0.62$. They argued that the lower $\mathrm{V}_{\mathrm{OC}}$ in CuSCN PSCs compared to Spiro OMeTAD analogues is due to the lower diffusion length of CuSCN than its actual film thickness [202]. Ito et al. [203] confirmed the role of CuSCN as hole extraction layers in PSCs by comparing the device with and without CuSCN. They obtained a PCE of $\sim 1.82 \%$ (HTM free, $\mathrm{PCE} \sim 1.35 \%)$ using the following architecture $\left(\mathrm{FTO} / \mathrm{TiO}_{2} /\right.$ thin $\mathrm{CH}_{3} \mathrm{NH}_{3} \mathrm{PbI}_{3} / \mathrm{CuSCN} / \mathrm{Au}$ ) which was further enhanced to $\sim 4.85 \%$ by improving the penetration of $\mathrm{CH}_{3} \mathrm{NH}_{3} \mathrm{PbI}_{3}$ into $\mathrm{TiO}_{2}$ pores using hot air during spin coating. In another report [204], the same group introduced a $\mathrm{Sb}_{2} \mathrm{~S}_{3}$ layer between $\mathrm{TiO}_{2}$ and $\mathrm{CH}_{3} \mathrm{NH}_{3} \mathrm{PbI}_{3}$ and noticed that the $\mathrm{Sb}_{2} \mathrm{~S}_{3}$ layer not only enhanced PCE to $\sim 5.24 \%$, but also increased the device stability under light exposure without encapsula tion. However, the enhanced stability is attributed to a less reactive surface of $\mathrm{Sb}_{2} \mathrm{~S}_{3}$ as compared to $\mathrm{TiO}_{2}$, which is believed to react with perovskite eventually leading to its crystal decomposition [205,206]. Qin et al. [207] achieved a PCE 12.4\% using $\mathrm{CH}_{3} \mathrm{NH}_{3} \mathrm{PbI}_{3}$ based 
Table 6

Device architecture and photovoltaic parameters of inorganic hole transport materials based PSCs.

\begin{tabular}{|c|c|c|c|c|c|c|}
\hline \multirow[t]{2}{*}{ Device Configuration } & \multirow[t]{2}{*}{ Perovskite Deposition method } & \multicolumn{4}{|c|}{ Photovoltaic parameters } & \multirow[t]{2}{*}{ Ref. } \\
\hline & & Voc (V) & $\operatorname{Jsc}\left(\mathbf{m A ~ c m}{ }^{2}\right)$ & FF & PCE (\%) & \\
\hline \multicolumn{7}{|l|}{ CuI } \\
\hline $\mathrm{CL} / \mathrm{mpTiO}_{2} / \mathrm{CH}_{3} \mathrm{NH}_{3} \mathrm{Pbl}_{3} / \mathrm{CuI} / \mathrm{Au}$ & OSSD & 0.55 & 17.8 & 0.62 & 6.0 & {$[196]$} \\
\hline $\mathrm{CuI} / \mathrm{CH} 3 \mathrm{NH} 3 \mathrm{PbI} 3 / \mathrm{PCBM} / \mathrm{Al}$ & GSC & 1.04 & 21.06 & 0.62 & 13.58 & {$[58]$} \\
\hline \multicolumn{7}{|l|}{ CuSCN } \\
\hline $\mathrm{CL} / \mathrm{mp} \mathrm{TiO}{ }_{2} / \mathrm{CH}_{3} \mathrm{NH}_{3} \mathrm{Pbl}_{3} / \mathrm{CuSCN} / \mathrm{Au}$ & OSSD & 0.63 & 14.5 & 0.53 & 4.85 & {$[203]$} \\
\hline $\mathrm{CL} / \mathrm{mpTiO}_{2} / \mathrm{Sb}_{2} \mathrm{~S}_{3} / \mathrm{CH}_{3} \mathrm{NH}_{3} \mathrm{PbI}_{3} / \mathrm{CuSCN} / \mathrm{Au}$ & OSSD & 0.57 & 17.23 & 0.52 & 5.12 & {$[204]$} \\
\hline $\mathrm{CL} / \mathrm{CH}_{3} \mathrm{NH}_{3} \mathrm{PbI}_{3} \mathrm{Cl}_{\mathrm{x}} / \mathrm{CuSCN} / \mathrm{Au}$ & OSSD & 0.72 & 14.4 & 0.61 & 6.4 & {$[202]$} \\
\hline $\mathrm{CL} / \mathrm{mes}^{-\mathrm{TiO}_{2}} / \mathrm{CH}_{3} \mathrm{NH}_{3} \mathrm{Pbl}_{3} / \mathrm{CuSCN} / \mathrm{Au}$ & SD & 1.01 & 19.7 & 0.62 & 12.4 & {$[207]$} \\
\hline $\mathrm{CuSCN} / \mathrm{CH} 3 \mathrm{NH} 3 \mathrm{PbI} 3 / \mathrm{C} 60 / \mathrm{BCP} / \mathrm{Ag}$ & SD & 0.92 & 21.4 & 0.68 & 13.4 & {$[60]$} \\
\hline $\mathrm{CuSCN} / \mathrm{CH} 3 \mathrm{NH} 3 \mathrm{PbI} 3 / \mathrm{C} 60 / \mathrm{BCP} / \mathrm{Ag}$ & OSSD & 1.00 & 21.9 & 0.75 & 16.6 & {$[60]$} \\
\hline \multicolumn{7}{|l|}{ NiO } \\
\hline $\mathrm{CL}-\mathrm{NiO} / \mathrm{NP}-\mathrm{NiO} / \mathrm{CH}_{3} \mathrm{NH}_{3} \mathrm{PbI}_{3} / \mathrm{PCBM} / \mathrm{Al}$ & OSSD & 0.83 & 4.9 & 0.35 & 1.5 & {$[215]$} \\
\hline $\mathrm{CL}-\mathrm{NiO} / \mathrm{CH}_{3} \mathrm{NH}_{3} \mathrm{PbI}_{3} / \mathrm{C}_{60} / \mathrm{BCP} / \mathrm{Al}$ & OSSD & 0.74 & 12.95 & 0.60 & 5.7 & {$[219]$} \\
\hline $\mathrm{NP}-\mathrm{NiO} / \mathrm{CH} 3 \mathrm{NH}_{3} \mathrm{PbI}_{3 \mathrm{x}} \mathrm{Clx} / \mathrm{PCBM} / \mathrm{Ag}$ & DSVD & 0.78 & 14.2 & 0.65 & 7.26 & {$[208]$} \\
\hline $\mathrm{CL}-\mathrm{NiO} / \mathrm{CH}_{3} \mathrm{NH}_{3} \mathrm{PbI}_{3} / \mathrm{PCBM} / \mathrm{BCP} / \mathrm{Al}$ & $\mathrm{SD}$ & 0.92 & 11.77 & 0.68 & 7.40 & {$[31]$} \\
\hline $\mathrm{CL}-\mathrm{NiO} / \mathrm{CH}_{3} \mathrm{NH}_{3} \mathrm{PbI}_{3} / \mathrm{PCBM} / \mathrm{BCP} / \mathrm{Al}$ & OSSD & 0.92 & 12.43 & 0.68 & 7.8 & [219] \\
\hline $\mathrm{nc}-\mathrm{NiO} / \mathrm{CH}_{3} \mathrm{NH}_{3} \mathrm{PbI}_{3} / \mathrm{PCBM} / \mathrm{Au}$ & SD & 0.88 & 16.27 & 0.63 & 9.11 & {$[216]$} \\
\hline $\mathrm{CL}-\mathrm{NiO} / \mathrm{nc}-\mathrm{NiO} / \mathrm{CH}_{3} \mathrm{NH}_{3} \mathrm{PbI}_{3} / \mathrm{PC}_{71} \mathrm{BM} / \mathrm{BCP} / \mathrm{Al}$ & $\mathrm{SD}$ & 1.00 & 14.65 & 0.64 & 9.44 & {$[31]$} \\
\hline CL-NiO/nc- NiO/CH${ }_{3} \mathrm{NH}_{3} \mathrm{PbI}_{3} / \mathrm{PCBM} / \mathrm{BCP} / \mathrm{Al}$ & SD & 1.04 & 13.24 & 0.69 & 9.51 & {$[31]$} \\
\hline $\mathrm{CL}-\mathrm{NiO} / \mathrm{CH}_{3} \mathrm{NH}_{3} \mathrm{PbI}_{3} / \mathrm{PCBM} / \mathrm{BCP} / \mathrm{Au}$ & SED & 1.10 & 15.17 & 0.59 & 9.84 & [218] \\
\hline $\mathrm{CL} / \mathrm{mp} \mathrm{TiO} / 2 / \mathrm{NiO} / \mathrm{CH}_{3} \mathrm{NH}_{3} \mathrm{PbI}_{3} /$ carbon & SD & 0.89 & 18.2 & 0.71 & 11.4 & [73] \\
\hline $\mathrm{CL}-\mathrm{NiO} / \mathrm{nc}-\mathrm{NiO} / \mathrm{CH}_{3} \mathrm{NH}_{3} \mathrm{PbI}_{3} / \mathrm{PCBM} / \mathrm{BCP} / \mathrm{Al}$ & SD & 0.96 & 19.8 & 0.61 & 11.6 & {$[220]$} \\
\hline $\mathrm{CL}-\mathrm{NiO} / \mathrm{mp} \mathrm{Al} \mathrm{O}_{3} / \mathrm{CH}_{3} \mathrm{NH}_{3} \mathrm{PbI}_{3} / \mathrm{PCBM} / \mathrm{BCP} / \mathrm{Ag}$ & OSSD & 1.04 & 17.9 & 0.73 & 13.5 & {$[221]$} \\
\hline $\mathrm{CL} / \mathrm{mp} \mathrm{TiO}{ }_{2} / \mathrm{ZrO}_{2} / \mathrm{NiO} /$ carbon- $\mathrm{CH}_{3} \mathrm{NH}_{3} \mathrm{PbI}_{3}$ & $\mathrm{SD}$ & 0.91 & 21.63 & 0.76 & 14.9 & [224] \\
\hline CL-Cu: $\mathrm{NiO} / \mathrm{CH}_{3} \mathrm{NH}_{3} \mathrm{PbI}_{3} / \mathrm{PCBM} / \mathrm{C}_{60} / \mathrm{Ag}$ & OSSD & 1.11 & 19.01 & 0.73 & 15.4 & {$[30]$} \\
\hline $\mathrm{CL}-\mathrm{NiO} / \mathrm{CH}_{3} \mathrm{NH}_{3} \mathrm{PbI}_{3} / \mathrm{ZnO} / \mathrm{Al}$ & TSSD & 1.01 & 21.00 & 0.76 & 16.1 & [44] \\
\hline $\mathrm{mp}-\mathrm{NiO} / \mathrm{CH}_{3} \mathrm{NH}_{3} \mathrm{PbI}_{3} / \mathrm{PCBM} / \mathrm{LiF} / \mathrm{Al}$ & SET & 1.06 & 20.2 & 0.81 & 17.3 & {$[62]$} \\
\hline \multicolumn{7}{|l|}{$\mathrm{Cu}_{2} \mathrm{O}$} \\
\hline $\mathrm{Cu}_{2} \mathrm{O} / \mathrm{CH}_{3} \mathrm{NH}_{3} \mathrm{PbI}_{3} / \mathrm{PCBM} / \mathrm{Al}$ & OSSD & 0.89 & 16.52 & 0.56 & 8.23 & {$[229]$} \\
\hline $\mathrm{CL} / \mathrm{CH}_{3} \mathrm{NH}_{3} \mathrm{PbI}_{3} \mathrm{Cl}_{\mathrm{x}} / \mathrm{Cu}_{2} \mathrm{O} / \mathrm{Au}$ & VASP & 0.96 & 15.8 & 0.59 & 8.91 & {$[230]$} \\
\hline $\mathrm{Cu}_{2} \mathrm{O} / \mathrm{CH}_{3} \mathrm{NH}_{3} \mathrm{PbI}_{3} / \mathrm{PCBM} / \mathrm{Ag}$ & $\mathrm{SD}$ & 0.95 & 17.5 & 0.66 & 11.03 & {$[231]$} \\
\hline $\mathrm{Cu}_{2} \mathrm{O} / \mathrm{CH}_{3} \mathrm{NH}_{3} \mathrm{PbI}_{3} / \mathrm{PCBM} / \mathrm{Al} / \mathrm{Ca}$ & OSSD & 1.07 & 16.52 & 0.75 & 13.35 & {$[64]$} \\
\hline $\mathrm{CuO}_{\mathrm{x}} / \mathrm{CH}_{3} \mathrm{NH}_{3} \mathrm{PbI}_{3} / \mathrm{C}_{60} / \mathrm{BCP} / \mathrm{Ag}$ & FDC & 0.99 & 23.2 & 0.74 & 17.1 & {$[232]$} \\
\hline \multicolumn{7}{|l|}{ GO } \\
\hline $\mathrm{GO} / \mathrm{CH}_{3} \mathrm{NH}_{3} \mathrm{PbI}_{3}{ }_{x} \mathrm{Cl}_{\mathrm{x}} / \mathrm{PCBM} / \mathrm{ZnO} / \mathrm{Al}$ & OSSD & 1.00 & 17.46 & 0.71 & 12.40 & {$[242]$} \\
\hline $\mathrm{CL} / \mathrm{mp} \mathrm{T_{0 }} / \mathrm{CH}_{3} \mathrm{NH}_{3} \mathrm{PbI}_{3} / \mathrm{GO} /$ Spiro OMTAD/Au & SD & 1.04 & 20.2 & 0.73 & 15.1 & {$[65]$} \\
\hline \multicolumn{7}{|l|}{$\mathrm{WO}_{3}$} \\
\hline $\mathrm{WO}_{3} / \mathrm{CH}_{3} \mathrm{NH}_{3} \mathrm{PbI}_{3} / \mathrm{PCBM} / \mathrm{Al}$ & SD & 0.92 & 18.1 & 0.64 & 7.68 & {$[253]$} \\
\hline $\mathrm{WO}_{3} / \mathrm{CH}_{3} \mathrm{NH}_{3} \mathrm{PbI}_{3} / \mathrm{PCBM} / \mathrm{Ag}$ & TSSD & 0.93 & 16.6 & 0.64 & 9.8 & {$[254]$} \\
\hline \multicolumn{7}{|l|}{$\mathbf{V O}_{\mathbf{x}}$} \\
\hline $\mathrm{VO}_{\mathrm{X}} / \mathrm{CH}_{3} \mathrm{NH}_{3} \mathrm{PbI}_{3} / \mathrm{PCBM} / \mathrm{Al}$ & OSSD & 0.9 & 22.29 & 0.7 & 14.23 & {$[252]$} \\
\hline PEDOT: PSS- $\mathrm{V}_{2} \mathrm{O}_{\mathrm{x}} / \mathrm{CH}_{3} \mathrm{NH}_{3} \mathrm{PbI}_{3} / \mathrm{C}_{60} / \mathrm{BCP} / \mathrm{Ag}$ & OSSD & 1.05 & 21.2 & 0.78 & 17.5 & {$[251]$} \\
\hline \multicolumn{7}{|l|}{ Quantum dots } \\
\hline $\mathrm{PbS} / \mathrm{CH}_{3} \mathrm{NH}_{3} \mathrm{PbI}_{3 /} / \mathrm{PCBM} / \mathrm{Al}$ & SD & 0.86 & 12.1 & 0.72 & 7.5 & {$[265]$} \\
\hline $\mathrm{CL} / \mathrm{mp} \mathrm{TiO}{ }_{2} / \mathrm{CH}_{3} \mathrm{NH}_{3} \mathrm{PbI}_{3} / \mathrm{CuInS}_{2}-\mathrm{ZnS} / \mathrm{Au}$ & TSSD & 0.92 & 18.6 & 0.48 & 8.38 & [266] \\
\hline
\end{tabular}

FDC: fast crystallization-deposition.

mesoscopic PSCs (FTO/ $\left.\mathrm{TiO}_{2} / \mathrm{CH}_{3} \mathrm{NH}_{3} \mathrm{PbI}_{3} / \mathrm{CuSCN} / \mathrm{Au}\right)$ with $\mathrm{V}_{\mathrm{OC}} \sim 1.02 \mathrm{~V}$. They used two step deposition technique to control the thickness of perovskite and also to attain an over layer of $\sim 200 \mathrm{~nm}$ to prevent direct contact between $\mathrm{TiO}_{2}$ and $\mathrm{CuSCN}$. The $\mathrm{CuSCN}$ layer was deposited using doctor blading technique at $65^{\circ} \mathrm{C}$, a method that is compatible with mass production of PSCs. Devices using CuSCN resulted in $65 \%$ and $9 \%$ higher $\mathrm{J}_{\mathrm{SC}}$ and $\mathrm{V}_{\mathrm{OC}}$ compared to HTM free architecture. Inspired from the progress in mesoscopic PSCs, research ers also employed CuSCN in inverted planar PSCs in following architecture (FTO/CuSCN/ $\left.\mathrm{CH}_{3} \mathrm{NH}_{3} \mathrm{PbI}_{3-\mathrm{x}} \mathrm{Cl} / \mathrm{PCBM} / \mathrm{Ag}\right)$ [208]. Despite the fact that FTO/CuSCN interface demonstrated > 90\% PL quenching efficiency (Fig. 13), the PCE was limited to $3.8 \%$ due to low shunt resistance for thinner CuSCN layers and higher series resistance for the thicker layers. Further research is required to tune its performance in planar heterojunction devices.

The highest PCE $(\sim 16.6 \%)$ in PSCs using CuSCN is reported by Ye et al. in the inverted planar PSCs [60] of ITO/CuSCN/ $\mathrm{CH}_{3} \mathrm{NH}_{3} \mathrm{PbI}_{3} /$ $\mathrm{C}_{60} / \mathrm{BCP} / \mathrm{Ag}$ architecture. The CuSCN layer was electrodeposited leading to a lower surface roughness and smaller contact resistance between the $\mathrm{CH}_{3} \mathrm{NH}_{3} \mathrm{PbI}_{3}$ layer and $\mathrm{CuSCN}$ thereby. The perovskite film was deposited via drop casting assisted one step spin coating leading to high perovskite coverage. The device showed a high $\mathrm{V}_{\mathrm{OC}} \sim 1 \mathrm{~V}$ and $\mathrm{FF} \sim 0.75$, higher compared to $\sim 0.9 \mathrm{~V}$ and $\sim 0.68$ for corresponding devices made via a typical sequential deposition method of perovskite. It is clear that deposition method of the HTM, as well as that of the perovskite absorber, play an important role in the performance of the PSCs. A dense and thin HTM layer $(\sim 100 \mathrm{~nm})$ lead to excellent transparency in the visible light spectrum range and also an efficient 
hole transfer at the HTM/perovskite interface. Moreover, the perovs kite surface roughness and surface relaxation affects the performance of PSCs. Smoother perovskite film may reduce cost of PSCs as thinner HTM coverage is needed compared to rough films.

\subsubsection{Nickel oxide (NiO)}

Since the work of Irwin et al. reporting enhancement in perfor mance of polymer bulk heterojunction solar cells (BHJ) by replacing the PEDOT: PSS layer by a thin p type semiconducting NiO layer [209], it became one of the HTM of choice in OPV and DSSCs [210 214]. Owing to large energy gap, good conductivity of holes and deep VB edge level (5.2 $5.4 \mathrm{eV}$ ), which match well with the $\mathrm{VB}$ of $\mathrm{CH}_{3} \mathrm{NH}_{3} \mathrm{PbI}_{3}$ perovskite $(5.4 \mathrm{eV}), \mathrm{NiO}$ is marked as a promising material for $\mathrm{p}$ type or inverted PSCs. Docampo et al. [162] first reported a thin NiO layer as HTM using $\mathrm{CH}_{3} \mathrm{NH}_{3} \mathrm{PbI}_{3-\mathrm{x}} \mathrm{Cl}_{\mathrm{x}}$ PSCs and noticed that a low coverage of perovskite surface lead to direct contact between the HTM (NiO) and the ETL (PCBM) resulting in low device performance PCE 0.1\%. Subsequently, Tian et al. reported mesoporous $\mathrm{NiO}$ as HTM in mesoscopic architecture ( $\mathrm{CL} \mathrm{NiO} / \mathrm{NP} \mathrm{NiO} / \mathrm{CH}_{3} \mathrm{NH}_{3} \mathrm{PbI}_{3} / \mathrm{PCBM} / \mathrm{Al}$ ) [215] with notable rise in PCE $(\sim 1.5 \%)$ by controlling the thickness of the $\mathrm{BL} \mathrm{NiO}$ and $\mathrm{NP} \mathrm{NiO}$ to be 80 and $120 \mathrm{~nm}$, respectively.

The PCE for the NiO based inverted mesoscopic PSCs has been further improved by Zhu et al. using NiO nanocrystal (NC) [216]. Sol gel and two step deposition methods have been used to control the thickness of NiO layer and perovskite, respectively. An optimized thickness of $\mathrm{NiO} \mathrm{NC}$ and perovskite $(\sim 40 \mathrm{~nm}$ and $\sim 250 \mathrm{~nm}$ thickness, respectively) yielded $\mathrm{PCE} \sim 9.1 \%$ and $\mathrm{V}_{\mathrm{OC}} \sim 0.88 \mathrm{~V}$ in inverted PSCs (NiO $\left.\mathrm{NC} / \mathrm{CH}_{3} \mathrm{NH}_{3} \mathrm{PbI}_{3} / \mathrm{PCBM} / \mathrm{Al}\right)$. Similarly, post treatment of NiO layer by $\mathrm{O}_{2}$ plasma showed a PCE 7.3\% with $\mathrm{V}_{\mathrm{OC}} \sim 0.78 \mathrm{~V}$ [208]. The $\mathrm{NiO}$ was electrodeposited whereas the perovskite layer was synthesized via vacuum evaporated technique in a device architecture $\mathrm{FTO} / \mathrm{NiO} /$ $\mathrm{CH}_{3} \mathrm{NH}_{3} \mathrm{PbI}_{3-\mathrm{x}} \mathrm{Cl}_{\mathrm{x}} / \mathrm{PCBM} / \mathrm{Ag}$. In a similar work, Hu et al. [217] carried out UVO treatment for NiO layers in a planar inverted PSC(ITO/NiO (solution) $/ \mathrm{CH}_{3} \mathrm{NH}_{3} \mathrm{PbI}_{3} / \mathrm{PCBM} / \mathrm{Al}$ ) while also controlling the pin hole free structure of perovskite layer using sequential deposition method. An optimized thickness of $\mathrm{NiO}$ and a 10 min UVO treatment yielded a $\mathrm{PCE} \sim 7.6 \%$ and impressive $\mathrm{V}_{\mathrm{OC}} \sim 1.05 \mathrm{~V}$. These studies showed that the quality of $\mathrm{NiO}$ film and its surface treatment to remove defect states and impurities is crucial to obtaining high PCE in PSCs. Nevertheless, various reports employed $\mathrm{NiO}$ as HTM in the inverted planar structure and the reported PCE is in the range of $\sim 610 \%[216,218,219]$. The higher PCE 15.4\% $\left(\mathrm{J}_{\mathrm{SC}} \sim 19 \mathrm{~mA} \mathrm{~cm}{ }^{-2}, \mathrm{FF} \sim 0.73\right.$ and $\left.\mathrm{V}_{\mathrm{OC}} \sim 1.1 \mathrm{~V}\right)$ for the $\mathrm{NiO}$ based inverted planar PSCs is reported by Kim et al. [30] using solution processed $\mathrm{Cu}$ doped $\mathrm{NiO}_{\mathrm{x}}$ which is remarkably higher than a pristine $\mathrm{NiO}$ based device (PCE 8.9\%, $\mathrm{J}_{\mathrm{SC}} \sim 4.1 \mathrm{~mA} \mathrm{~cm}{ }^{-2}, \mathrm{FF} \sim 0.6$ and $\mathrm{V}_{\mathrm{OC}} \sim 1.1 \mathrm{~V}$ ). The enhancement of $\mathrm{J}_{\mathrm{SC}}$ and FF is due to the improved electrical conductivity of 5 at $\% \mathrm{Cu}: \mathrm{NiO}_{\mathrm{x}}$ which enabled more efficient charge extraction from the $\mathrm{CH}_{3} \mathrm{NH}_{3} \mathrm{PbI}_{3}$ absorber. Moreover, the general applicability of $\mathrm{Cu}: \mathrm{NiO}_{\mathrm{x}}$ in perovskite of larger $\mathrm{E}_{\mathrm{g}}$ $\left[\mathrm{CH}_{3} \mathrm{NH}_{3} \mathrm{~Pb}\left(\mathrm{I}_{1-\mathrm{x}} \mathrm{Br}_{\mathrm{x}}\right)_{3}\right]$ solar cells has been demonstrated which exhibit
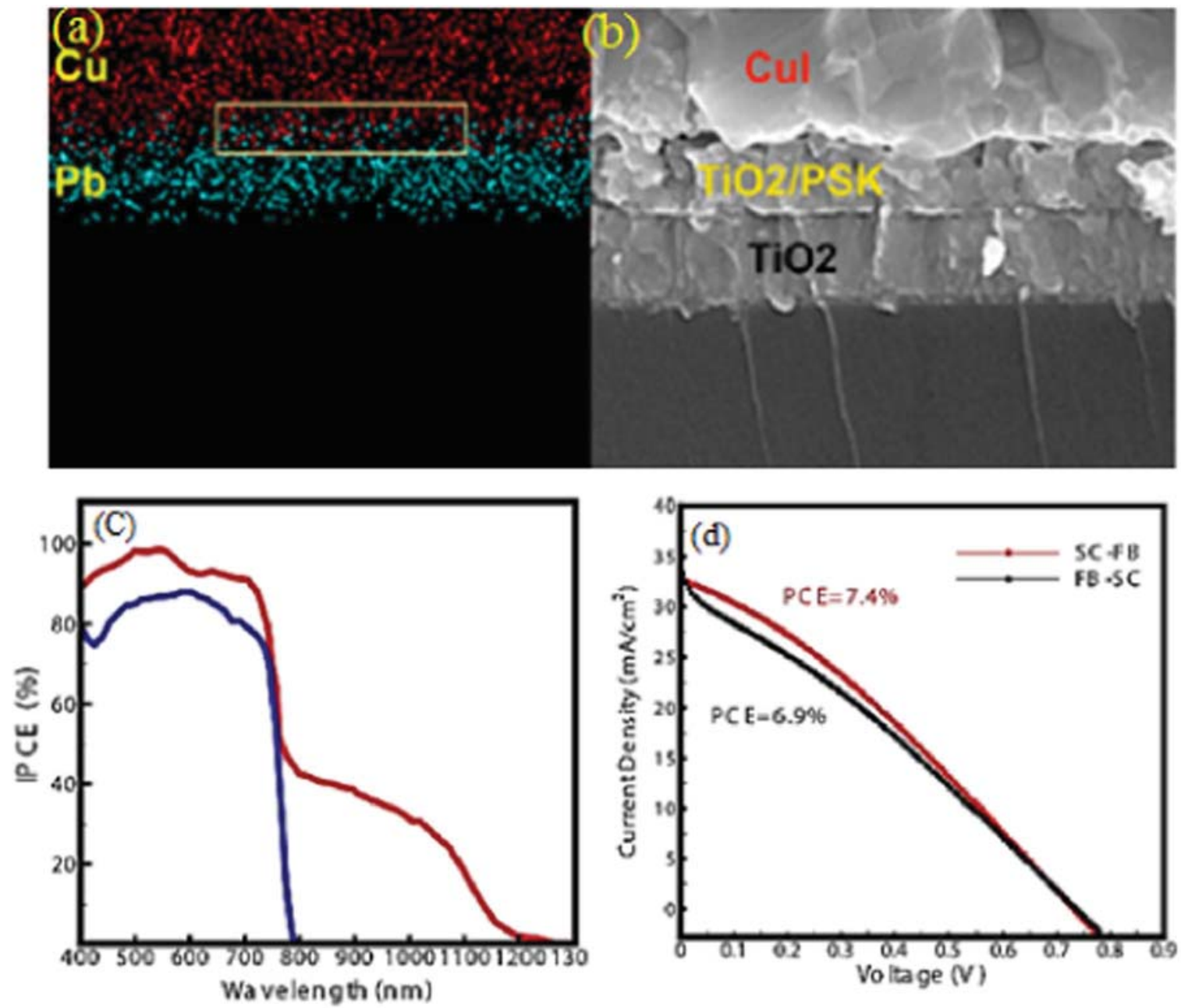

Fig. 12. (a) X-ray spectroscopy image confirm diffusion of $\mathrm{Cu}$ atoms into the perovskite layer at the interface of perovskite/CuI (rectangular box), (b) Cross sectional FE SEM images of theTiO ${ }_{2}$ /perovskite/CuI layer, (c) Photon-to-electron conversion efficiency of PSCs with CuI (red curve) and Spiro- OMTAD (blue curve) as HTM, and (d) J-V curves of devices prepared with CuI as the HTM in the scan direction of forward bias to short circuit (FB SC) and short circuit to forward bias (SC FB). Figure are reproduced with permission from Ref. [198]. John Wiley and Sons. 

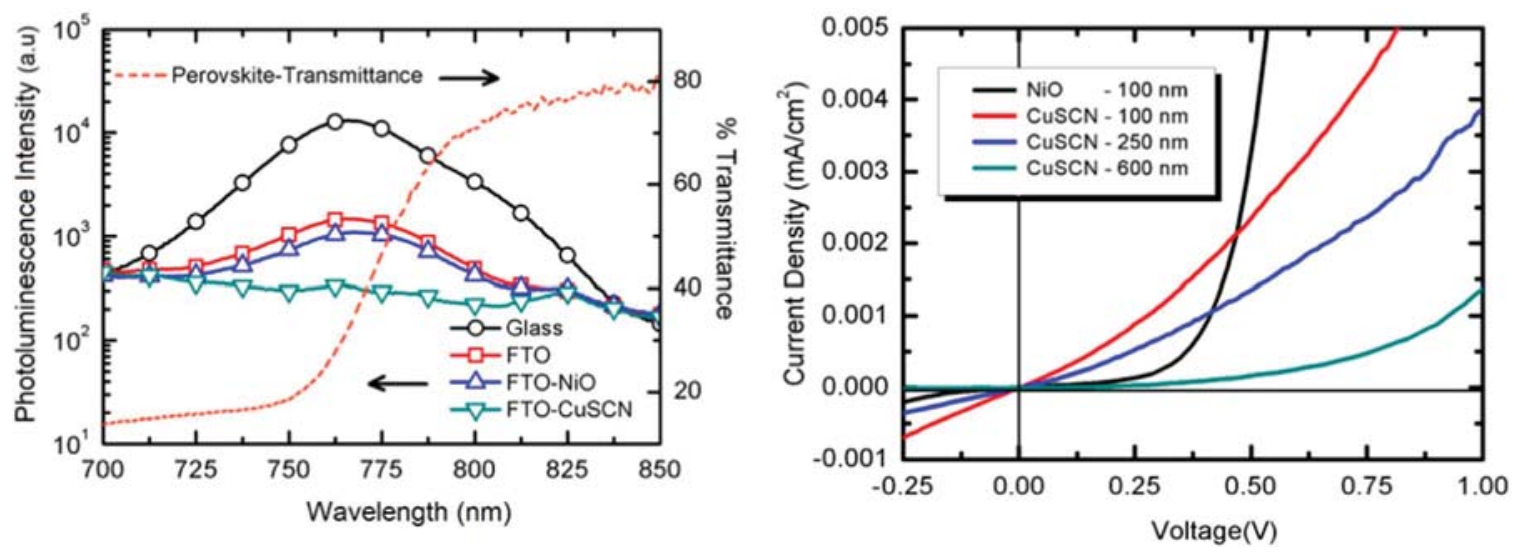

Fig. 13. (Left) Photoluminescence (PL) intensity of CH3NH3PbI3 xClx on (i) glass, (ii) FTO, (iii) FTO/NiO, and (iv) FTO/CuSCN. Maximum charge quenching is showed for perovskite on FTO/CuSCN, and, dark I V curves of NiO and CuSCN based PSCs (right). Figures are reproduced with permission from [208]. Copyright of American Chemical Society.

high $\mathrm{V}_{\mathrm{OC}} \sim 1.11 .2 \mathrm{~V}[30]$.

Chen and Guo groups reported a systematic study on the effect of HTM and perovskite morphologies and a correlation between band alignment and the $\mathrm{PV}$ parameters in $\mathrm{NiO}$ based inverted PSCs $[31,219,220]$. In the inverted planar PSCs $\left(\mathrm{CL} \mathrm{NiO} / \mathrm{CH}_{3} \mathrm{NH}_{3} \mathrm{PbI}_{3} /\right.$ $\mathrm{PCBM} /$ bathocuproine $\mathrm{BCP} / \mathrm{Al}$ ), they reported $\mathrm{PCE} \sim 7.8 \%$ and $\mathrm{V}_{\mathrm{OC}} \sim 0.92 \mathrm{~V}$ for a $\sim 60 \mathrm{~nm}$ thick perovskite layer which is nearly double than that of PSCs employing PEDOT: PSS (PCE 3.9\% and $\mathrm{V}_{\mathrm{OC}} \sim 0.62 \mathrm{~V}$ ). The higher PV parameters in the former are due to good alignment of the $\mathrm{VB}$ of $\mathrm{NiO}$ with $\mathrm{VB}$ of perovskite. Another reason for the high $\mathrm{V}_{\mathrm{OC}}$ in NiO PSCs is their better perovskite surface coverage, 93\% for ITO/NiO compared with $85 \%$ for ITO/PEDOT: PSS, which prevents contact of the HTM with the ETL and thereby avoids charge recombination. In another report, the same group enhanced the PCE to 9.51\% using mesoscopic inverted structure composed of (ITO/NiO (solution) $/ \mathrm{NiO}_{\mathrm{nc}} \mathrm{CH}_{3} \mathrm{NH}_{3} \mathrm{PbI}_{3} / \mathrm{PCBM} /(\mathrm{BCP}) / \mathrm{Al}$ ) structure [31]. The high PCE was attributed to the mesoporous layers $\left(\mathrm{NiO}_{\mathrm{nc}}\right)$ which accommodated thicker perovskite layers and prevented the risk of morphological defects, that could otherwise determine a decay of photovoltaic performance in the planar structure (PCE 7.8\%). To fill the nano pores of the $\mathrm{NiO}_{\mathrm{nc}}$ with high surface coverage, sequential deposition method was used that led to $\sim 250 \mathrm{~nm}$ thick mesoscopic junction, which is large enough to absorb $90 \%$ of the incident light. An increased light harvesting efficiency (LHE) was observed in the mesoscopic device compared to a planar one. While the IPCE for planar device was still higher in the short wavelength range (400 $500 \mathrm{~nm}$ ), the mesoscopic devices possessed enhanced IPCE at longer wavelengths.

The PCE was further enhanced to $\sim 10.7 \%$ by the same group when the $\mathrm{NiO}$ was deposited using sputtering to get a homogenous and uniform HTM layer [220]. Such as layer not only improved its contact with the substrate but also allowed them to obtain a uniform morphology of perovskite layer over it. The PCE was further increased to $\sim 11.6 \%$ at optimized oxygen doping in argon atmosphere.

In order to minimize the losses during light harvesting and charge transfer at the interfaces, Chen et al. [221] reported a hybrid interfacial layer of "compact $\mathrm{NiO} / \mathrm{mp} \mathrm{Al}_{2} \mathrm{O}_{3}$ " in inverted PSCs device of CL NiO/ $\mathrm{Al}_{2} \mathrm{O}_{3} / \mathrm{CH}_{3} \mathrm{NH}_{3} \mathrm{PbI}_{3} / \mathrm{PCBM} / \mathrm{BCP} / \mathrm{Ag}$ with high $\mathrm{PCE} \sim 13.5 \%$ with im pressive $\mathrm{V}_{\mathrm{OC}} \sim 1.04 \mathrm{~V}$. This interfacial layer exerted an important "dual blocking effect" as shown in Fig. 14. It acts as a barrier between the FTO and $\mathrm{CH}_{3} \mathrm{NH}_{3} \mathrm{PbI}_{3}$ and also helps to block the shunt paths between $\mathrm{NiO} / \mathrm{PCBM}$ via the $\mathrm{mp} \mathrm{Al}_{2} \mathrm{O}_{3}$ layer filled with perovskite crystals.

Another interesting device design for PSCs is metal back contact free, inspired from monolithic DSSCs [222,223]. Typically, carbon black/graphite are stacked on top of perovskite layer. Mei et al. used 5 ammoniumvaleric acid iodide modified perovskite ((5 AVA $)_{\mathrm{x}}(\mathrm{MA})_{1-\mathrm{x}}$ $\mathrm{PbI}_{3}$ ) as an absorber in HTM free PSCs that resulted in PCE 12.8\%
[29]. These results demonstrate the potential of earth abundant carbon materials for cost effective PSCs. Zonghao Liu et al. [73] replaced mesoporous $\mathrm{ZrO}_{2}$ by NiO in the state of the art monolithic PSCs which resulted in an impressive $\mathrm{PCE} \sim 11.4 \%$ ( $\mathrm{V}_{\mathrm{OC}} \sim 0.89 \mathrm{~V}$ and $\left.\mathrm{FF} \sim 0.71\right)$. In the PSCs with architecture $\mathrm{CL} / \mathrm{mpTiO}_{2} / \mathrm{NiO} / \mathrm{C}\left(\mathrm{CH}_{3} \mathrm{NH}_{3} \mathrm{PbI}_{3}\right)$, $\mathrm{CH}_{3} \mathrm{NH}_{3} \mathrm{PbI}_{3}$ was deposited via a two step deposition method while the mesoporous $\mathrm{NiO}$ and $\mathrm{TiO}_{2}$ layers are fabricated by screen printing technique. Subsequently, $\mathrm{Xu}$ et al. [224] reported a structure of $\mathrm{TiO}_{2} /$ $\mathrm{ZrO}_{2} / \mathrm{NiO} /$ carbon $\mathrm{CH}_{3} \mathrm{NH}_{3} \mathrm{PbI}_{3}$ with $\mathrm{PCE} \sim 14.9 \%$ and $\mathrm{V}_{\mathrm{OC}} \sim 0.91 \mathrm{~V}$ which was higher compared to a $\mathrm{TiO}_{2}$ only based counterpart (PCE 10.4\% and $\mathrm{V}_{\mathrm{OC}} \sim 0.86 \mathrm{~V}$ ). Cao et al. [225] added a $800 \mathrm{~nm}$ mesoporous NiO layer screen printed just underneath of the $10 \mu \mathrm{m}$ carbon black/graphite top contact to improve charge collection and reduce charge recombination leading to a PCE $15 \%$. The highest PCE 17.3\%, $\mathrm{V}_{\mathrm{OC}} \sim 1.06 \mathrm{~V}$ achieved by Seok et al. [62] using inverted planar PSCs, in which a well ordered nanostructured NiO film was prepared through a pulsed laser deposition (PLD) method. This efficiency is the highest so far for PSCs using inorganic HTMs.

In summary, the $\mathrm{p}$ type semiconductor $\mathrm{NiO}$ has been demonstrated to be an efficient HTM in PSCs with impressive photovoltaic perfor mance with $\mathrm{V}_{\mathrm{OC}} \sim 1.11 \mathrm{~V}$, closer to that achieved in a state of the art mesoporous PSCs configuration using spiroOMeTAD. The robust and abundant NiO material promises a cost effective and potentially stable commercially deployable perovskite solar cells.

\subsubsection{Cuprous oxide $\left(\mathrm{Cu}_{2} \mathrm{O}\right)$}

High hole mobility $100 \mathrm{~cm}^{2} \mathrm{~V}^{-1} \mathrm{~s}^{-1}$ [63], long carrier diffusion length and direct band gap $(\sim 2.17 \mathrm{eV})[226]$ are the main reasons for using $\mathrm{Cu}_{2} \mathrm{O}$ as HTM in heterojunction solar cells [227]. Moreover, simulation results showing that a PCE $>13 \%$ could be achieved with an optimized $\mathrm{Cu}_{2} \mathrm{O}$ as HTM in PSCs [228]. Therefore, owing to natural abundance of $\mathrm{Cu}_{2} \mathrm{O}$ becomes a promising alternative HTM in PSCs resulting in high PCE 8 $17 \%[64,229$ 231] as listed in Table 6. Nejand et al. [230] deposited $\mathrm{Cu}_{2} \mathrm{O}$ layer on pinhole free $\mathrm{CH}_{3} \mathrm{NH}_{3} \mathrm{PbI}_{3-\mathrm{x}} \mathrm{Cl}_{\mathrm{x}}$ using magnetron sputtering in planar structure, yielding a PCE $\sim 8.93 \%$ with $\mathrm{V}_{\mathrm{OC}} \sim 0.96 \mathrm{~V}$ compared to $\sim 11.5 \%$ and $\sim 0.99 \mathrm{~V}$ pin hole free Spiro OMTAD device shown in Fig. 15. Similarly, $\mathrm{Yu}$ et al. [231] sputter $\mathrm{Cu}$ with a thermal oxidation control to get ultrathin $\mathrm{Cu}_{2} \mathrm{O}$ layer $(5 \mathrm{~nm})$ as $\mathrm{HTM}$ in inverted planar PSCs. A PCE 11.03\% with $\mathrm{V}_{\mathrm{OC}} \sim 0.95 \mathrm{~V}$ was demonstrated. To simplify the film process of HTM and improve the PCE of PSCs Zuo et al. [64] presented a facile low temperature method to prepare $\mathrm{Cu}_{2} \mathrm{O}$ and use it as HTM in the inverted structure ITO/HTM $/ \mathrm{CH}_{3} \mathrm{NH}_{3} \mathrm{PbI}_{3} / \mathrm{PCBM} / \mathrm{Al} / \mathrm{Ca}$ which showing a significantly enhanced $\mathrm{V}_{\mathrm{OC}} \sim 1.07 \mathrm{~V}, \mathrm{~J}_{\mathrm{SC}} \sim 16.52 \mathrm{~mA} \mathrm{~cm}^{-2}$, $\mathrm{FF} \sim 0.75$ and high PCE 13.35\% compared with $\mathrm{V}_{\mathrm{OC}} \sim 0.95 \mathrm{~V}$, $\mathrm{J}_{\mathrm{SC}} \sim 14.82 \mathrm{~mA} \mathrm{~cm}^{-2}, \mathrm{FF} \sim 0.78$ and PCE $\sim 11.04 \%$ for PEDOT: PSS based device. However, the highest PCE $17.1 \%$ and $\mathrm{V}_{\mathrm{OC}} \sim 0.99 \mathrm{~V}$ reported by 

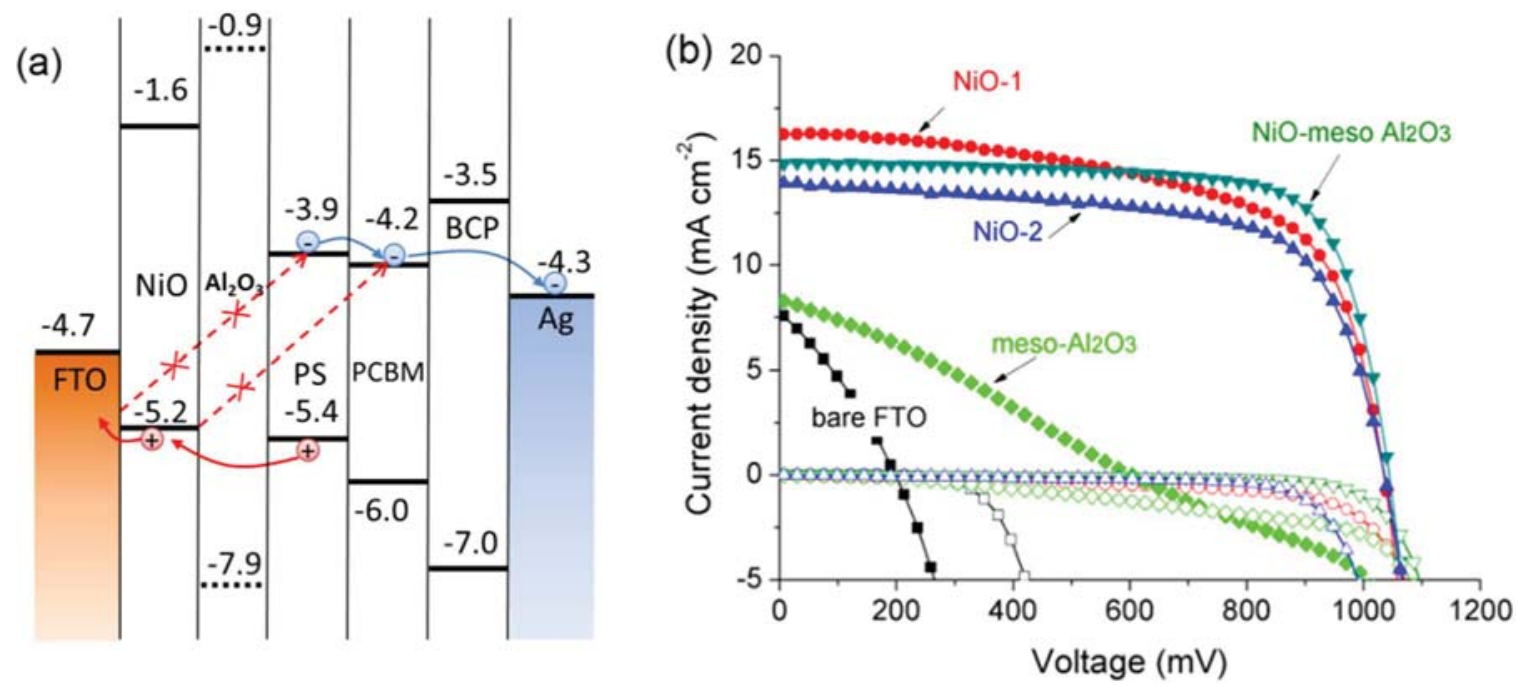

Fig. 14. The energy levels (versus vacuum) of various material components employed in the device showing the dual blocking effect of the hybrid "compact $\mathrm{NiO}_{\mathrm{m}} \mathrm{m}-\mathrm{Al}_{2} \mathrm{O}_{3}$ " interfacial layer and $\mathrm{J}-\mathrm{V}$ curves of the compared solar cells measured at 1 sun (and also their dark $\mathrm{J}-\mathrm{V}$ curves). The devices were scanned from $\mathrm{J}_{\mathrm{SC}}$ to $\mathrm{V}_{\mathrm{OC}}$. Figure is reproduced with permission from reference [221]. Copyright of Royal society of chemistry.

Sun et al. [232] using $\mathrm{CuO}_{\mathrm{x}}$ from facile solution processed in inverted planar PSCs. Therefore, low cost, facile synthesis, and high device performance, recommended $\mathrm{Cu}_{2} \mathrm{O}$ as $\mathrm{HTM}$ for facilitating the devel opment of industrial scale perovskite solar cell technology.

\subsubsection{Graphene oxide (GO)}

GO has also been used as an HTM in polymer solar cells owing to its suitable VB (5.2 eV) [233], high charge mobility (3000 27,000) $\mathrm{cm}^{2} \mathrm{~V}^{-1} \mathrm{~s}^{-1}$ and electronic conductivity [234 236]. It is also equipped with unique properties ranging from superior thermal conductivity $\sim 600 \mathrm{~W} \mathrm{~m}^{-1} \mathrm{~K}^{-1}$ [237,238], and high optical transmittance [239]. Owing to their unique characteristics, nanocomposites of $\mathrm{GO} / \mathrm{TiO}_{2}$ are used as ETL in PSCs which not only assisted to decrease the deposition temperature from 500 to $150{ }^{\circ} \mathrm{C}$ but also enhanced the photovoltaic performance from $\mathrm{PCE} \sim 10 \%, \mathrm{~V}_{\mathrm{OC}} \sim 1 \mathrm{~V}$ in pristine $\mathrm{TiO}_{2}$ PSCs to PCE 15.60\%, $\mathrm{V}_{\mathrm{OC}} 1.05 \mathrm{~V}$ [240]. Moreover, an ultrathin graphene quantum dot layer between $\mathrm{TiO}_{2}$ and perovskite layer enhanced the PCE from $\sim 8.81$ to $\sim 10.15 \%$ [241]. These results encouraged Wu et al. [242] to investigate suitability of GO as a HTM using the inverted planar architecture ITO/GO/ $\mathrm{CH}_{3} \mathrm{NH}_{3} \mathrm{PbI}_{3-\mathrm{x}} \mathrm{Cl}_{\mathrm{x}} /$ $\mathrm{PCBM} / \mathrm{ZnO} / \mathrm{Al}$. A $\sim 2 \mathrm{~nm}$ thick layer of $\mathrm{GO}$ improved $\mathrm{CH}_{3} \mathrm{NH}_{3} \mathrm{PbI}_{3-\mathrm{x}} \mathrm{Cl}_{\mathrm{x}}$ crystal domain and the surface coverage which led to high $\mathrm{PCE} \sim 12.4 \%$ with high $\mathrm{V}_{\mathrm{OC}} \sim 1.0 \mathrm{~V}$ and $\mathrm{J}_{\mathrm{SC}} \sim 17.46 \mathrm{~mA} \mathrm{~cm}^{-2} . \mathrm{Li}$ et al. [65] improved the interface between perovskite and HTM (Spiro
OMeTAD) using GO as a buffer layer which decreased the contact angle between perovskite and HTM from $~ 13.4$ to zero degree (as shown in Fig. 16) resulting in an enhancement of the $\mathrm{J}_{\mathrm{SC}}$ from $\sim 18.5$ to $\sim 20.2 \mathrm{~mA} \mathrm{~cm}^{-2}$. Moreover, this buffer layer retarded the charge recombination leading to significant enhancement in $\mathrm{V}_{\mathrm{OC}}$ and $\mathrm{FF}$ from $\sim 0.93 \mathrm{~V}$ and $\sim 0.64$ to $\sim 1.04 \mathrm{~V}$ and 0.73 , respectively. Consequently, the PCE increased by $\sim 45 \%$, i.e., from $\sim 10$ to $\sim 15.1 \%$ using GO as dual function buffer layer in mesoscopic PSCs. The best performance $\sim 18.2 \%$ in GO based PSCs is reported when it is inserted as a buffer layer between Spiro OMeTAD and perovskite to improve hole extrac tion [89]. Notably the device also showed a stable performance for $16 \mathrm{~h}$ under continuous light soaking.

\subsubsection{Molybdenum oxide $\left(\mathrm{MoO}_{3}\right)$}

$\mathbf{M o O}_{3}$ has been used to improve hole injection and extraction in organic photovoltaics (OPVs) [243,244] and organic light emitting diodes (OLEDs)[245], respectively. Therefore, several attempts have been done for using it in PSCs as HTM due to its non toxicity and ambient conditions stability. Kim et al. [246] used $\mathrm{MoO}_{3}$ as an interfacial layer combine with N,N0 Di(1 naphthyl) N,N0 diphenyl (1,10 biphenyl) 4,40 diamine (NPB) as HTM in the fully vacuum processed inverted planar PSCs. $\mathrm{MoO}_{3}$ developed an ohmic contact between ITO and perovskite layer resulting in a high built in field and showed $\mathrm{V}_{\mathrm{OC}} \sim 1.12 \mathrm{~V}$ and $\mathrm{PCE} \sim 13.7 \%$ in the above device. Similarly,
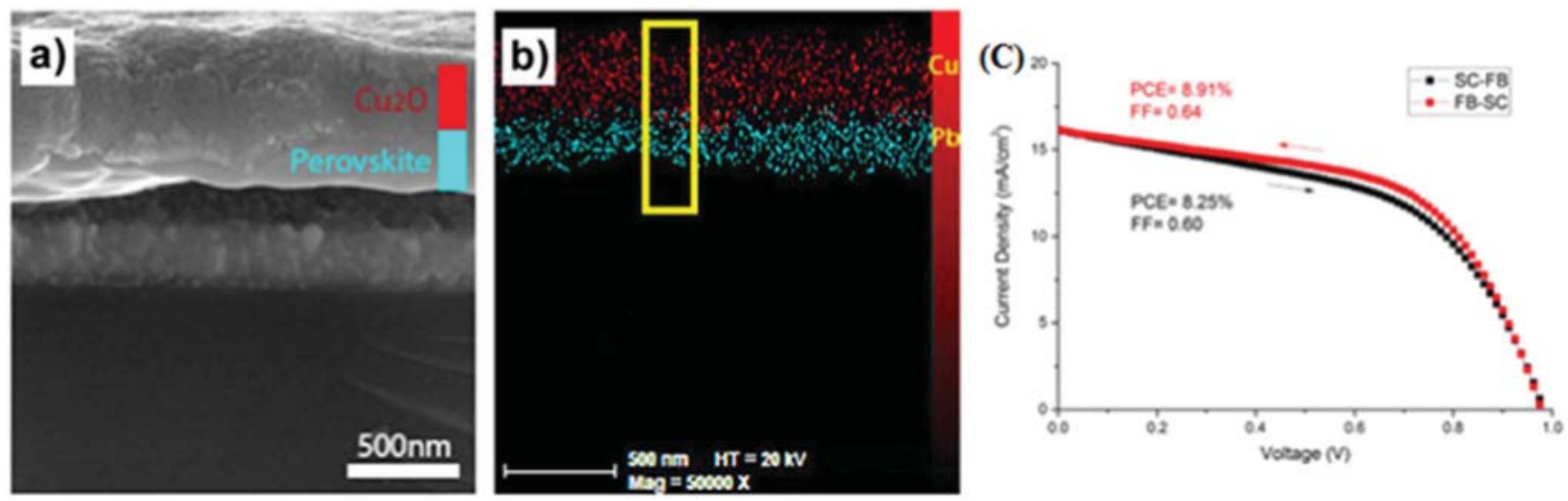

Fig. 15. Cross sectional (a) FE-SEM and (b) EDS map of pinhole-free FTO/TiO $/ \mathrm{CH}_{3} \mathrm{NH}_{3} \mathrm{PbI}_{3} \mathrm{Cl}_{\mathrm{x}} / \mathrm{Cu}_{2} \mathrm{O}$ indicating the presence of $\mathrm{Cu}$ (red) and $\mathrm{Pb}$ (light blue) atoms and (c) $\mathrm{J}-\mathrm{V}$ curves of prepared device using pinhole-free perovskite layers with a scanning direction of forward bias to short circuit (FB-SC) or short circuit to forward bias (SC-FB). Figure are reproduced with permission from Ref. [230].Copyright of Wiley. 


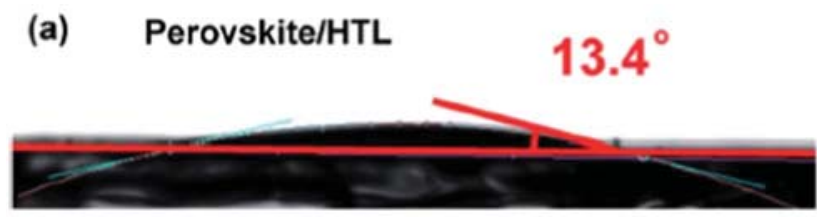

(b) Perovskite/GO/HTL (c)

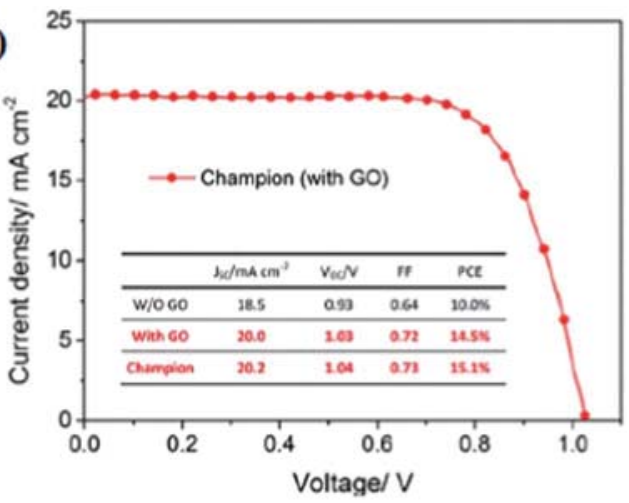

Fig. 16. Comparison of the contact angle between HTM (Spiro-OMeTAD) and perovskite layer without (a) and (b) with GO, and (c) J-V curve for the champion device with GO layer. Figures are reproduced with permission from Ref. [65]. Copy right of Royal Society of Chemistry.

Hou et al. [187] incorporated a $\mathrm{MoO}_{3}$ with PEDOT: PSS as HTM in inverted planar PSCs. $\mathrm{MoO}_{3}$ dramatically increased the PCE to $14.78 \%$, which is $\sim 30 \%$ higher compared to pristine PEDOT: PSS based device. Moreover, a thin $\mathrm{MoO}_{3}$ layer has been used in the conventional structure PSCs (n i p architecture) between the HTM and metal contact to reduce contact resistance at the interfaces, which not only increase the PCE but also increase the stability of the device [247 250].

\subsubsection{Vanadium oxide $\left(\mathrm{VO}_{X}\right)$}

The fact that inorganic HTMs typically require high temperature deposition hampers the choice of substrates and inhabits the large scale production. A remedy is low temperature solution processable $\mathbf{V O}_{\mathbf{x}}$ which also shows high transmittance; and therefore, allow maximum sunlight to reach the perovskite absorber layer [251,252]. Haocheng et al. [252] reported PCE 14.14\% in inverted PSCs based on $\mathrm{VO}_{\mathrm{x}}$. A notable $\mathrm{V}_{\mathrm{OC}} \sim 0.9 \mathrm{~V}$ and negligible hysteresis were reported. Similarly, Haitao er al [251] used $\mathrm{V}_{2} \mathrm{O}_{\mathrm{x}}$ as a buffer layer between perovskite and PEDOT: PSS that enhanced the VB of the latter from $\sim 5.1$ to $\sim 5.4 \mathrm{eV}$. A remarkable hysteresis free $\mathrm{PCE} \sim 17.5 \%$ and $\mathrm{V}_{\mathrm{OC}}$ of $1.05 \mathrm{~V}$ were achieved. The performance was significantly higher when compared to pristine PEDOT: PSS (PCE $14.2 \%$ and $\mathrm{V}_{\mathrm{OC}} 0.85 \mathrm{~V}$ ) and pristine $\mathrm{V}_{2} \mathrm{O}_{\mathrm{x}}$ (PCE14.8\%, $\mathrm{V}_{\mathrm{OC}} 0.98 \mathrm{~V}$ ).

\subsubsection{Tungsten oxide $\left(W O_{X}\right)$}

WO $\mathbf{x}$ is another low temperature inorganic HTM reported for PSCs. Zhiwei et al. [253] reported a solvothermal method to fabricate $\mathrm{WO}_{3}$ nanocrystal as HTM in inverted PSCs and showed PCE 7.68\% $\left(\mathrm{V}_{\mathrm{OC}} 0.92 \mathrm{~V}\right)$. Subsequently, Zong Liang et al. [254] treated $\mathbf{W O}_{\mathbf{3}}$ with UV ozone to improve the surface coverage of perovskite layer that resulted in PCE 9.8\%.

\subsubsection{Nanocrystals}

Nanocrystals of $\mathrm{CuInS}_{2}$ and $\mathrm{Cu}_{2} \mathrm{ZnSnS}_{4}$ (CZTS) are known as promising light absorbing materials due to their direct band gap (1.5 eV) [255] and low temperature solution processability [256,257]. The VB level of $\mathrm{CuInS}_{2}(5.6 \mathrm{eV})$ matches well with that of $\mathrm{CH}_{3} \mathrm{NH}_{3} \mathrm{PbI}_{3}$ (5.6 eV); and therefore, could be a promising HTM. Chong et al. [258] employed $\mathrm{CuInS}_{2}$ via low temperature processing in a device (ITO/ $\mathrm{CuInS}_{2} / \mathrm{Al}_{2} \mathrm{O}_{3} / \mathrm{CH}_{3} \mathrm{NH}_{3} \mathrm{PbI}_{3} / \mathrm{Ag}$ ) with a $\mathrm{Al}_{2} \mathrm{O}_{3}$ as scaffold layer and showed an optimized PCE of $\sim 5.3 \%$. Later on, Laraib et al. [259] introduced CZTS nanocrystal as HTM synthesized at $\mathrm{T}<100{ }^{\circ} \mathrm{C}$ in planar PSCs. CZTS showed an excellent HTM characteristics as inter face layer which enhanced the charge transfer yielding a PCE of $\sim 15.4 \%$ and an exceptionally high $\mathrm{FF} \sim 0.81$.

\subsubsection{Quantum dots}

A strategy to improve PV performance of solar cells is broaden the light harvesting to near infrared (NIR) region which has been widely utilized in quantum dots (QDs) sensitized solar cells [260] An example for this is PbS QDs that are characterized by a large excitonic Bohr radius $\sim 18 \mathrm{~nm}$, a low bulk energy band gap of about $0.41 \mathrm{eV}$ [261], which is tunable with size [262]. Recently, PbS QDs are reported as a co sensitizer together with $\mathrm{CH}_{3} \mathrm{NH}_{3} \mathrm{PbI}_{3}$ in a heterojunction solar cell by Etgar et al. [263] also Seok's group [264] however, the PCE was limited $<4 \%$. An improvement in PCE to $7.5 \%$ is reported by Long et al. [265] which employed colloidal PbS QDs as HTM for planar PSCs by tuning the VB level close to the $\mathrm{CH}_{3} \mathrm{NH}_{3} \mathrm{PbI}_{3}$. Another QD HTM is $\mathrm{CuInS}_{2}$, reported by Mei et al. [266] in mesoporous PSCs. CuInS ${ }_{2}$ QDs provides a PCE $\sim 6.57 \%$ further improved to $\sim 8.38 \%$ by modifying the surface of $\mathrm{CuInS}_{2}$ QDs by cation exchange to form $\mathrm{CuInS}_{2} / \mathrm{ZnS}$ core/ shell QDs. The modified HTM enhanced charge transport/transfer and the device performance thereby. These QDs could offer a versatile and new pathway for the future development of cost effective inorganic HTMs.

\section{Hole transport materials and stability of perovskite solar cells}

High efficiency, long term stability, and a low cost are the main factors determining the success of a PV technology [267 270]. Although PSCs can be fabricated via solution processing, a method that can be applied for cost effective mass production, and their PCE has reached a value as high as $\sim 22.1 \%$ [21], they are typically unstable when exposed to humidity, high temperatures, and light [271,272]. The factors inducing instability in PSCs can be classified as intrinsic and extrinsic as in Fig. 17 [273]. Whereas intrinsic instability in the devices arises from (i) structural instability, (ii) ionic polarization of perovskite crystals in presence of electric field (hysteresis), and (iii) selective contacts, i.e., ETL and HTM and their interfaces with perovskite, the external instability is caused due to electrical biasing, prolonged light soaking, UV irradiation, humidity, oxygen, and temperature [29] $[174,274]$.

Crystalline phases of the perovskite can change as a result of different temperatures and pressures which consequently affects the stability of the device. The structural stability of common perovskite $\mathrm{ABX}_{3}$ can be understood from the tolerance factor ( $t$ ), which is given by the following Eq. (1).

$t=\frac{r_{A}+r_{X}}{\sqrt{2}\left(r_{B}+r_{X}\right)}$

where $r_{A}, r_{B}$ and $r_{X}$ are the ionic radii of the $\mathrm{A}, \mathrm{B}$ and $\mathrm{X}$ ions, respectively. For a perfectly packed cubic perovskite structure $t=1$ [288]. Moreover, temperature has also a significant impact on the structural stability of the perovskite because of the fact that rising temperature transforms the symmetry from tetragonal to cubic [289]. Density functional theory study showed that the $\mathrm{CH}_{3} \mathrm{NH}_{3} \mathrm{PbBr}_{3}$ trans form from Pm3m to Im3 just below $1 \mathrm{GPa}$ pressure and amorphization occurs at $\sim 2.8 \mathrm{GPa}$ without the cations undergoing long range orienta 


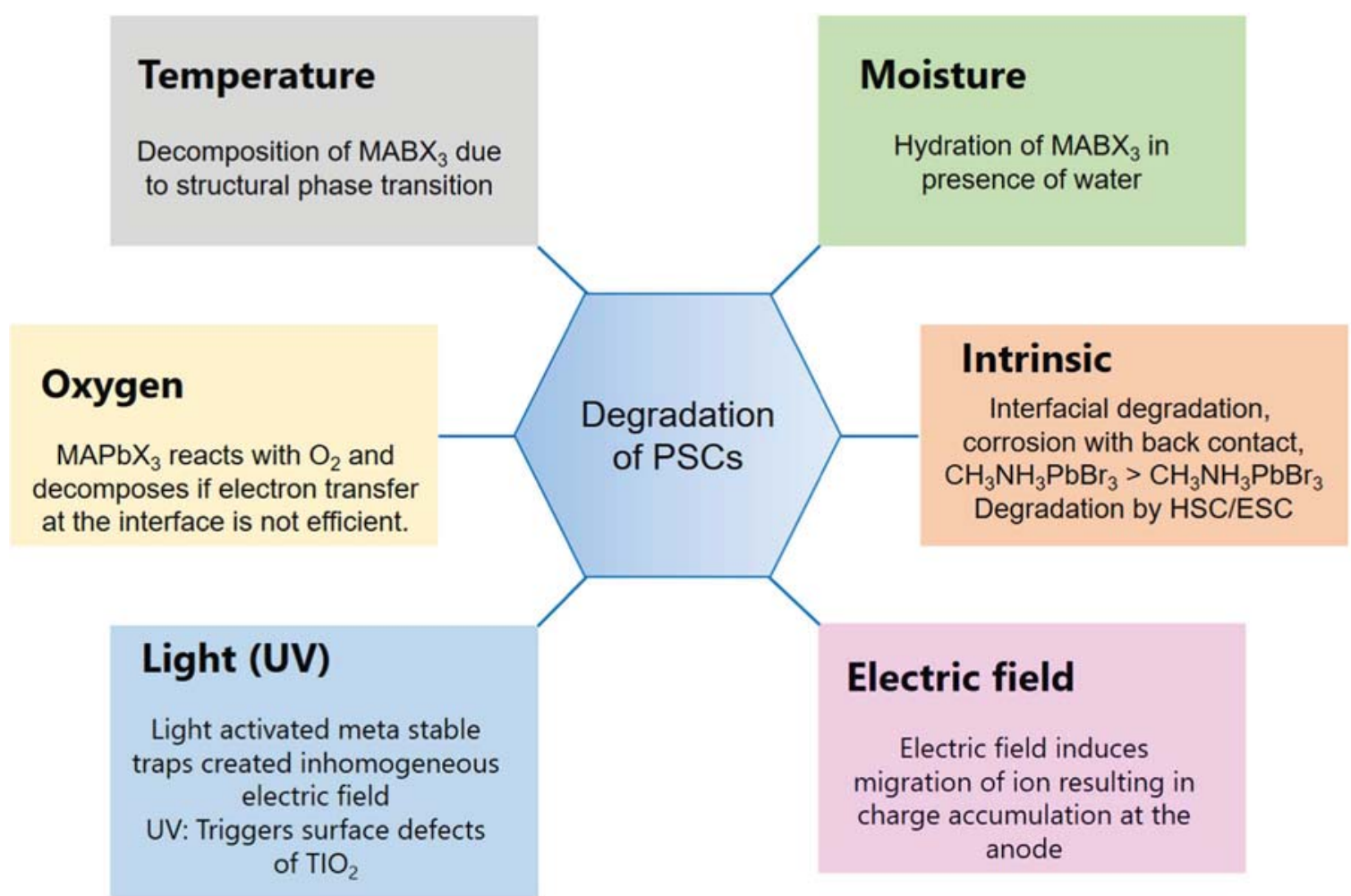

Fig. 17. Factors inducing instability in perovskite solar cells can be classified as external, i.e., temperature [275,276], moisture [277,278], oxygen [279], light (including UV light) [280 282] and electric field [283 287], and internal [206,281].

tion. The major source of volume reduction under compression is from the tilting, and to a lesser extent shrinking, of the $\mathrm{PbBr}_{6}$ octahedra. The amorphized sample was recrystallized upon release of pressure [290].

During the process of synthesizing, assembling and outdoor testing of PSCs, oxygen and moisture in the atmosphere may attack and enter the device causing degradation [291]. This is due to the fact that the $\mathrm{CH}_{3} \mathrm{NH}_{3} \mathrm{PbI}_{3}$ is very sensitive to water, which hydrolyzes and conse quently degrades the perovskite accordingly to Eq. $(2$ 2c) [292].

$\mathrm{CH}_{3} \mathrm{NH}_{3} \mathrm{PbI}_{3}$ (s) $\leftrightarrow \mathrm{PbI}_{2}$ (s) $+\mathrm{CH}_{3} \mathrm{NH}_{3} \mathrm{I}$ (aq)

$$
\begin{aligned}
& \mathrm{CH}_{3} \mathrm{NH}_{3} \mathrm{I}(\mathrm{aq}) \leftrightarrow \mathrm{CH}_{3} \mathrm{NH}_{2} \text { (aq) }+\mathrm{HI}(\mathrm{aq}) \\
& 4 \mathrm{HI}(\mathrm{aq})+\mathrm{O}_{2}(\mathrm{~g}) \leftrightarrow 2 \mathrm{I}_{2} \text { (s) }+2 \mathrm{H}_{2} \mathrm{O}(\mathrm{l}) \\
& 2 \mathrm{HI}(\mathrm{aq}) \leftrightarrow \mathrm{I}_{2}(\mathrm{~s})+\mathrm{H}_{2} \text { (g) }
\end{aligned}
$$

$\mathrm{CH}_{3} \mathrm{NH}_{3} \mathrm{I}$ decomposes into $\mathrm{CH}_{3} \mathrm{NH}_{2}$ and $\mathrm{HI}$ as shown in reaction (2a) where the HI degrades in two ways either in the presence of oxygen $(2 \mathrm{~b})$ or due to photochemical reaction under UV irradiation (2c).

(A)

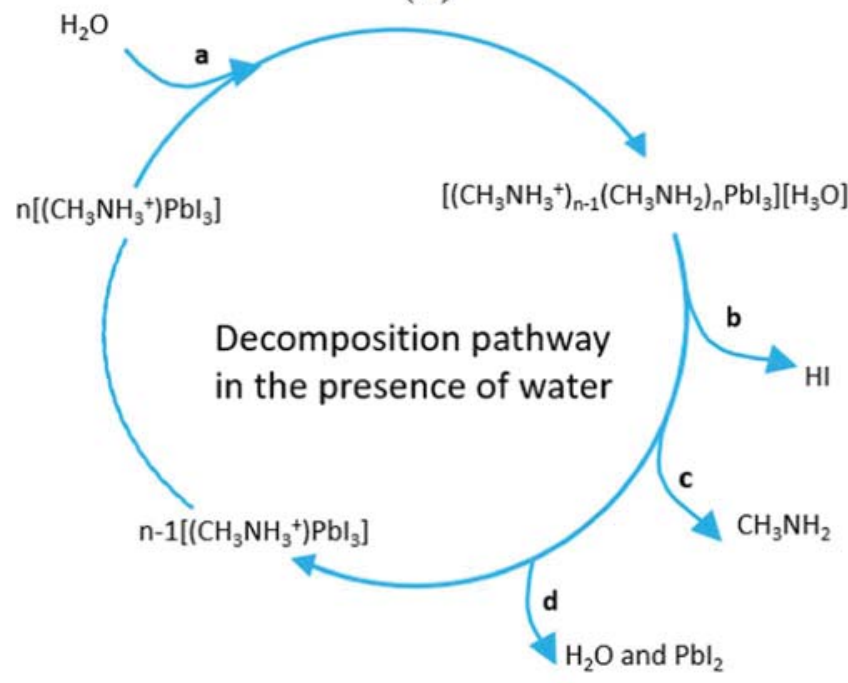

(B)

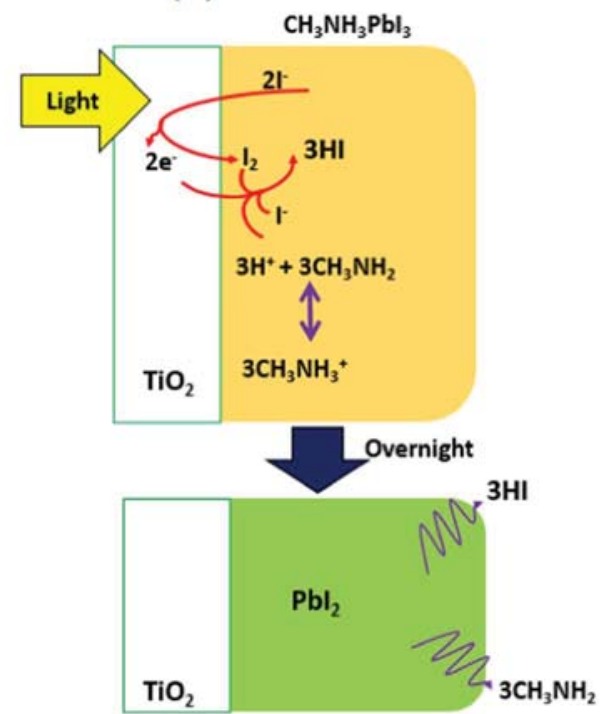

Fig. 18. (a) Illustration of the possible degradation pathway of the perovskite in the presence of water. A water molecule, $a$, is required to initiate the decomposition process where both hydrogen iodide ( $b$, soluble in water) and methyl ammonia (c, volatile and dissolve in water). Finally a yellow solid is formed showing presence of PbI $\mathrm{I}_{2}$, $\mathrm{d}$ [293], and (b) schematic of perovskite degradation when exposed to sunlight [204]. Figure reproduced with permission from the reference. Copy right of American Chemical Society. 
(a)

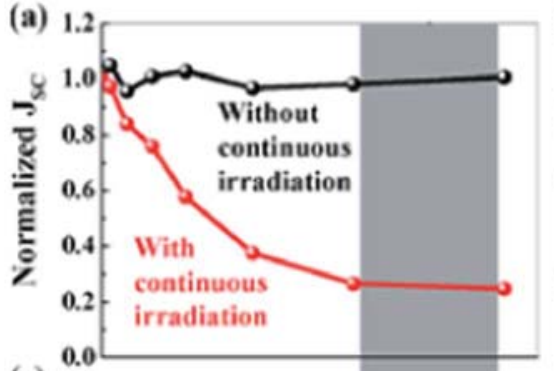

(c) 1.2

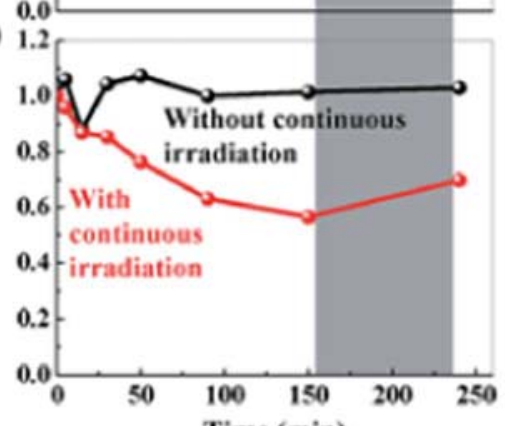

(b)

(d) 1.2

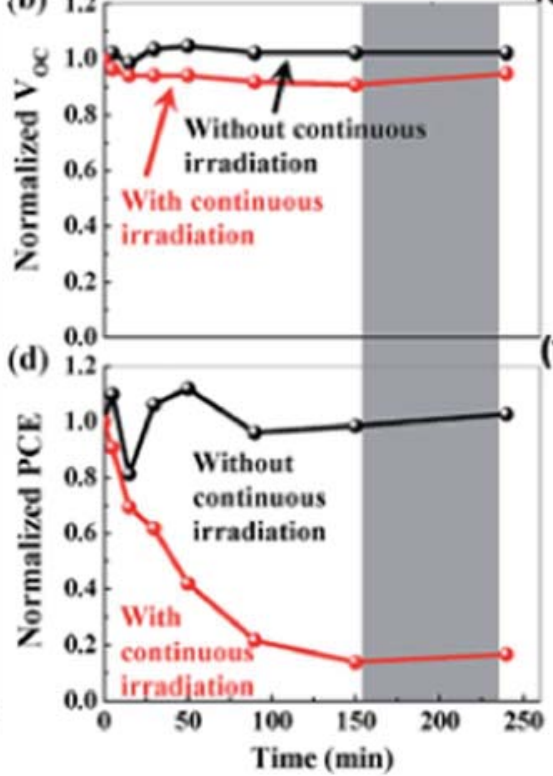

(e)

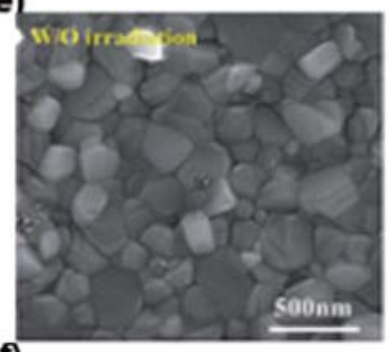

(f)

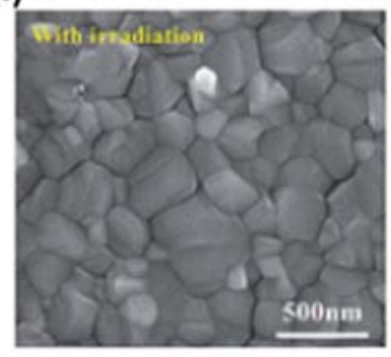

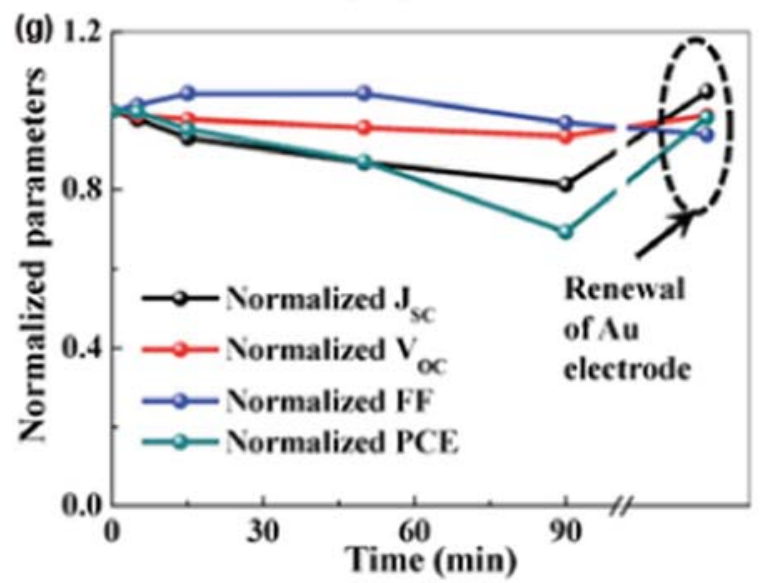

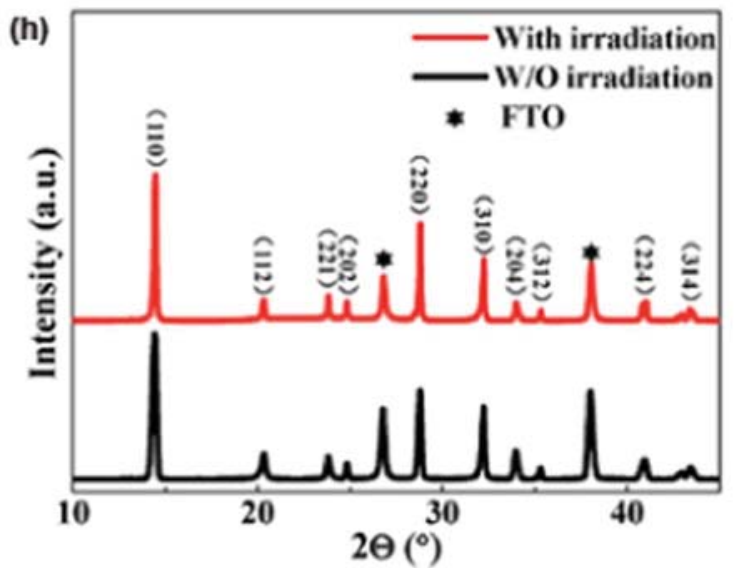

Fig. 19. Comparison of normalized PV parameters (a d) of the planar PSCs as a function of irradiation and without irradiation time for 90 min at high humidity (50 60\%), (e and f) SEM images of fresh and degraded perovskite layer in dark, (g) normalized PV parameters and their comparison with the renewal of Au electrode, and (h) compared the XRD pattern of exposed device and unexposed one [295]. Figure reproduced with permission from the reference. Copy right of The Royal Society of Chemistry.

The perovskite crystals decompose under exposure of light, ingres sion of water, humidity, and temperature. One simple plausible mechanism proposed by Jarvist et al. [293] is shown in Fig. 18a. When a perovskite layer is exposed to water, a single water molecule is sufficient to initiate the reaction and degrade the material. It is a well known fact that $\mathrm{TiO}_{2}$ contains oxygen vacancies, particularly at the surface which are considered to be electron donating sites [280]. The electrons in these sites resides $\sim 1 \mathrm{eV}$ below the conduction band interacting with the oxygen molecules present in the atmosphere.

Similarly, instability in PSCs also partly arises in the presence of UV light and also due to a possible reaction between the $\mathrm{TiO}_{2}$ ETL and perovskite [280]. The degradation occurs at $\mathrm{TiO}_{2}$ nanoparticle layer and perovskite interface introduces a possibility of ion migration at the ETL perovskite interface thereby leading to decomposition of perovs kite crystal, even in absence of humidity [205,294]. Fig. 18b shows the schematic representation of perovskite degradation in the presence of light exposure which decomposes to $\mathrm{PbI}_{2}, \mathrm{CH}_{3} \mathrm{NH}_{2}$ and $\mathrm{HI}$ (Eq. (3)). Furthermore, it is observed that the perovskite layer degrades upon exposure to constant illumination at the $\mathrm{TiO}_{2}$ perovskite interface as described in Eq. (3 3c) [204].

$\mathrm{CH}_{3} \mathrm{NH}_{3} \mathrm{PbI}_{3} \leftrightarrow \mathrm{PbI}_{2}+\mathrm{CH}_{3} \mathrm{NH}_{2} \uparrow+\mathrm{HI} \uparrow$

$2 \mathrm{I}^{-} \leftrightarrow \mathrm{I}_{2}+2 \mathrm{e}^{-}$
$3 \mathrm{CH}_{3} \mathrm{NH}_{3}{ }^{+} \leftrightarrow 3 \mathrm{CH}_{3} \mathrm{NH}_{2} \uparrow+3 \mathrm{H}^{+}$

$\mathrm{I}^{-}+\mathrm{I}_{2}+3 \mathrm{H}^{+}+2 \mathrm{e}^{-} \leftrightarrow 3 \mathrm{HI} \uparrow$

It is believed that the photo induced degradation occurs mainly at the HTM/metal (Au) interface [295]. Due to the solar irradiation, the PSCs performance deteriorated and the PCE plummeted to $2.46 \%$ from $18 \%$ in just $180 \mathrm{~min}$ as shown in Fig. 19d [295]. As can be seen (Fig. 19a c), a significant decline in $\mathrm{J}_{\mathrm{SC}}$ and $\mathrm{FF}$ can be observed while the degradation of $\mathrm{V}_{\mathrm{OC}}$ is slow. Meanwhile, the morphological compar ison of the perovskite films with and without UV irradiation shows minor change with irradiation, as illustrated in Fig. 19(e and f). Interestingly the degradation recovered partially when the illuminated device was kept in the dark for about $90 \mathrm{~min}$ as can be seen from Fig. 19g. However, the fact that most of the photoinduced degradation was irreversible led to an assumption that the degradation might be due to moisture because the devices were tested at the ambient condition. In order to know the cause of degradation, same fresh devices were kept in the dark where they showed relatively lower degradation as compared to those under light irradiation (Fig. 19a d). This demonstrated that degradation is not significant in the presence of humidity alone and it is triggered when humidity is coupled with photon dose, as also recently indicated by Manshor et al. [281]. Wei et al. [295] compared the photoinduced degradation effect in both 
mesoporous and planar PSCs where they showed relatively higher degradation in the latter. The mesoporous device maintains $60 \%$ of its initial PCE value while the planar rivals showed merely $20 \%$ perfor mance at similar experimental conditions. The XRD pattern of the both fresh and degraded devices were measured where all the peaks can still be indexed to the perovskite (Fig. 19h). It shows that the photoinduced degradation is different than the moisture induced one as the latter showed $\mathrm{PbI}_{2}$ peaks after decomposition whereas the former did not. Initially the cause of this degradation was understood to be UV light that creates electron hole pairs in the mesoporous $\mathrm{TiO}_{2}$ structure [280]. Subsequently Wei et al. [295] reported higher degradation in planar counterparts where thinner $\mathrm{TiO}_{2}$ ETLs should be less effected by UV light. This demonstrated that besides the $\mathrm{TiO}_{2} /$ perovskite interface, degradation also takes place at the HTM/perovskite or HTM/Au interfaces, respectively. The performance of their degraded cells recovered when the back contact $(\mathrm{Au})$ of the degraded device was replaced with the fresh one (Fig. 19g). Similarly, the $\mathrm{TiO}_{2}$ perovksite interface is also known to cause degradation in PSCs owing to the reactivity of mesoporous $\mathrm{TiO}_{2}$ or planar layer [206] which is overcome by introducing thermodynamically stable $\mathrm{TiO}_{2}$ nanorods [205,296,297].

The HTM is considered to be one of the dominant factors inducing instability in these devices. The most successful employed HTMs are organic HTM layer $(\sim 300 \mathrm{~nm})$, typically small molecules (spiroOMeTAD), conducting polymers (P3HT, PTAA and PEDOT: PSS etc.), and inorganic HTMs (CuPc, NiO, $\mathrm{CuO}$ etc.), as a hole selective contact [48]. The organic HTMs among these are sensitive to moisture and oxygen; and therefore, cause degradation in PSCs [29,83,110,292,298 305]. A common example is the widely employed Li salt (Li TFSI) doped spiroOMeTAD react with humidity and de grades in a few seconds owing to its hygroscopic nature [133,142,306 310]. Towards stable PSCs, research on HTM perspective can be classified as: (i) dopant free HTMs [142,307,309,310], (ii) inorganic [224,311 313] or organic alternatives [302,303,314] to the typically employed hygroscopic Spiro OMeTAD, (iii) post modification of HTM or encapsulation to protect the device from humidity [298,300,305,315 317], and (iv) alternative additives to $\mathrm{Li}$ salt [110,318 320]. We divide our discussion in two sub section: (i) $\mathrm{n} \mathrm{i} \mathrm{p}$ device (mesoporous or planar), employing an $n$ type layer over the TCO in conjunction with perovskite and a thin layer of HTM (typically spiroOMeTAD), and (ii) p i n devices, also called inverted planar PSCs, employing a p type layer, typically PEDOT: PSS on FTO followed by a perovskite and ETL layers on it. Following the scope of this paper, our discussions are limited to the role of HTM layer in these architectures to achieve stability.

\subsection{Degradation induced by spiroOMeTAD and P3HT}

High efficiency PSCs often employ P3HT and spiroOMeTAD as HTMs [321,322]. The amorphous spiroOMeTAD has a low hole mobility, which could be improved by p dopants such as Li salts. However, the dopant, owing to its hygroscopic nature, acts as a humidity centre. Snaith et al. [53] showed that Li doped spiroOMeTAD degrades significantly faster than that of pristine spiroOMeTAD counterpart.

The HTM forms the outermost layer in a typical PSC architecture and serves as a protective shield to the perovskite layer. Apart from the intrinsic electronic properties of the HTM, three basic features such as hydrophobicity, permeability and density are pre requisite for an efficient stable PSCs. Towards this end, PMMA is employed as HTM in PSCs which is hydrophobic in nature; and therefore, it simulta neously inhibit the ingress of moisture and evaporation of $\mathrm{MAPbI}_{3}$ as shown in Fig. 20a. However, PMMA owing to insulator behaviour is not capable to transport charges; and therefore, it is composited with a high conducting p type conductors such as SWNTs. The P3HT SWNTs composite is one of the best candidates due to the exceptional charge transport properties together with its chemical stability. The composite P3HT/SWNTs PMMA as HTM not only acted as a strong protective layer against moisture ingress but also showed outstanding thermal stability compared to other HTMs as shown in Fig. 20b.

The faster degradation of spiroOMeTAD is also evident in another report by Cao et al. [323] PSCs with perthiolated trisulfur annulated hexa peri hexabenzocoronene (TSHBC) as HTM retained $>85 \%$ of their initial PCE (12.8\% for pristine and 14\% when doped with graphene) after 10 days (devices were stored in air with humidity 45\%). In contrast, PSCs fabricated using spiroOMeTAD retained only $20 \%$ of their initial PCE at similar experimental conditions (Fig. 21a). In addition, the contact angle of water on both TSHBC and TSHBC/ graphene were $107^{\circ}$ while it was $70^{\circ}$ only on spiroOMeTAD confirming the hydrophobicity of the former. Another alternative to spiroOMeTAD is PEDOT: PSS, which is also widely employed in high performance inverted BHJ PSCs; however, its hygroscopic and acidic characteristics are unfavourable for stable device operation. The device stability is improved significantly when polymer such as PMMA or polycarbonate (PC) mixed with carbon nanotubes are employed as HTM. The stability is also improved when hydrophobic HTMs replaced the hygroscopic Li salt [324].

Despite the fact the Spiro MeOTAD is one of champions and arguably most employed HTMs, it is recently shown to induce degradation at $\mathrm{HTM} /$ perovskite interface due to the chemical reaction between Spiro MeOTAD ${ }^{+}$and $\mathrm{I}^{-}$[325]. This puts a question mark on whether PSCs employing Spiro MeOTAD could really deliver long term operational stability. A remedy could be to employ buffer layers between perovskite and HTM, as reported by Koushik et al. [90]. An ultrathin $\mathrm{Al}_{2} \mathrm{O}_{3}$ layer between perovskite and HTM not only demon strated a remarkable stabilized PCE $18 \%$, but also showed a stable shelf life for 70 days (retaining $6070 \%$ of initial performance). A reference device without the buffer layer only retained $12 \%$ of initial PCE. A similar improvement in stability is reported when montmor illonite layer is employed between HTM and perovskite [326].

The Spiro MeOTAD can in fact also induce degradation by reacting with metal back contact $(\mathrm{Ag} / \mathrm{Au})$ at alleviated temperature $\left(>70^{\circ} \mathrm{C}\right)$ due to diffusion of metal ions into the HTM [327]. This is overcome by employing a thin buffer layers such as $\mathrm{Cr}$.

\subsection{Alternative HTMs towards stable perovskite solar cells}

Alternative THMs (to commonly employed organic and unstable Spiro OMeTAD and PEDOT: PSS) such as hydrophobic CuI showed excellent ambient stability compared to PEDOT: PSS (Fig. 21b) [323]. The $\mathrm{CuI}$ based device retained $90 \%$ of its initial efficiency after 14 days whereas the PEDOT: PSS rivals showed only $27 \%$ of the initial performance. Another stable inorganic HTM is CuPc, a p type semi conductor which is characterized by a lower band gap, and higher hole mobility $\left(10^{-3}\right.$ to $\left.10^{-2} \mathrm{~cm}^{2} \mathrm{~V}^{-1} \mathrm{~s}^{-1}\right)$ compared to spiroOMeTAD $\left(4 \times 10^{-4} \mathrm{~cm}^{2} \mathrm{~V}^{-1} \mathrm{~s}^{-1}\right)$ [140]. A remarkable PCE $16.3 \%$ was achieved so far using $\mathrm{CuPc}$ as HTM and carbon as counter electrode. The CuPc based PSCs showed a more stable performance compared to a doped spiroOMeTAD counterparts when tested for $600 \mathrm{~h}$. Erin et al. [249] investigated a range of metal contact HTM configurations such as Au, $\mathrm{Ag}, \mathrm{MoO}_{\mathrm{x}} / \mathrm{Au}, \mathrm{MoO}_{\mathrm{x}} / \mathrm{Ag}$, and $\mathrm{MoO}_{\mathrm{x}} / \mathrm{Al}$. The devices based on $\mathrm{MoO}_{\mathrm{x}} / \mathrm{Al}$ exhibited higher stability than relatively expensive $\mathrm{Ag}$ and $\mathrm{Au}$ electro des. In addition, the thickness of the $\mathrm{MoO}_{\mathrm{x}}$ interlayer demonstrated a profound impact on the device stability and other PV parameters where the devices exhibited optimal performance with thin $\mathrm{MoO}_{\mathrm{x}}$ interlayer.

Recently, an interlayer of graphene oxide (GO) between the perovskite and HTM demonstrated excellent stability and also PV performance (18.2\%) [89]. Although the addition of GRMs does not influence the shelf life, it is beneficial for the stability of PSCs under several aging conditions. In particular, $\mathrm{mTiO}_{2}+\mathrm{G}$ PSCs retain more than $88 \%$ of the initial PCE after $16 \mathrm{~h}$ of prolonged 1 sun illumination at the maximum power point. Moreover, when subjected to prolonged 
(a)

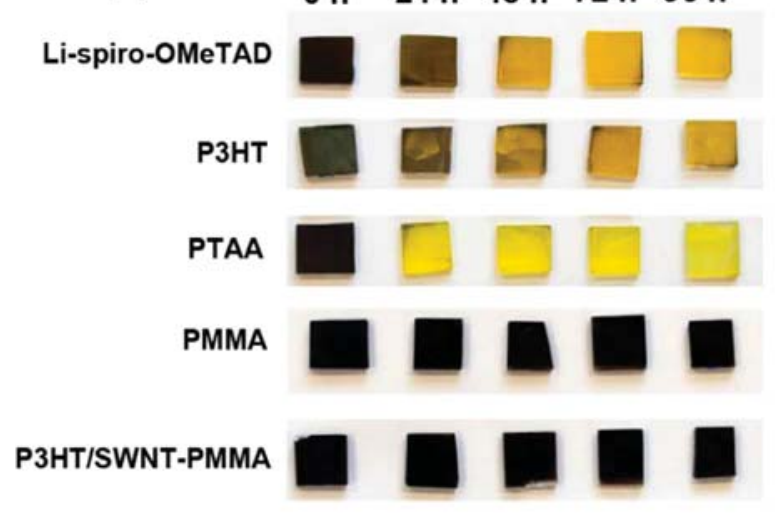

(b)

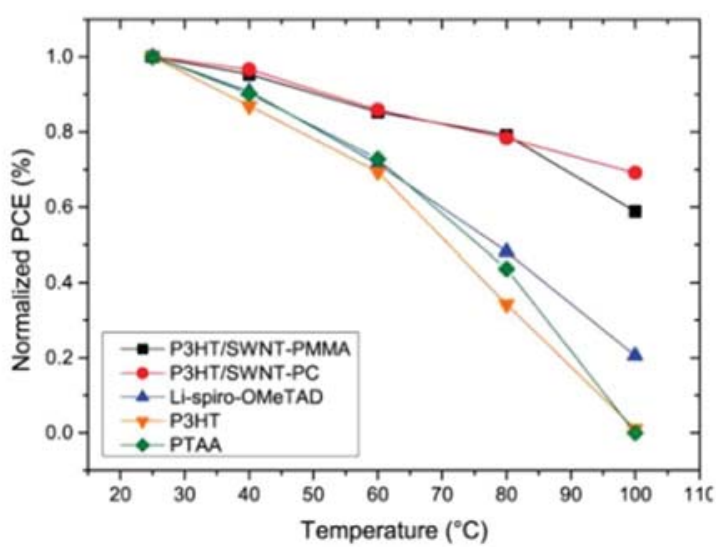

Fig. 20. (a) Effect of protective HTM layers on perovskite films at elevated temperature and humidity. The colour of PSCs changes from almost black to yellow for all organic HTMs except for the films covered with PMMA only or a composite of CNT and PMMA, (b) PCE of PSCs employing range of HTMs as a function of temperature [53]. Figure reproduced with permission from the reference. Copy right of American Chemical Society.

(a)

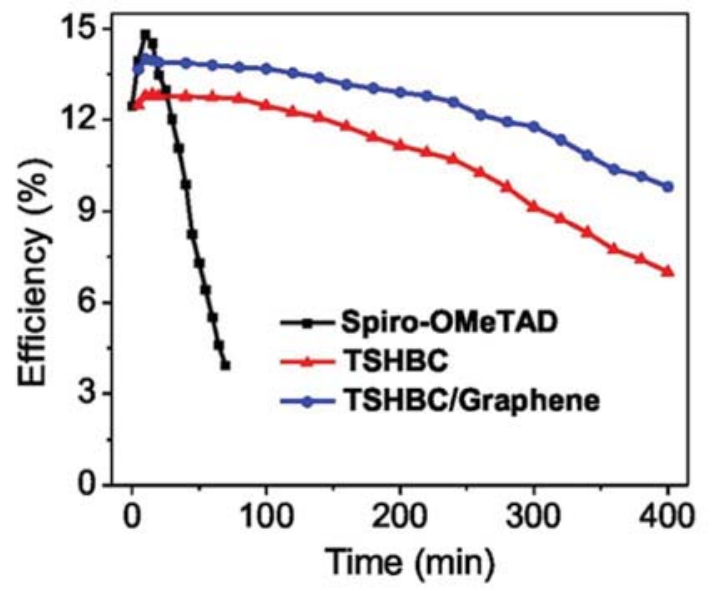

(b)

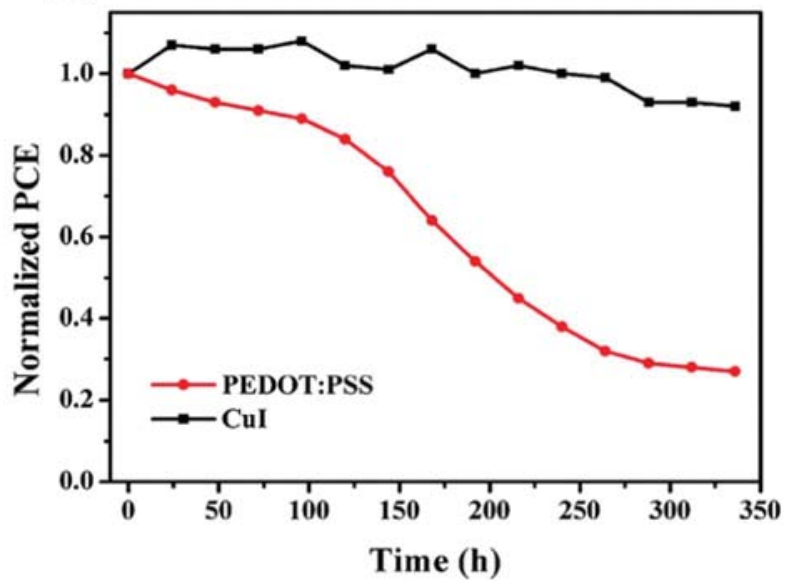

Fig. 21. (a) PV performance of various PSCs as a function of time stored under illumination at AM1.5G and a humidity 45\%. The PSCs compared in (a) employ spiroOMeTAD, TSHBC and TSHBC/graphene [323] as HTM. Figure (b) shows normalized PCE of PEDOT: PSS and CuI based PSCs as a function of storage time in air [58]. Figure reproduced with permission from the references.

heating at $60^{\circ} \mathrm{C}$, the $\mathrm{GO}$ based structures show enhanced stability with respect to $\mathrm{mTiO}_{2}+\mathrm{G}$ PSCs, as a result of thermally induced modification at the $\mathrm{mTiO}_{2}+\mathrm{G} /$ perovskite interface. Similarly, a remarkable stability under 1 sun illumination was also shown by incorporating inorganic selective contacts such as $\mathrm{NiMgLiO}$ and $\mathrm{TiO}_{\mathrm{x}}$ (in conjunction with PCBM). The devices showed $>90 \%$ of initial performance after $1000 \mathrm{~h}$ of light soaking. This important report employed large area PSCs of area $1 \mathrm{~cm}^{2}$, contrary to typical devices size $\sim 0.1 \mathrm{~cm}^{2}$ [328].

\subsection{Dopant free hole transport materials for stable PV operation}

Chemical doping, often used to improve the electric conductivity of the HTMs, not only induces instability in devices but also increases its cost. Initially it was observed that HTMs in their pristine form yielded inferior performance due to their poor charge mobility; however, recently PSCs with high performance were fabricated even without doping. Xiao et al. employed DR3TBDTT along with polydimethylsiloxane (PDMS) as HTM without additives and showed a more stable performance as compared to Li TFSI and TBP doped spiroOMeTAD [305]. Similarly, Han et al. [133] employed a new p type dopant free HTM called (TTF 1), which yielded a PCE 11.03\% and notably higher stability compared with a spiroOMeTAD analogue. In Fig. 22a the performance of TTF 1 as HTM is compared with that of $\mathrm{p}$ type spiroOMeTAD. The estimated life time of PSCs based on
TTF 1 was about $360 \mathrm{~h}$ while it was only $120 \mathrm{~h}$ for spiroOMeTAD based devices. A promising dopant free polymer based HTM (TFF 1) showed a comparable performance to that of spiroOMeTAD doped with Li TFSI and 3 times higher stability to the former credited to its hydrophobic alkyl chain and dopant free nature.

Furthermore, Wang et al. [329] employed dopant free HTM (SAF OMe, to be defined later) with a PCE $12.4 \%$ which is comparable to the chemically doped spiroOMeTAD (PCE 14.84\%). Fig. 22b compared the stability of PSCs based on N2,N2,N2',N2',N7,N7,N7',N7' octa kis(4 methoxyphenyl) 10 phenyl $10 \mathrm{H}$ spiro[acridine $9,9^{\prime} \mathrm{fl}$ uor ene] $2,2^{\prime}, 7,7^{\prime}$ tetraamine (SAF OMe) and spiroOMeTAD under $\sim 30 \%$ humidity without any encapsulation. The devices were tested for $\sim 240 \mathrm{~h}$ and $\sim 39 \%$ and $\sim 53 \%$ drop in power output was observed for $\mathrm{SAF}$ OMe and spiroOMeTAD, respectively. Moreover, the SAF OMe device showed larger contact angle $\left(86.6^{\circ}\right)$ versus the spiroOMeTAD counterpart $\left(76.1^{\circ}\right)$ which confirmed the more hydrophobic nature of the former.

\subsection{Non conventional HTMs (including composite HTM)}

A stable PSC employing 2TPA $n$ DP (where $n=1,2,3$, 4, full name not given) as HTM with an optimized PCE $12.86 \%$ is shown in Fig. 22c. It was revealed that the charge transfer resistance was higher 
(a)

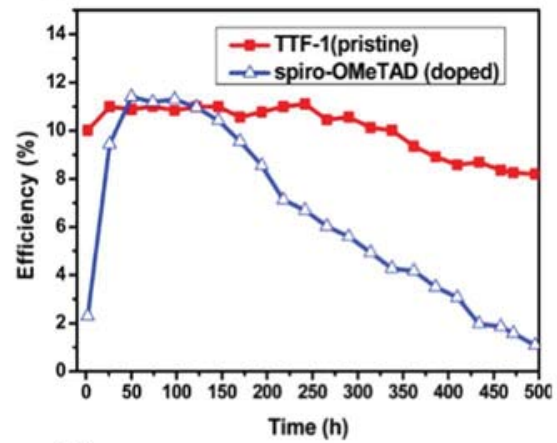

(d)

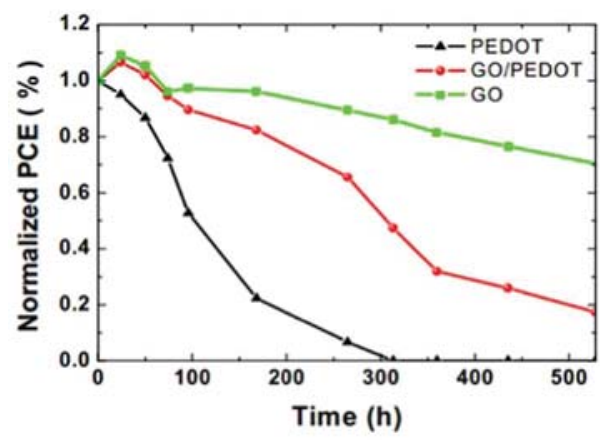

(b)

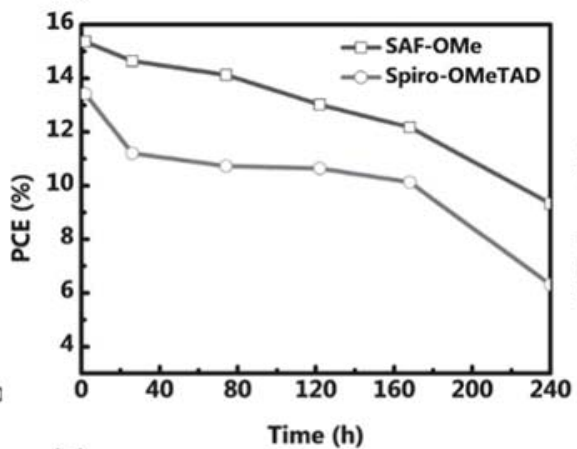

(e)

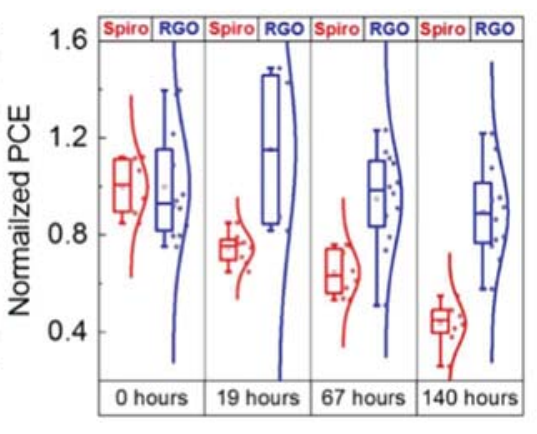

(c)

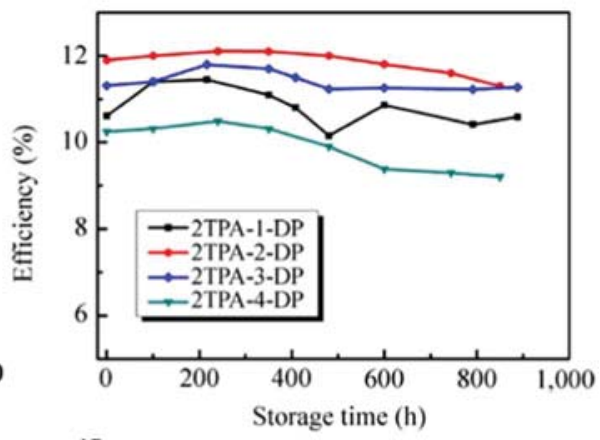

(f)

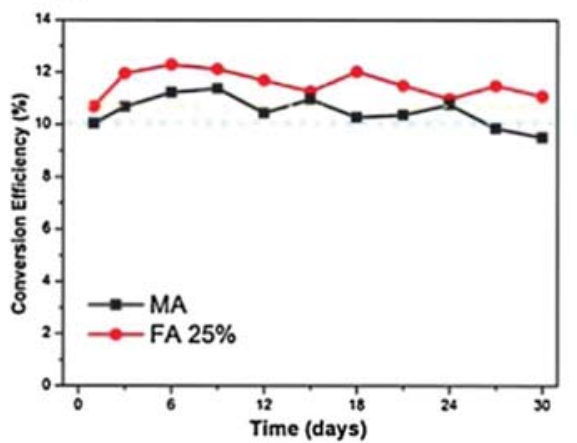

Fig. 22. Stability test of PSCs based on various HTMs (a) TTF-1 pristine and spiroOMeTAD doped HTM [133], (b) SAF-OMe and spiroOMeTAD [329], (c) efficiencies of PSCs with 2TPA-n-DP(n=1, 2, 3, 4) as a function of storage time [34], (d) PEDOT, GO/PEDOT, and GO [330], (e) normalized PCE of cells using Spiro-OMeTAD (red) and RGO (blue) [331], and (f) long-term stability for the PSCs containing $(\mathrm{FA})_{0.25}(\mathrm{MA})_{0.75} \mathrm{PbI}_{3}[332]$. Figures are reproduced with permission from the references.

for the device incorporating an HTM as compared a HTM free rival, showing better electron blocking ability of the 2TPA n DP. Moreover, these devices exhibited stable performance when tested at room temperature for $\sim 900 \mathrm{~h}$ [34]. Kim et al. [330] employed composite of GO and PEDOT: PSS as HTM in PSCs and were tested for long term stability (temperature of $\sim 2124{ }^{\circ} \mathrm{C}$ and humidity of $\sim 38$ 55\%) with out any encapsulation (Fig. 22d) with the best PCE 9.7\%. The PCE of PEDOT: PSS HTM declined sharply; however, the stability improved to some extent by making a composite with GO (PEDOT: PSS/GO). An even better and more stable performance was achieved with GO only as HTM. The composite HTM based device showed stable performance as compared to pristine counterpart. The better performance of composite HTM might be due to fact that GO could prohibit direct contact of ITO with highly acidic PEDOT: PSS.

Recently Palma et al. [331] employed reduced graphene oxide (RGO) as HTM and tested its shelf life stability for $\sim 2000 \mathrm{~h}$ and for $\sim 120 \mathrm{~h}$ under light soaking (Fig. 22e). The devices were unsealed and kept at ambient temperature in the dark and at a relative humidity $\sim 50 \%$. The control spiroOMeTAD based device showed notable drop in power output: the PCE, FF, $\mathrm{V}_{\mathrm{OC}}$, and $\mathrm{J}_{\mathrm{SC}}$ dropped by $85 \%, 5 \%, 6 \%$, and $51 \%$, respectively, whereas the drop in these values were much lower for RGO based PSCs. The deterioration in the device performance was due to Li TFSI which dissociated from the spiroOMeTAD owing to its hydrophilic nature at relative humidity and at ambient temperature.

\subsection{Stability of HTM free and monolithic perovskite solar cells}

HTMs contribute $\sim 1520 \%$ of the total material cost for unencap sulated PSCs [45]. Therefore, a cheaper HTM or HTM free device with high performance will significantly reduce the cost. Monolithic PSCs (those employing a thick carbon layer as back contact) by Mei et al. [29] which employed $\mathrm{TiO}_{2}$ and $\mathrm{ZrO}_{2}$ scaffold infiltrated with perovskite reported a PCE $12.8 \%$ and also showed very stable performance for $\sim 1000 \mathrm{~h}$ under 1 sun light soaking. In another report on HTM free PSCs [332] which used various ratio of methylammonium to forma midinium ( $\mathrm{MAPbI}_{3}$ and $\mathrm{MA}_{0.75} \mathrm{FA}_{0.25} \mathrm{PbI}_{3}$ ), a stable performance was noted for $\sim 750 \mathrm{~h}$ (Fig. 22f).

In another report [333] on HTM free device $\left(\mathrm{TiO}_{2} / \mathrm{CH}_{3} \mathrm{NH}_{3} \mathrm{PbI}_{3} /\right.$ Carbon), long term stability was demonstrated for over $2000 \mathrm{~h}$ (Fig. 23a). The devices were stored at room temperature without any encapsulation. The $\mathrm{V}_{\mathrm{OC}}$ showed a slight decline (from 0.87 to $0.83 \mathrm{~V}$ ) while FF exhibited relatively stable performance. The PCE decreased mainly due to drop in the $\mathrm{J}_{\mathrm{SC}}$. The PCE dropped to $\sim 3.72 \%$ from the initial value of $\sim 6.21 \%$. A similar report on HTM free PSCs [334] showed a drop in PCE, FF and $\mathrm{J}_{\mathrm{SC}}$ (Fig. 23b); however, the $\mathrm{V}_{\mathrm{OC}}$ showed a slight increase. Long term stability of PEDOT: PSS and $\mathrm{CuO}_{\mathrm{x}} \mathrm{HTMs}$ are compared in Fig. 23c where the $\mathrm{CuO}_{\mathrm{x}}$ maintained $90 \%$ of its initial PCE after $200 \mathrm{~h}$ while the PDDOT: PSS showed a 50\% drop [232].

Finally, as shown in Fig. 23d the PCE of $\mathrm{MAPbBr}_{3}$ device showed retention even after an air exposure of $\sim 300 \mathrm{~h}$ [335]. The FF ( 0.67) remained roughly constant while a slight increase in the $\mathrm{J}_{\mathrm{SC}}$ from $\sim 14.5 \mathrm{~mA} \mathrm{~cm}^{-2}$ to $\sim 15.0 \mathrm{~mA} \mathrm{~cm}^{-2}$ and $\mathrm{V}_{\mathrm{OC}}$ from $\sim 1.04$ to $\sim 1.05 \mathrm{~V}$ was observed. The PCE increased notably, especially during the initial days, and remain constant afterwards. It is clear that HTM free or envir onmentally friendly HTM alternatives exhibited stable performance along with a comparable $\mathrm{V}_{\mathrm{OC}}$ to the expensive and toxic counterparts. The stability of various PSCs as a function of different HTMs is listed in Table 7. In general, inorganic HTMs and HTM free PSCs demonstrated superior stability compared to their organic counterparts.

\section{Outlook}

Perovskite solar cells can be conceptually seen as a multilayer structure with the perovskite layer sandwiched between a hole transport material (HTM) and an electron transport layer and two conductive electrodes. In this article we have reviewed the HTMs developed in perovskite solar cells. Being one of the three main layers constituting the perovskite solar cell, apart from the electrodes, HTMs have a huge bearing on performance, i.e. power conversion efficiency and stability. From reviewing the literature, just noting the sheer breadth and number of the materials and their derivatives 
(a)

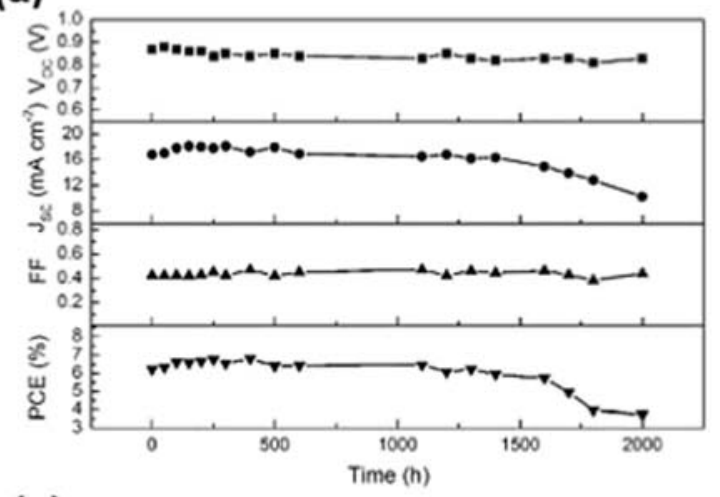

(c)

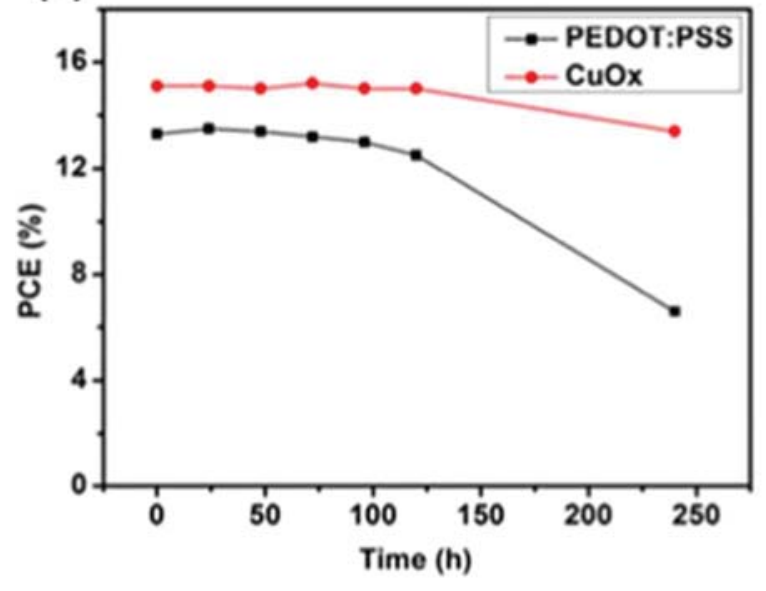

(b)
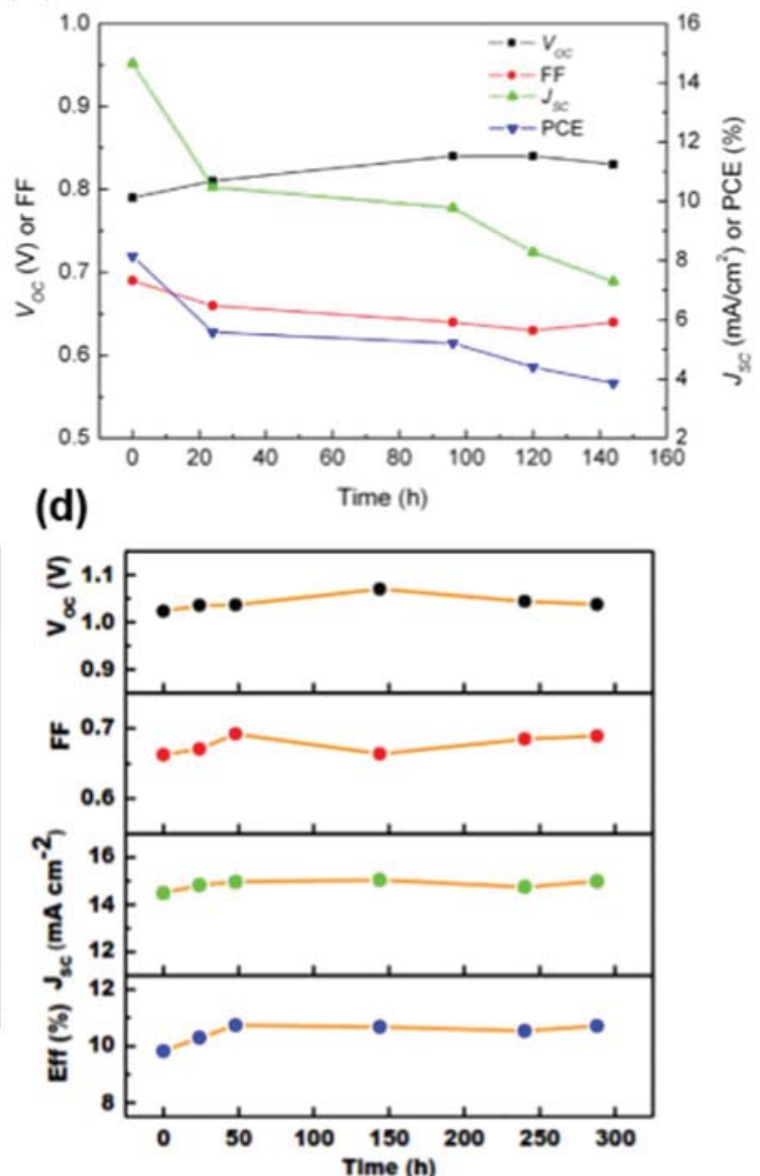

Fig. 23. (a) Long-term stability performance of various HTM-free PSCs stored in air at room temperature without encapsulation [333], (b) photovoltaic parameters as a function of aging time for the device with a $35 \mathrm{~nm} \mathrm{CH} \mathrm{NH}_{3} \mathrm{PbI}_{3}{ }_{\mathrm{x}} \mathrm{Cl}_{\mathrm{x}}$ [334], (c) stability test of unencapsulated PSCs employing PEDOT;PSS and CuO ${ }_{\mathrm{x}}$ as HTM performed in air [232], and (d) stability of the device subjected to light soaking at room temperature without encapsulation [335]. Figures are reproduced with permission from the references.

investigated whilst at the same time observing that the costly Spiro OMeTAD continues to be a hugely popular choice in laboratories world wide, it becomes apparent that there is still work to do to confidently develop or identify a handful (or less) of consensus HTMs. These must guarantee high efficiency, high stability, low cost, and good film forming properties over large areas all at the same time.

A good HTM possesses relevant energy levels that ensure facile passage of photogenerated holes from the perovskite layer into the HTM (i.e. matching ionization potentials) whilst also ensuring selectivity, i.e. imped ing the recombination of electrons at such a contact (thus low electron affinities are sought). To ensure minimal losses during transport in order to maintain high fill factors, HTMs also require large hole mobilities (and relatively small thicknesses) as well as high transparency to ensure passage of light (either from the bottom TCO electrode or reflected from the top metal electrode). Spiro OMeTAD, initially developed for solid state dye sensitized solar cells, has been adopted since the very first investigations as a common HTM with various additives in order to enhance performance. Although PCEs reached with this material are remarkable, considerations on costs and stability have led researchers to develop and incorporate a vast number of alternatives. These range from organic based semiconducting and conducting polymers (e.g. PTAA, PEDOT: PSS, P3HT, CNT compo sites) as well as inorganic materials such as $\mathrm{CuI}, \mathrm{CuSCN}, \mathrm{NiO}, \mathrm{Cu}_{2} \mathrm{O}, \mathrm{MoO}_{3}$ and GO. Sifting through the literature some general trends start to appear. Firstly, that doped organic transport layers, although typically guaranteeing higher efficiency, tend to be more prone to degradation over time compared to their pristine counterparts. Secondly that some of the inorganic HTMs may result in improved stability, especially if replacing a material like
PEDOT: PSS which is affected by humidity due to its hygroscopic nature. One can draw parallels with the field of organic semiconductor light emitting diodes and solar cells, for example, where these inorganic layers have become more favored in time, mainly as a result of their stronger stability. We envisage a similar trend also for perovskite solar cells as a result of stability being one of the major issues related to this technology. It is also interesting to note that the importance of the properties of the transport layer depends on different illumination and operating conditions. Whereas the role of the electron extracting layers has been highlighted for delivering remarkable performance not only under 1 sun but also under artificial indoor illumination [349,350], the role of HTMs under these light harvesting conditions remains to be investigated. Additionally, as a general remark it, however, remains to be investigated on a larger number of studies how the inorganic HTMs are deposited and perform over the large area module scale rather than just on the small cell level. Furthermore, although at the start it is best to adopt the solution that works best for each layer, for long term massive throughputs it is still not clear, apart from general remarks that can be found in some articles what is the impact of vacuum based vs solution based deposition on costs of the PV technology (which is a crucial parameter for entering the market). Thus we call for more detailed future studies on this aspect.

In fact a good HTM requires good film forming properties ensuring as uniform coverage as possible. In the common $\mathrm{n} i \mathrm{p}$ architecture, furthermore, the HTMs lie just under the top electrode so it is the first material (barring lateral permeation) to come into contact with humidity and oxygen as well as interfacing with the perovskite. Thus, its resistance to chemical degradation as well as guaranteeing a stable 
Table 7

A comparison of stability of various hole transporting materials or HTM free (with and without dopants).

\begin{tabular}{|c|c|c|c|c|c|c|c|}
\hline HTM & Device configuration & & Initial PCE & Percentage reduction in PCE & Rel. H (\%) & Test duration & Ref. \\
\hline DR3TBDTT+PDMS & $\mathrm{FTO} / \mathrm{CL} / \mathrm{MAI}_{3}{ }_{x} \mathrm{Clx} / \mathrm{HTM} / \mathrm{Au}$ & No & 8.3 & $2 \%$ & $>50$ & 3 days & [305] \\
\hline Spiro-OMeTAD+AgTFSI & $\mathrm{FTO} / \mathrm{CL} / \mathrm{nc}-\mathrm{Al}_{2} \mathrm{O}_{3} / \mathrm{MAPbI}_{3}{ }_{\mathrm{x}} \mathrm{Cl}_{\mathrm{x}} / \mathrm{HTM} / \mathrm{Ag}$ & Yes & 12.0 & $15 \%$ & $<15$ & 120 days & [108] \\
\hline PMMA & FTO/CL/ $\mathrm{Al}_{2} \mathrm{O}_{3}$-peroskite/perovskite/HTM/Ag & & 11.1 & $\sim 9 \%$ & & $90 \mathrm{~h}$ & [53] \\
\hline $2 \mathrm{TPA}-n-\mathrm{DP}$ & $\mathrm{FTO} / \mathrm{CL} / \mathrm{MAPbI}_{3} / \mathrm{HTM} / \mathrm{Au}$ & & 12.96 & $10 \%$ & & $900 \mathrm{~h}$ & {$[34]$} \\
\hline HTM free & $\mathrm{FTO} / \mathrm{MAPbI}_{3} / \mathrm{SBNP}+\mathrm{NA}$ & No & 13.5 & $0 \%$ & & 30 days & [336] \\
\hline HTM free & $\mathrm{FTO} / \mathrm{TiO}_{2} / \mathrm{MAPbI}_{3} /$ Carbon & No & 13.53 & $5 \%$ & High\% & 20 days & [70] \\
\hline PEDOT: PSS & $\mathrm{FTO} / \mathrm{HTM} / \mathrm{MAX}_{3} / \mathrm{PCBM} / \mathrm{Al}$ & & 13.28 & $80 \%$ & & $350 \mathrm{~h}$ & [58] \\
\hline TTF-1 & $\mathrm{FTO} / \mathrm{CL} / \mathrm{mp}-\mathrm{TiO}_{2} / \mathrm{MAI}_{3} / \mathrm{HTM} / \mathrm{Ag}$ & No & 11.03 & $20 \%$ & 40 & $360 \mathrm{~h}$ & [133] \\
\hline TSHBC & $\mathrm{FTO} / \mathrm{TiO}_{2} / \mathrm{MAI}_{3} / \mathrm{HTM} / \mathrm{Au}$ & & 12.8 & $15 \%$ & 45 & $240 \mathrm{~h}$ & [323] \\
\hline CzPAF-SBF & ITO/ZnO/MAPbI3/HTM/Au & No & 17.03 & $29 \%$ & 28 & $500 \mathrm{~h}$ & [303] \\
\hline Spiro-OMeTAD & ITO/ZnO/MAPbI3/HTM/Au & Yes & 16.45 & $55 \%$ & 28 & $500 \mathrm{~h}$ & [303] \\
\hline CzPAF-SBFN & ITO/ZnO/MAPbI3/HTM/Au & No & 15.90 & & 28 & & [303] \\
\hline $\mathrm{CuPc}$ & $\mathrm{FTO} / \mathrm{mp}-\mathrm{TiO}_{2} / \mathrm{MAPbI}_{3}+\mathrm{HTM} /$ carbon & No & 16.1 & $<10 \%$ & & $600 \mathrm{~h}$ & [140] \\
\hline P3HT/SWNTs-PMMA & FTO/CL/ $\mathrm{Al}_{2} \mathrm{O}_{3}$-peroskite/perovskite/HTM/Ag & No & 12.9 & $\sim 5 \%$ & & $60 \mathrm{~s}$ & [53] \\
\hline PTAA & FTO/TiO $/$ /MAPbI3/HTM/PEDOT: PSS/ITO & No & 15.8 & $<5 \%$ & & 20 days & [337] \\
\hline $\mathrm{CuI}$ & $\mathrm{FTO} / \mathrm{HTM} / \mathrm{MAX}_{3} / \mathrm{PCBM} / \mathrm{Al}$ & & 13.58 & $90 \%$ & & 14 days & {$[58]$} \\
\hline $\mathrm{CuOx}$ & $\mathrm{ITO} / \mathrm{HTM} / \mathrm{MAPbI}_{3} / \mathrm{C}_{6 \mathrm{o}} / \mathrm{BCP} / \mathrm{Ag}$ & & 17.1 & $10 \%$ & & $200 \mathrm{~h}$ & [74] \\
\hline $\mathrm{NiOx}$ & $\mathrm{FTO} / \mathrm{NiOx} / \mathrm{MAPbI}_{3} / \mathrm{PCBM} / \mathrm{Ag}$ & No & 14.42 & $\sim 20 \%$ & $4556 \%$ & $150 \mathrm{~h}$ & [338] \\
\hline $\mathrm{Cu}-\mathrm{NiOx}$ & $\mathrm{ITO} / \mathrm{Cu}-\mathrm{NiOx} / \mathrm{MAPbI}_{3} / \mathrm{PC}_{61} \mathrm{BM} / \mathrm{Au}$ & Yes & 15.40 & $10 \%$ & & $240 \mathrm{~h}$ & [30] \\
\hline Random copolymer & $\mathrm{FTO} / \mathrm{SnO}_{2} / \mathrm{MAPbI}_{3} / \mathrm{RCP} / \mathrm{Au}$ & No & 17.3 & $0 \%$ drop & $75 \%$ & $1400 \mathrm{~h}$ & [339] \\
\hline MeOTPA & $\mathrm{FTO} / \mathrm{c}-\mathrm{TiO}_{2} / / \mathrm{TiO}_{2}-\mathrm{MAPbI}_{3} / \mathrm{HTM} / \mathrm{Au}$ & No & 16.1 & $0 \%$ drop & $30 \%$ & $1000 \mathrm{~h}$ & [340] \\
\hline Polymeric triarylamine & $\mathrm{FTO} / \mathrm{mp}-\mathrm{TiO}_{2} / / \mathrm{MAPbI}_{3} / \mathrm{HTM}(\mathrm{V} 873) / \mathrm{Au}$ & No & 12.3 & $0 \%$ drop & & $40 \mathrm{~h}$ & [341] \\
\hline TPA & $\mathrm{FTO} / \mathrm{c}-\mathrm{TiO}_{2} / / \mathrm{TiO}_{2}-\mathrm{MAPbI}_{3} / \mathrm{HTM}(\mathrm{Z1013}) / \mathrm{Au}$ & No & 15.4 & $0 \%$ drop & $30 \%$ & 4 weeks & [342] \\
\hline $\mathrm{ODA}^{-\mathrm{FeS}_{2} \mathrm{NPs}}$ & $\mathrm{FTO} / \mathrm{mp}-\mathrm{TiO}_{2} / \mathrm{MAPbI}_{3} / \mathrm{HTM} / \mathrm{Au}$ & No & 12.6 & $8 \%$ drop & $50 \%$ & $1000 \mathrm{~h}$ & [343] \\
\hline pBBTa-BDT2 & $\mathrm{FTO} / \mathrm{c}-\mathrm{TiO}_{2} / \mathrm{MAPbI}_{3} / \mathrm{HTM} / \mathrm{Au}$ & No & 12.3 & $0 \%$ & $65 \%$ & $500 \mathrm{~h}$ & [344] \\
\hline DEPT-SC & $\mathrm{FTO} / \mathrm{c}-\mathrm{TiO}_{2} / \mathrm{mp}-\mathrm{TiO}_{2} / \mathrm{MAPbI}_{3} / \mathrm{HTM} / \mathrm{Au}$ & Yes & 11.52 & $30 \%$ & $35 \%$ & $240 \mathrm{~h}$ & [345] \\
\hline X25 & $\mathrm{FTO} / \mathrm{c}-\mathrm{TiO}_{2} / \mathrm{mp}-\mathrm{TiO}_{2} / \mathrm{MAPbI}_{3} / \mathrm{HTM} / \mathrm{Au}$ & No & 17.4 & $<3 \%$ & $10 \%$ & 15 days & [346] \\
\hline $\mathrm{Cu}-\mathrm{CrOx}$ & $\mathrm{FTO} / \mathrm{HTM} / \mathrm{MAPbI}_{3} / \mathrm{PCBM} / \mathrm{Ag}$ & Yes & 11.48 & $10 \%$ & $25 \%$ & $144 \mathrm{~h}$ & [347] \\
\hline DNA-CTMA & $\mathrm{FTO} / \mathrm{HTM} / \mathrm{MAPbI}_{3} / \mathrm{PCBM} / \mathrm{Al}$ & No & 13.6 & $12 \%$ & $40 \%$ & 50 days & [182] \\
\hline CSWNT-GO & $\mathrm{FTO} / \mathrm{TiO}_{2} / \mathrm{MAPbI}_{3} / \mathrm{HTM} / \mathrm{Au}$ & Yes & 10.4 & $\sim 5 \%$ & $7080 \%$ & 10 days & [348] \\
\hline
\end{tabular}

CzPAF-SBF: 7-(9,9'-spirobifl uorene-2-yl)-N- (7-(9,9'-spirobifluorene-2-yl)-9,9-dioctyl-9H-fluoren-2-yl)-N- (4-(9H-carbazol-9-yl)phenyl)-9,9-dioctyl-9H-fluoren-2-amine.

CzPAF-SBFN: 7-(7'-carbonitrile-9,9'-spirobifl uorene-2-yl)-N-(7-(7'-carbonitrile-9,9'-spirobifluorene-2-yl)-9,9-dioctyl-9H-fluoren-2-yl)-N-(4-(9H-carbazol-9-yl)phenyl)-9,9-dioctyl9H-fl uoren-2-amine.

ODA-FeS 2 NPs: octadecylamine-capped pyrite nanoparticles.

pBBTa-BDT2: 4,8-dithien-2-yl-benzo[1,2-d;4,5-d']bistriazole-alt-benzo[1,2-b:4,5-b']dithiophenes.

DEPT-SC: $\alpha, \alpha^{\prime}$-diethoxyethyl-oligothiophenes.

$\mathrm{X} 25$ : Full name is not available.

electronic interface is mandatory. Examples of solutions developed to ensure stability involve guaranteeing stable electronic properties and stable materials over broad temperature ranges and against the permeation of water vapors. We have detailed examples of HTMs made of composite materials/layers, even deposited from different techniques in the case of bilayers, leading to better performance/ stability. Although increasing manufacturing costs, these may be considered effective strategies to decouple the different effect of HTMs (e.g. interfacial and permeation barriers effects vs bulk mobility, blocking and film coverage effects) so further studies along these lines will lead to further understanding on the different properties and effects of HTMs on overall device efficiency and stability.

\section{Acknowledgements}

A.F. acknowledge Alexander von Humboldt Foundation for the postdoctoral research fellowship award.

\section{Appendix A. Supporting information}

Supplementary data associated with this article can be found in the online version at doi:10.1016/j.nanoen.2017.02.025.

\section{References}

[1] J. Burschka, N. Pellet, S.-J. Moon, R. Humphry-Baker, P. Gao, M.K. Nazeeruddin, M. Grätzel, Sequential deposition as a route to high-performance perovskitesensitized solar cells, Nature 499 (2013) 316319.

[2] J.H. Heo, S.H. Im, J.H. Noh, T.N. Mandal, C.-S. Lim, J.A. Chang, Y.H. Lee, H.j. Kim, A. Sarkar, M.K. Nazeeruddin, M. Grätzel, S.I. Seok, Efficient inorganic- organic hybrid heterojunction solar cells containing perovskite compound and polymeric hole conductors, Nat. Photonics 7 (2013) 486491.

[3] J.-H. Im, C.-R. Lee, J.-W. Lee, S.-W. Park, N.-G. Park, 6.5\% Efficient Perovskite Quantum-Dot-Sensitized Solar Cell, Nanoscale 3 (2011) 40884093.

[4] H.-S. Kim, C.-R. Lee, J.-H. Im, K.-B. Lee, T. Moehl, A. Marchioro, S.-J. Moon, R. Humphry-Baker, J.-H. Yum, J.E. Moser, M. Grätzel, N.-G. Park, Lead iodide perovskite sensitized all-solid-state submicron thin film mesoscopic solar cell with efficiency exceeding 9\%, Sci. Rep. 2 (2012) 591.

[5] A. Kojima, K. Teshima, Y. Shirai, T. Miyasaka, Organometal halide perovskites as visible-light sensitizers for photovoltaic cells, J. Am. Chem. Soc. 131 (2009) 60506051.

[6] P. Gao, M. Grätzel, M.K. Nazeeruddin, Organohalide lead perovskites for photovoltaic applications, Energy Environ. Sci. 7 (2014) 24482463.

[7] G.E. Eperon, S.D. Stranks, C. Menelaou, M.B. Johnston, L.M. Herz, H.J. Snaith, Formamidinium lead trihalide: a broadly tunable perovskite for efficient planar heterojunction solar cells, Energy Environ. Sci. 7 (2014) 982988.

[8] T.M. Koh, K. Fu, Y. Fang, S. Chen, T.C. Sum, N. Mathews, S.G. Mhaisalkar, P.P. Boix, T. Baikie, Formamidinium-containing metal-halide: an alternative material for near-IR absorption perovskite solar cells, J. Phys. Chem. C. 118 (2013) 1645816462

[9] N. Pellet, P. Gao, G. Gregori, T.-Y. Yang, M.K. Nazeeruddin, J. Maier, M. Grätzel, Mixed-Organic-Cation Perovskite Photovoltaics for Enhanced Solar-Light Harvesting, Angew. Chem. Int. Ed. 53 (2014) 31513157.

[10] H.J. Snaith, Perovskites: the emergence of a new era for low-cost, high-efficiency solar cells, J. Phys. Chem. Lett. 4 (2013) 36233630.

[11] Q. Lin, A. Armin, R.C.R. Nagiri, P.L. Burn, P. Meredith, Electro-optics of perovskite solar cells, Nat. Photonics 9 (2015) 106112.

[12] S.D. Stranks, G.E. Eperon, G. Grancini, C. Menelaou, M.J.P. Alcocer, T. Leijtens, L.M. Herz, A. Petrozza, H.J. Snaith, Electron-hole diffusion lengths exceeding 1 Micrometer in an organometal trihalide perovskite absorber, Science 342 (2013) 341344.

[13] Q. Dong, Y. Fang, Y. Shao, P. Mulligan, J. Qiu, L. Cao, J. Huang, Solar cells. Electron-hole diffusion lengths $>175 \mu \mathrm{m}$ in solution-grown $\mathrm{CH}_{3} \mathrm{NH}_{3} \mathrm{PbI}_{3}$ single crystals, Science 347 (2015) 967970.

[14] T. Leijtens, S.D. Stranks, G.E. Eperon, R. Lindblad, E.M.J. Johansson, I.J. Mcpherson, H. Rensmo, J.M. Ball, M.M. Lee, H.J. Snaith, Electronic properties of meso-superstructured and planar organometal halide perovskite films: charge trapping, photodoping, and carrier mobility, ACS Nano 8 (2014) 
71477155

[15] C.S. Ponseca Jr, T.J. Savenije, M. Abdellah, K. Zheng, A. Yartsev, Tr Pascher, T. Harlang, P. Chabera, T. Pullerits, A. Stepanov, J.-P. Wolf, V. Sundström, Organometal halide perovskite solar cell materials rationalized: ultrafast charge generation, high and microsecond-long balanced mobilities, and slow recombination, J. Am. Chem. Soc. 136 (2014) 51895192.

[16] C. Wehrenfennig, G.E. Eperon, M.B. Johnston, H.J. Snaith, L.M. Herz, High charge carrier mobilities and lifetimes in organolead trihalide perovskites, Adv. Mater. 26 (2014) 15841589.

[17] G. Xing, N. Mathews, S. Sun, S.S. Lim, Y.M. Lam, M. Grätzel, S. Mhaisalkar, T.C. Sum, Long-range balanced electron-and hole-transport lengths in organicinorganic $\mathrm{CH}_{3} \mathrm{NH}_{3} \mathrm{PbI}_{3}$, Science 342 (2013) 344347 .

[18] M. Samiee, S. Konduri, B. Ganapathy, R. Kottokkaran, H.A. Abbas, A. Kitahara, P. Joshi, L. Zhang, M. Noack, V. Dalal, Defect density and dielectric constant in perovskite solar cells, Appl. Phys. Lett. 105 (2014) 153502.

[19] C.C. Stoumpos, C.D. Malliakas, M.G. Kanatzidis, Semiconducting tin and lead iodide perovskites with organic cations: phase transitions, high mobilities, and near-infrared photoluminescent properties, Inorg. Chem. 52 (2013) 90199038

[20] H. Oga, A. Saeki, Y. Ogomi, S. Hayase, S. Seki, Improved understanding of the electronic and energetic landscapes of perovskite solar cells: high local charge carrier mobility, reduced recombination, and extremely shallow traps, J. Am. Chem. Soc. 136 (2014) 1381813825.

[21] Nerl, Best research cell efficiencies, NREL, Editor, 2016.

[22] M. Saliba, S. Orlandi, T. Matsui, S. Aghazada, M. Cavazzini, J.-P. Correa-Baena, P. Gao, R. Scopelliti, E. Mosconi, K.-H. Dahmen, F. De angelis, A. Abate, A. Hagfeldt, G. Pozzi, M. Graetzel, M.K. Nazeeruddin, A molecularly engineered hole-transporting material for efficient perovskite solar cells, Nat. Energy 1 (2016) 15017.

[23] D. Bi, S.-J. Moon, L. Häggman, G. Boschloo, L. Yang, E.M. Johansson, M.K. Nazeeruddin, M. Grätzel, A. Hagfeldt, Using a two-step deposition technique to prepare perovskite $\left(\mathrm{CH}_{3} \mathrm{NH}_{3} \mathrm{PbI}_{3}\right)$ for thin film solar cells based on $\mathrm{ZrO}_{2}$ and $\mathrm{TiO}_{2}$ mesostructures, RSC Adv. 3 (2013) 1876218766.

[24] M.M. Lee, J. Teuscher, T. Miyasaka, T.N. Murakami, H.J. Snaith, Efficient hybrid solar cells based on meso-superstructured organometal halide perovskites, Science 338 (2012) 643647.

[25] M. Liu, M.B. Johnston, H.J. Snaith, Efficient planar heterojunction perovskite solar cells by vapour deposition, Nature 501 (2013) 395398.

[26] Q. Hu, J. Wu, C. Jiang, T. Liu, X. Que, R. Zhu, Q. Gong, Engineering of electronselective contact for perovskite solar cells with efficiency exceeding $15 \%$, ACS Nano 8 (2014) 1016110167.

[27] W. Ke, G. Fang, J. Wan, H. Tao, Q. Liu, L. Xiong, P. Qin, J. Wang, H. Lei, G. Yang, M. Qin, X. Zhao, Y. Yan, Efficient hole-blocking layer-free planar halide perovskite thin-film solar cells, Nat. Commun. 6 (2015) 6700.

[28] L. Etgar, P. Gao, Z. Xue, Q. Peng, A.K. Chandiran, B. Liu, M.K. Nazeeruddin, M. GräTzel, Mesoscopic $\mathrm{CH}_{3} \mathrm{NH}_{3} \mathrm{PbI}_{3} / \mathrm{TiO}_{2}$ heterojunction solar cells, J. Am. Chem. Soc. 134 (2012) 1739617399.

[29] A. Mei, X. Li, L. Liu, Z. Ku, T. Liu, Y. Rong, M. Xu, M. Hu, J. Chen, Y. Yang M. Grätzel, H. Han, A hole-conductor free, fully printable mesoscopic perovskite solar cell with high stability, Science 345 (2014) 295298.

[30] J.H. Kim, P.W. Liang, S.T. Williams, N. Cho, C.C. Chueh, M.S. Glaz, D.S. Ginger, A.K.Y. Jen, High-Performance and environmentally stable planar heterojunction perovskite solar cells based on a solution-processed copper-doped nickel oxide hole-transporting layer, Adv. Mater. 27 (2015) 695701.

[31] K.-C. Wang, J.-Y. Jeng, P.-S. Shen, Y.-C. Chang, E.W.-G. Diau, C.-H. Tsai, T.Y. Chao, H.-C. Hsu, P.-Y. Lin, P. Chen, p-Type mesoscopic nickel oxide/ organometallic perovskite heterojunction solar cells, Sci. Rep. 4 (2014) 4756

[32] A. Fakharuddin, F. De Rossi, T.M. Watson, L. Schmidt-Mende, R. Jose, Research Update: behind the high efficiency of hybrid perovskite solar cells, APL Mater. 4 (2016) 091505.

[33] W. Tress, N. Marinova, O. Inganäs, M.K. Nazeeruddin, S.M. Zakeeruddin, M. Graetzel, The role of the hole-transport layer in perovskite solar cells-reducing recombination and increasing absorption. in: IEEE Proceedings of the 40th Photovoltaic Specialist Conference (PVSC). IEEE, 2014, pp. 15631566.

[34] L. Zhu, J. Xiao, J. Shi, J. Wang, S. Lv, Y. Xu, Y. Luo, Y. Xiao, S. Wang, Q. Meng, X. Li, D. Li, Efficient $\mathrm{CH}_{3} \mathrm{NH}_{3} \mathrm{PbI}_{3}$ perovskite solar cells with 2TPA-n-DP holetransporting layers, Nano Res. 8 (2015) 11161127.

[35] S. Chen, Y. Hou, H. Chen, M. Richter, F. Guo, S. Kahmann, X. Tang, T. Stubhan, H. Zhang, N. Li, N. Gasparini, C.O.R. Quiroz, L.S. Khanzada, G.J. Matt, A. Osvet, C.J. Brabec, Exploring the limiting open-circuit voltage and the voltage loss mechanism in planar $\mathrm{CH}_{3} \mathrm{NH}_{3} \mathrm{PbBr}_{3}$ perovskite solar cells, Adv. Energy Mater. 6 (2016) 1600132.

[36] N.K. Elumalai, A. Uddin, Open circuit voltage of organic solar cells: an in-depth review, Energy Environ. Sci. 9 (2016) 391410.

[37] Y. Shao, Y. Yuan, J. Huang, Correlation of energy disorder and open-circuit voltage in hybrid perovskite solar cells, Nat. Energy 1 (2016) 15001.

[38] W. Tress, Maximum efficiency and open-circuit voltage of perovskite solar cells, in: N.-G. Park, M. Grätzel, T. Miyasaka (Eds.), Organic-Inorganic Halide Perovskite Photovoltaics: From Fundamentals to Device Architectures, Springer International Publishing, Switzerland, 2016, pp. 5377.

[39] H. Back, G. Kim, J. Kim, J. Kong, T.K. Kim, H. Kang, H. Kim, J. Lee, S. Lee, $\mathrm{K}$. Lee, Achieving long-term stable perovskite solar cells via ion neutralization, Energy Environ. Sci. 9 (2016) 12581263.

[40] Y. Kato, L.K. Ono, M.V. Lee, S. Wang, S.R. Raga, Y. Qi, Silver iodide formation in methyl ammonium lead iodide perovskite solar cells with silver top electrodes, Adv. Mater. Interfaces 2 (2015) 1500195.

[41] E. Edri, S. Kirmayer, M. Kulbak, G. Hodes, D. Cahen, Chloride inclusion and hole transport material doping to improve methyl ammonium lead bromide perovskite-based high open-circuit voltage solar cells, J. Phys. Chem. Lett. 5 (2014) 429433.

[42] C.-G. Wu, C.-H. Chiang, S.H. Chang, A perovskite cell with a record-high-Voc of $1.61 \mathrm{~V}$ based on solvent annealed $\mathrm{CH}_{3} \mathrm{NH}_{3} \mathrm{PbBr}_{3} / \mathrm{ICBA}$ active layer, Nanoscale 8 (2016) 40774085.

[43] Y. Zhang, W. Liu, F. Tan, Y. Gu, The essential role of the poly (3-hexylthiophene) hole transport layer in perovskite solar cells, J. Power Sources 274 (2015) 12241230.

[44] J. You, L. Meng, T.-B. Song, T.-F. Guo, Y.M. Yang, W.-H. Chang, Z. Hong, H. Chen, H. Zhou, Q. Chen, Y. Liu, N.D. Marco, Y. Yang, Improved air stability of perovskite solar cells via solution-processed metal oxide transport layers, Nat. Nanotechnol. 11 (2016) 7581.

[45] F. Di Giacomo, A. Fakharuddin, R. Jose, T.M. Brown, Progress, challenges and perspectives in flexible perovskite solar cells, Energy Environ. Sci. 9 (2016) 30073035 .

[46] A. Alnuaimi, I. Almansouri, A. Nayfeh, Effect of mobility and band structure of hole transport layer in planar heterojunction perovskite solar cells using 2D TCAD simulation, J. Comput. Electron. 15 (2016) 11101118.

[47] P. Dhingra, P. Singh, P.J.S. Rana, A. Garg, P. Kar, Hole-transporting materials for perovskite-sensitized solar cells, Energy Technol. 4 (2016) 891938.

[48] Z. Yu, L. Sun, Recent progress on hole-transporting materials for emerging organometal halide perovskite solar cells, Adv. Energy Mater. 5 (2015) 1500213.

[49] W.H. Nguyen, C.D. Bailie, E.L. Unger, M.D. Mcgehee, Enhancing the holeconductivity of spiro-OMeTAD without Oxygen or Lithium Salts by Using Spiro(TFSI $)_{2}$ in perovskite and dye-sensitized solar cells, J. Am. Chem. Soc. 136 (2014) 1099611001.

[50] D. Shi, X. Qin, Y. Li, Y. He, C. Zhong, J. Pan, H. Dong, W. Xu, T. Li, W. Hu, J.L. Brédas, O.M. Bakr, Spiro-OMeTAD single crystals: remarkably enhanced charge-carrier transport via mesoscale ordering, Sci. Adv. 2 (2016) e1501491.

[51] N. Ahn, D.-Y. Son, I.-H. Jang, S.M. Kang, M. Choi, N.-G. Park, Highly reproducible perovskite solar cells with average efficiency of $18.3 \%$ and best efficiency of $19.7 \%$ fabricated via Lewis base adduct of lead (II) iodide, J. Am. Chem. Soc. 137 (2015) 86968699.

[52] I. Mcculloch, M. Heeney, C. Bailey, K. Genevicius, I. Macdonald, M. Shkunov, D. Sparrowe, S. Tierney, R. Wagner, W. Zhang, M.L. Chabinyc, R.J. Kline, M.D. Mcgehee, M.F. Toney, Liquid-crystalline semiconducting polymers with high charge-carrier mobility, Nat. Mater. 5 (2006) 328333.

[53] S.N. Habisreutinger, T. Leijtens, G.E. Eperon, S.D. Stranks, R.J. Nicholas, H.J. Snaith, Carbon nanotube/polymer composites as a highly stable hole collection layer in perovskite solar cells, Nano Lett. 14 (2014) 55615568.

[54] W.S. Yang, J.H. Noh, N.J. Jeon, Y.C. Kim, S. Ryu, J. Seo, S.I. Seok, Highperformance photovoltaic perovskite layers fabricated through intramolecular exchange, Science 348 (2015) 12341237.

[55] S.A. Rutledge, A.S. Helmy, Carrier mobility enhancement in poly (3, 4-ethylenedioxythiophene)-poly (styrenesulfonate) having undergone rapid thermal annealing, J. Appl. Phys. 114 (2013) 133708.

[56] J.H. Heo, H.J. Han, D. Kim, T.K. Ahn, S.H. Im, Hysteresis-less inverted $\mathrm{CH}_{3} \mathrm{NH}_{3} \mathrm{PbI}_{3}$ planar perovskite hybrid solar cells with $18.1 \%$ power conversion efficiency, Energy Environ. Sci. 8 (2015) 16021608.

[57] Y. Kokubun, H. Watanabe, M. Wada, Electrical properties of CuI thin films, Jpn. J. Appl. Phys. 10 (1971) 864.

[58] W.-Y. Chen, L.-L. Deng, S.-M. Dai, X. Wang, C.-B. Tian, X.-X. Zhan, S.-Y. Xie, R.B. Huang, L.-S. Zheng, Low-cost solution-processed copper iodide as an alternative to PEDOT: pss hole transport layer for efficient and stable inverted planar heterojunction perovskite solar cells, J. Mater. Chem. A 3 (2015) 1935319359.

[59] R. Dhakal, Y. Huh, D. Galipeau, X. Yan, AlSb compound semiconductor as absorber layer in thin film solar cells, in: L.A. Kosyachenko (Ed.)Solar Cells - New Aspects and Solutions, InTech, 2011, pp. 341357.

[60] S. Ye, W. Sun, Y. Li, W. Yan, H. Peng, Z. Bian, Z. Liu, C. Huang, CuSCN-based inverted planar perovskite solar cell with an average PCE of 15.6\%, Nano Lett. 15 (2015) 37233728

[61] S. Liu, R. Liu, Y. Chen, S. Ho, J.H. Kim, F. So, Nickel oxide hole injection/ transport layers for efficient solution-processed organic light-emitting diodes, Chem. Mater. 26 (2014) 45284534.

[62] J.H. Park, J. Seo, S. Park, S.S. Shin, Y.C. Kim, N.J. Jeon, H.-W. Shin, T.K. Ahn, J.H. Noh, S.C. Yoon, C.S. Hwang, S.I. Seok, Efficient $\mathrm{CH}_{3} \mathrm{NH}_{3} \mathrm{PbI}_{3}$ perovskite solar cells employing nanostructured p-Type NiO electrode formed by a pulsed laser deposition, Adv. Mater. 27 (2015) 40134019.

[63] A. Musa, T. Akomolafe, M.J. Carter, Production of cuprous oxide, a solar cell material, by thermal oxidation and a study of its physical and electrical properties, Sol. Energy Mater. Sol. Cells 51 (1998) 305316.

[64] C. Zuo, L. Ding, Solution-processed $\mathrm{Cu}_{2} \mathrm{O}$ and $\mathrm{CuO}$ as hole transport materials for efficient perovskite solar cells, Small 11 (2015) 55285532.

[65] W. Li, H. Dong, X. Guo, N. Li, J. Li, G. Niu, L. Wang, Graphene oxide as dual functional interface modifier for improving wettability and retarding recombination in hybrid perovskite solar cells, J. Mater. Chem. A 2 (2014) 2010520111.

[66] E. Edri, S. Kirmayer, A. Henning, S. Mukhopadhyay, K. Gartsman, Y. Rosenwaks, G. Hodes, D. Cahen, Why lead methylammonium tri-iodide perovskite-based solar cells require a mesoporous electron transporting scaffold (but not necessarily a hole conductor), Nano Lett. 14 (2014) 10001004.

[67] S. Aharon, S. Gamliel, B. El Cohen, L. Etgar, Depletion region effect of highly efficient hole conductor free $\mathrm{CH}_{3} \mathrm{NH}_{3} \mathrm{PbI}$ perovskite solar cells, Phys. Chem. Chem. Phys. 16 (2014) 1051210518.

[68] L. Liu, A. Mei, T. Liu, P. Jiang, Y. Sheng, L. Zhang, H. Han, Fully printable mesoscopic perovskite solar cells with organic silane self-Assembled monolayer, J. 
Am. Chem. Soc. 137 (2015) 17901793.

[69] Z. Yang, C.-C. Chueh, F. Zuo, J.H. Kim, P.-W. Liang, A.K.-Y. Jen, HighPerformance Fully Printable Perovskite Solar Cells via Blade-Coating Technique under the Ambient Condition, Adv. Energy Mater. 5 (2015) 1500328.

[70] H. Wei, J. Xiao, Y. Yang, S. Lv, J. Shi, X. Xu, J. Dong, Y. Luo, D. Li, Q. Meng, Freestanding flexible carbon electrode for highly efficient hole-conductor-free perovskite solar cells, Carbon 93 (2015) 861868.

[71] Y. Yang, K. Ri, A. Mei, L. Liu, M. Hu, T. Liu, X. Li, H. Han, The size effect of $\mathrm{TiO}_{2}$ nanoparticles on a printable mesoscopic perovskite solar cell, J. Mater. Chem. A 3 (2015) 91039107.

[72] Z. Wei, H. Chen, K. Yan, X. Zheng, S. Yang, Hysteresis-free multi-walled carbon nanotube-based perovskite solar cells with a high fill factor, J. Mater. Chem. A 3 (2015) 2422624231.

[73] L. Zhang, T. Liu, L. Liu, M. Hu, Y. Yang, A. Mei, H. Han, The effect of carbon counter electrodes on fully printable mesoscopic perovskite solar cells, J. Mater. Chem. A 3 (2015) 91659170.

[74] A. Guerrero, G. Garcia-Belmonte, I. Mora-Sero, J. Bisquert, Y.S. Kang, T.J. Jacobsson, J.-P. Correa-Baena, A. Hagfeldt, Properties of contact and bulk impedances in hybrid lead halide perovskite solar cells including inductive loop elements, J. Phys. Chem. C. 120 (2016) 80238032.

[75] E.J. Juarez-Perez, M. Wußler, F. Fabregat-Santiago, K. Lakus-Wollny, E. Mankel, T. Mayer, W. Jaegermann, I. Mora-Sero, Role of the selective contacts in the performance of lead halide perovskite solar cells, J. Phys. Chem. Lett. 5 (2014) 680685.

[76] F. Fabregat-Santiago, G. Garcia-Belmonte, I. Mora-Sero, J. Bisquert, Characterization of nanostructured hybrid and organic solar cells by impedance spectroscopy, Phys. Chem. Chem. Phys. 13 (2011) 90839118.

[77] A. Fakharuddin, I. Ahmed, Z. Khalidin, M.M. Yusoff, R. Jose, Charge transport through split photoelectrodes in dye-sensitized solar cells, J. Appl. Phys. 115 (2014) 164509.

[78] H. Choi, C.-K. Mai, H.-B. Kim, J. Jeong, S. Song, G.C. Bazan, J.Y. Kim, A.J. Heeger, Conjugated polyelectrolyte hole transport layer for inverted-type perovskite solar cells, Nat. Commun. 6 (2015) 7348.

[79] K. Rakstys, A. Abate, M.I. Dar, P. Gao, V. Jankauskas, G. Jacopin, E. Kamarauskas, S. Kazim, S. Ahmad, M. Grätzel, M.K. Nazeeruddin, Triazatruxene-based hole transporting materials for highly efficient perovskite solar cells, J. Am. Chem. Soc. 137 (2015) 1617216178.

[80] M. Salado, J. Idigoras, L. Calio, S. Kazim, M.K. Nazeeruddin, J.A. Anta, S. Ahmad, Interface play between perovskite and hole selective layer on the performance and stability of perovskite solar cells, ACS Appl. Mater. Interfaces 8 (2016) 3441434421.

[81] Y. Zhang, M. Liu, G.E. Eperon, T.C. Leijtens, D. Mcmeekin, M. Saliba, W. Zhang, M. De Bastiani, A. Petrozza, L.M. Herz, M.B. Johnston, H. Lin, H.J. Snaith, Charge selective contacts, mobile ions and anomalous hysteresis in organicinorganic perovskite solar cells, Mater. Horiz. 2 (2015) 315322.

[82] W. Tress, N. Marinova, O. Inganäs, M.K. Nazeeruddin, S.M. Zakeeruddin, M. Graetzel, Predicting the open-circuit voltage of $\mathrm{CH}_{3} \mathrm{NH}_{3} \mathrm{PbI}_{3}$ Perovskite Solar Cells Using Electroluminescence And Photovoltaic Quantum Efficiency Spectra: The Role Of Radiative And Non-radiative Recombination, Adv. Energy Mater. 5 (2015) 1400812.

[83] B. Cai, Y. Xing, Z. Yang, W.-H. Zhang, J. Qiu, High performance hybrid solar cells sensitized by organolead halide perovskites, Energy Environ. Sci. 6 (2013) 14801485

[84] Y. Zou, D. Gendron, R. Badrou-Aïch, A. Najari, Y. Tao, M. Leclerc, A. HighMobility Low-Bandgap, Poly(2,7-carbazole) Derivative for Photovoltaic Applications, Macromolecules 42 (2009) 28912894.

[85] M. Saliba, T. Matsui, J.-Y. Seo, K. Domanski, J.-P. Correa-Baena, M.K. Nazeeruddin, S.M. Zakeeruddin, W. Tress, A. Abate, A. Hagfeldt, M. Gratzel, Cesium-containing triple cation perovskite solar cells: improved stability, reproducibility and high efficiency, Energy Environ. Sci. 9 (2016) 19891997.

[86] E. Edri, S. Kirmayer, D. Cahen, G. Hodes, High open-circuit voltage solar cells based on organic inorganic lead bromide perovskite, J. Phys. Chem. Lett. 4 (2013) 897902

[87] S. Ryu, J.H. Noh, N.J. Jeon, K. Chan, Y., W.S. Yang, J. Seo, S.I. Seok, Voltage output of efficient perovskite solar cells with high open-circuit voltage and fill factor, Energy Environ. Sci. 7 (2014) 26142618.

[88] J.H. Heo, D.H. Song, S.H. Im, Planar $\mathrm{CH}_{3} \mathrm{NH}_{3} \mathrm{PbBr}_{3}$ hybrid solar cells with $10.4 \%$ power conversion efficiency, fabricated by controlled crystallization in the spincoating process, Adv. Mater. 26 (2014) 81798183.

[89] A. Agresti, S. Pescetelli, B. Taheri, A.E. Del Rio Castillo, L. Cinà, F. Bonaccorso, A. Di Carlo, Graphene perovskite solar cells exceed 18\% Efficiency: a stability study, ChemSusChem 9 (2016) 26092619.

[90] D. Koushik, W.J.H. Verhees, Y. Kuang, S. Veenstra, D. Zhang, M.A. Verheijen, M. Creatore, R.E.I. Schropp, High-efficiency humidity-stable planar perovskite solar cells based on atomic layer architecture, Energy Environ. Sci. 10 (2017) 91100

[91] Q. Fu, X. Tang, L. Tan, Y. Zhang, Y. Liu, L. Chen, Y. Chen, Versatile molybdenum isopropoxide for efficient mesoporous perovskite solar cells: simultaneously optimized morphology and interfacial engineering, J. Phys. Chem. C. 120 (2016) 1508915095.

[92] J. Burschka, A. Dualeh, F. Kessler, E. Baranoff, N.-L. Cevey-Ha, C. Yi, M.K. Nazeeruddin, M. GräTzel, Tris (2-(1H-pyrazol-1-yl) pyridine) cobalt (III) as p-type dopant for organic semiconductors and its application in highly efficient solid-state dye-sensitized solar cells, J. Am. Chem. Soc. 133 (2011) 1804218045.

[93] N. Cai, S.-J. Moon, L. Cevey-Ha, T. Moehl, R. Humphry-Baker, P. Wang, S.M. Zakeeruddin, M. GräTzel, An organic D- $\pi$-A dye for record efficiency solid- state sensitized heterojunction solar cells, Nano Letters 11 (2011), 2011, pp. 14521456.

[94] K. Kakiage, Y. Aoyama, T. Yano, K. Oya, J.-i. Fujisawa, M. Hanaya, Highlyefficient dye-sensitized solar cells with collaborative sensitization by silyl-anchor and carboxy-anchor dyes, Chem. Commun. 51 (2015) 1589415897.

[95] I.-K. Ding, N. Tétreault, J. Brillet, B.E. Hardin, E.H. Smith, S.J. Rosenthal, F. Sauvage, M. Grätzel, M.D. Mcgehee, Pore-filling of spiro-OMeTAD in solid-state dye sensitized solar cells: quantification, mechanism, and consequences for device performance, Adv. Funct. Mater. 19 (2009) 24312436.

[96] T. Leijtens, J. Lim, J. Teuscher, T. Park, H.J. Snaith, Charge density dependent mobility of organic hole-transporters and $\mathrm{Mesoporous} \mathrm{TiO}_{2}$ determined by transient mobility spectroscopy: implications to dye-sensitized and organic solar cells, Adv. Mater. 25 (2013) 32273233.

[97] F. Fabregat-Santiago, J. Bisquert, L Cevey, P. Chen, M. Wang, S.M. Zakeeruddin, M. Gratzel, Electron transport and recombination in solid-state dye solar cell with spiroOMeTAD as hole conductor, J. Am. Chem. Soc. 131 (2009) 558562.

[98] H.J. Snaith, M. Grätzel, Enhanced charge mobility in a molecular hole transporter via addition of redox inactive ionic dopant: implication to dye-sensitized solar cells, Appl. Phys. Lett. 89 (2006) 262114.

[99] H. Zhou, Q. Chen, G. Li, S. Luo, T.-B. Song, H.-S. Duan, Z. Hong, J. You, Y. Liu, Y. Yang, Interface engineering of highly efficient perovskite solar cells, Science 345 (2014) 542546.

[100] X. Li, D. Bi, C. Yi, J.-D. Décoppet, J. Luo, S.M. Zakeeruddin, A. Hagfeldt, M. Grätzel, A vacuum flash assisted solution process for high-efficiency large-area perovskite solar cells, Science 353 (2016) 5862.

[101] N.J. Jeon, H.G. Lee, Y.C. Kim, J. Seo, J.H. Noh, J. Lee, S.I. Seok, o-Methoxy substituents in spiroOMeTAD for efficient inorganic organic hybrid perovskite solar cells, J. Am. Chem. Soc. 136 (2014) 78377840.

[102] M.-H. Li, C.-W. Hsu, P.-S. Shen, H.-M. Cheng, Y. Chi, P. Chen, T.-F. Guo, Novel spiro-based hole transporting materials for efficient perovskite solar cells, Chem. Commun. 51 (2015) 1551815521.

[103] P. Ganesan, K. Fu, P. Gao, I. Raabe, K. Schenk, R. Scopelliti, J. Luo, L.H. Wong, M. Grätzel, M.K. Nazeeruddin, A simple spiro-type hole transporting material for efficient perovskite solar cells, Energy Environ. Sci. 8 (2015) 19861991.

[104] L.K. Ono, P. Schulz, J.J. Endres, G.O. Nikiforov, Y. Kato, A. Kahn, Y. Qi, Airexposure-induced gas-molecule incorporation into spiro-MeOTAD films, J. Phys. Chem. Lett. 5 (2014) 13741379.

[105] F. Bussolotti, S. Kera, K. Kudo, A. Kahn, N. Ueno, Gap states in pentacene thin film induced by inert gas Exposure, Phys. Rev. Lett. 110 (2013) 267602.

[106] Z. Hawash, L.K. Ono, Y. Qi, Moisture and oxygen enhance conductivity of LiTFSIdoped Spiro-MeOTAD hole transport layer in perovskite solar cells, Adv. Mater. Interfaces 3 (2016) 1600117.

[107] Z. Hawash, L.K. Ono, S.R. Raga, M.V. Lee, Y. Qi, Air-exposure induced dopant redistribution and energy level shifts in spin-coated spiroMeOTAD films, Chem. Mater. 27 (2015) 562569.

[108] B. Xu, J. Huang, H. ÅGren, L. Kloo, A. Hagfeldt, L. Sun, AgTFSI as p-type dopant for efficient and stable solid-state dye-sensitized and perovskite solar cells, ChemSusChem 7 (2014) 32523256.

[109] T.M. Koh, S. Dharani, H. Li, R.R. Prabhakar, N. Mathews, A.C. Grimsdale, S.G. Mhaisalkar, Cobalt dopant with deep redox potential for organometal halide hybrid solar cells, ChemSusChem 7 (2014) 19091914.

[110] L. Badia, E. Mas-Marzá, R.S. Sánchez, E.M. Barea, J. Bisquert, I. Mora-Seró, New iridium complex as additive to the spiroOMeTAD in perovskite solar cells with enhanced stability, APL Mater. 2 (2014) 081507.

[111] K. Mahmood, B.S. Swain, A. Amassian, 16.1\% Efficient Hysteresis-Free Mesostructured Perovskite Solar Cells Based on Synergistically Improved ZnO Nanorod Arrays, Adv. Energy Mater. 5 (2015) 1500568.

[112] J.-H. Im, I.-H. Jang, N. Pellet, M. Grätzel, N.-G. Park, Growth of $\mathrm{CH}_{3} \mathrm{NH}_{3} \mathrm{PbI}_{3}$ cuboids with controlled size for high-efficiency perovskite solar cells, Nat. Nanotechnol. 9 (2014) 927932.

[113] D. Liu, T.L. Kelly, Perovskite solar cells with a planar heterojunction structure prepared using room-temperature solution processing techniques, Nat. Photonics 8 (2014) 133138.

[114] X. Xu, H. Zhang, J. Shi, J. Dong, Y. Luo, D. Li, Q. Meng, Highly efficient planar perovskite solar cells with a $\mathrm{TiO}_{2} / \mathrm{ZnO}$ electron transport bilayer, J. Mater. Chem. A 3 (2015) 1928819293.

[115] W. Ke, G. Fang, Q. Liu, L. Xiong, P. Qin, H. Tao, J. Wang, H. Lei, B. Li, J. Wan, G. Yang, Y. Yan, Low-Temperature Solution-Processed Tin Oxide as an Alternative Electron Transporting Layer for Efficient Perovskite Solar Cells, J. Am. Chem. Soc. 137 (2015) 67306733.

[116] J.P.C. Baena, L. Steier, W. Tress, M. Saliba, S. Neutzner, T. Matsui, F. Giordano, T.J. Jacobsson, A.R.S. Kandada, S.M. Zakeeruddin, A. Petrozza, A. Abate, M.K. Nazeeruddin, M. Grätzel, A. Hagfeldt, Highly efficient planar perovskite solar cells through band alignment engineering, Energy Environ. Sci. 8 (2015) 29282934.

[117] S.H. Hwang, J. Roh, J. Lee, J. Ryu, J. Yun, J. Jang, Size-controlled SiO nanoparticles as scaffold layers in thin-film perovskite solar cells, J. Mater. Chem. A 2 (2014) 1642916433.

[118] K. Wojciechowski, M. Saliba, T. Leijtens, A. Abate, H.J. Snaith, Sub-150C processed meso-superstructured perovskite solar cells with enhanced efficiency, Energy Environ. Sci. 7 (2014) 11421147.

[119] T. Leijtens, I.-K. Ding, T. Giovenzana, J.T. Bloking, M.D. Mcgehee, A. Sellinger, Hole transport materials with low glass transition temperatures and high solubility for application in solid-state dye-sensitized solar cells, ACS Nano 6 (2012) 14551462.

[120] N.J. Jeon, J. Lee, J.H. Noh, M.K. Nazeeruddin, M. Gratzel, S.I. Seok, Efficient 
inorganic organic hybrid perovskite solar cells based on pyrene arylamine derivatives as hole-transporting materials, J. Am. Chem. Soc. 135 (2013) 1908719090.

[121] H. Li, K. Fu, A. Hagfeldt, M. Grätzel, S.G. Mhaisalkar, A.C. Grimsdale, A Simple 3, 4-Ethylenedioxythiophene Based Hole-Transporting Material for Perovskite Solar Cells, Angew. Chem. Int. Ed. 53 (2014) 40854088.

[122] K. Do, H. Choi, K. Lim, H. Jo, J.W. Cho, M.K. Nazeeruddin, J. Ko, Star-shaped hole transporting materials with a triazine unit for efficient perovskite solar cells, Chem. Commun. 50 (2014) 1097110974.

[123] H.-H. Chou, Y.-H. Chiang, M.-H. Li, P.-S. Shen, H.-J. Wei, C.-L. Mai, P. Chen, C.Y. Yeh, Zinc porphyrin ethynylaniline conjugates as novel hole-transporting materials for perovskite solar cells with power conversion efficiency of $16.6 \%$, ACS Energy Lett. 1 (2016) 956962.

[124] H. Li, K. Fu, P.P. Boix, L.H. Wong, A. Hagfeldt, M. Grätzel, S.G. Mhaisalkar, A.C. Grimsdale, Hole-transporting small molecules based on thiophene cores for high efficiency perovskite solar cells, ChemSusChem 7 (2014) 34203425.

[125] H.-H. Chou, H.-H. Shih, C.-H. Cheng, Triptycene derivatives as high-T ${ }_{\mathrm{g}}$ host materials for various electrophosphorescent devices, J. Mater. Chem. 20 (2010) 798805

[126] A. Krishna, D. Sabba, H. Li, J. Yin, P.P. Boix, C. Soci, S.G. Mhaisalkar, A.C. Grimsdale, Novel hole transporting materials based on triptycene core for high efficiency mesoscopic perovskite solar cells, Chem. Sci. 5 (2014) 27022709.

[127] Z. Jiang, T. Ye, C. Yang, D. Yang, M. Zhu, C. Zhong, J. Oin, D. Ma, Star-Shaped Oligotriarylamines with Planarized Triphenylamine Core: solution-processable, High- $\mathrm{T}_{\mathrm{g}}$ Hole-Injecting and Hole-Transporting Materials for Organic LightEmitting Devices, Chem. Mater. 23 (2011) 771777.

[128] T. Higashino, H. Imahori, Porphyrins as excellent dyes for dye-sensitized solar cells: recent developments and insights, Dalton Trans, 44 (2015) 448463.

[129] M. Urbani, M. GräTzel, M.K. Nazeeruddin, T. Torres, Meso-substituted porphyrins for dye-sensitized solar cells, Chemical Reviews 114 (2014), 2014, pp. 1233012396

[130] B. Li, C. Zheng, H. Liu, J. Zhu, H. Zhang, D. Gao, W. Huang, Large planar $\pi$ conjugated porphyrin for interfacial engineering in pin perovskite solar cells, ACS Appl. Mater. Interfaces 8 (2016) 2743827443.

[131] P. Qin, S. Paek, M.I. Dar, N. Pellet, J. Ko, M. GräTzel, M.K. Nazeeruddin, Perovskite solar cells with $12.8 \%$ efficiency by using conjugated quinolizino acridine based hole transporting material, J. Am. Chem. Soc. 136 (2014) 85168519.

[132] H. Choi, S. Park, S. Paek, P. Ekanayake, M.K. Nazeeruddin, J. Ko, Efficient starshaped hole transporting materials with diphenylethenyl side arms for an efficient perovskite solar cell, J. Mater. Chem. A 2 (2014) 1913619140.

[133] J. Liu, Y. Wu, C. Qin, X. Yang, T. Yasuda, A. Islam, K. Zhang, W. Peng, W. Chen, L. Han, A dopant-free hole-transporting material for efficient and stable perovskite solar cells, Energy Environ. Sci. 7 (2014) 29632967.

[134] Y. Song, S. Lv, X. Liu, X. Li, S. Wang, H. Wei, D. Li, Y. Xiao, Q. Meng, Energy level tuning of TPB-based hole-transporting materials for highly efficient perovskite solar cells, Chem. Commun. 50 (2014) 1523915242.

[135] S. Do Sung, M.S. Kang, I.T. Choi, H.M. Kim, H. Kim, M. Hong, H.K. Kim, W.I. Lee, $14.8 \%$ perovskite solar cells employing carbazole derivatives as hole transporting materials, Chem. Commun. 50 (2014) 1416114163.

[136] A.W. Hains, Z. Liang, M.A. Woodhouse, B.A. Gregg, Molecular semiconductors in organic photovoltaic cells, Chem. Rev. 110 (2010) 66896735.

137] T. Stübinger, W. Brütting, Exciton diffusion and optical interference in organic donor acceptor photovoltaic cells, J. Appl. Phys. 90 (2001) 3632.

[138] C.V. Kumar, G. Sfyri, D. Raptis, E. Stathatos, P. Lianos, Perovskite solar cell with ow cost Cu-phthalocyanine as hole transporting material, RSC Adv. 5 (2015) 37863791.

[139] J. Seo, N.J. Jeon, W.S. Yang, H.-W. Shin, T.K. Ahn, J. Lee, J.H. Noh, S.I. Seok, Effective electron blocking of CuPC-doped spiro-OMeTAD for highly efficient inorganic-organic hybrid perovskite solar cells, Adv. Energy Mater. 5 (2015) 1501320.

[140] F. Zhang, X. Yang, M. Cheng, W. Wang, L. Sun, Boosting the efficiency and the stability of low cost perovskite solar cells by using CuPc nanorods as hole transport material and carbon as counter electrode, Nano Energy 20 (2016) 108116

[141] W. Ke, D. Zhao, C.R. Grice, A.J. Cimaroli, G. Fang, Y. Yan, Efficient fully-vacuumprocessed perovskite solar cells using copper phthalocyanine as hole selective layers, J. Mater. Chem. A 3 (2015) 2388823894.

[142] Y. Liu, Q. Chen, H.-S. Duan, H. Zhou, Y.M. Yang, H. Chen, S. Luo, T.-B. Song, L. Dou, Z. Hong, Y. Yang, A dopant-free organic hole transport material for efficient planar heterojunction perovskite solar cells, J. Mater. Chem. A 3 (2015) 1194011947.

[143] H. Choi, S. Paek, N. Lim, Y.H. Lee, M.K. Nazeeruddin, J. Ko, Efficient perovskite solar cells with $13.63 \%$ efficiency based on planar triphenylamine hole conductors, Chem. A Eur. J. 20 (2014) 1089410899.

[144] M.T. Dang, L. Hirsch, G. Wantz, P3HT: pcbm, best seller in polymer photovoltaic research, Adv. Mater. 23 (2011) 35973602.

[145] J. Xiao, J. Shi, H. Liu, Y. Xu, S. Lv, Y. Luo, D. Li, Q. Meng, Y. Li, Efficient $\mathrm{CH}_{3} \mathrm{NH}_{3} \mathrm{PbI}_{3}$ Perovskite Solar Cells Based on Graphdiyne (GD)-Modified P3HT Hole-Transporting Material, Adv. Energy Mater. 5 (2015) 1401943.

[146] D. Bi, L. Yang, G. Boschloo, A. Hagfeldt, E.M.J. Johansson, Effect of different hole transport materials on recombination in $\mathrm{CH}_{3} \mathrm{NH}_{3} \mathrm{PbI}_{3}$ perovskite-sensitized mesoscopic solar cells, J. Phys. Chem. Lett. 4 (2013) 15321536.

[147] S. Cho, J.-W. Jang, W. Zhang, A. Suwardi, H. Wang, D. Wang, J.L. MacmanusDriscoll, Single-Crystalline Thin Films for Studying Intrinsic Properties of $\mathrm{BiFeO}_{3}$ $\mathrm{SrTiO}_{3}$ Solid Solution Photoelectrodes in Solar Energy Conversion, Chem. Mater.
27 (2015) 66356641.

[148] H.A. Abbas, R. Kottokkaran, B. Ganapathy, M. Samiee, L. Zhang, A. Kitahara, M. Noack, V.L. Dalal, High efficiency sequentially vapor grown nip $\mathrm{CH}_{3} \mathrm{NH}_{3} \mathrm{PbI}_{3}$ perovskite solar cells with undoped P3HT as p-type heterojunction layer, APL Mater. 3 (2015) 016105

[149] B. Conings, L. Baeten, C. De Dobbelaere, J. D'haen, J. Manca, H.-G. Boyen, Perovskite-Based Hybrid Solar Cells Exceeding 10\% Efficiency with High Reproducibility Using a Thin Film Sandwich Approach, Adv. Mater. 26 (2014) 20412046.

[150] F. Di Giacomo, S. Razza, F. Matteocci, A. D'epifanio, S. Licoccia, T.M. Brown, A. Di Carlo, High efficiency $\mathrm{CH}_{3} \mathrm{NH}_{3} \mathrm{PbI}{ }_{(3}{ }_{\mathrm{X}} \mathrm{Cl}_{\mathrm{X}}$ perovskite solar cells with poly (3hexylthiophene) hole transport layer, J. Power Sources 251 (2014) 152156.

[151] M. Zhang, H. Yu, J.-H. Yun, M. Lyu, Q. Wang, L. Wang, Facile preparation of smooth perovskite films for efficient meso/planar hybrid structured perovskite solar cells, Chem. Commun. 51 (2015) 1003810041.

[152] M. Cai, V.T. Tiong, T. Hreid, J. Bell, H. Wang, Efficient hole transport materia composite based on poly (3-hexylthiophene) and bamboo-structure carbon nanotubes for high performance perovskite solar cells, J. Mater. Chem. A 3 (2015) 27842793.

[153] H. Chen, X. Pan, W. Liu, M. Cai, D. Kou, Z. Huo, X. Fang, S. Dai, Efficient panchromatic inorganic organic heterojunction solar cells with consecutive charge transport tunnels in hole transport material, Chem. Commun. 49 (2013) 72777279 .

[154] Y. Guo, C. Liu, K. Inoue, K. Harano, H. Tanaka, E. Nakamura, Enhancement in the efficiency of an organic inorganic hybrid solar cell with a doped P3HT holetransporting layer on a void-free perovskite active layer, J. Mater. Chem. A 2 (2014) 1382713830

[155] J.-H. Heo, S.H. Im, $\mathrm{CH}_{3} \mathrm{NH}_{3} \mathrm{PbI}_{3}$ /poly-3-hexylthiophen perovskite mesoscopic solar cells: performance enhancement by Li-assisted hole conduction, Physica Status Solidi Rapid Res. Lett. 8 (2014) 816821

[156] R. Li, X. Xiang, X. Tong, J. Zou, Q. Li, Wearable Double-Twisted Fibrous Perovskite Solar Cell, Adv. Mater. 27 (2015) 38313835.

[157] G. Namkoong, P. Boland, K. Lee, J. Dean, Design of organic tandem solar cells using PCPDTBT: pc ${ }_{61}$ BM and P3HT: pc ${ }_{71}$ BM, J. Appl. Phys. 107 (2010) 124515.

[158] N.J. Jeon, J.H. Noh, W.S. Yang, Y.C. Kim, S. Ryu, J. Seo, S.I. Seok, Compositional engineering of perovskite materials for high-performance solar cells, Nature 517 (2015) 476480.

[159] C. Bi, Q. Wang, Y. Shao, Y. Yuan, Z. Xiao, J. Huang, Non-wetting surface-driven high-aspect-ratio crystalline grain growth for efficient hybrid perovskite solar cells, Nat. Commun. 6 (2015) 7747.

[160] T.-W. Lee, O. Kwon, M.-G. Kim, S.H. Park, J. Chung, S.Y. Kim, Y. Chung, J.Y. Park, E. Han, D.H. Huh, J.-J. Park, L. Pu, Hole-injecting conducting-polymer compositions for highly efficient and stable organic light-emitting diodes, Appl. Phys. Lett. 87 (2005) 231106.

[161] L. Meng, J. You, T.-F. Guo, Y. Yang, Recent advances in the inverted planar structure of perovskite solar cells, Acc. Chem. Res. 49 (2016) 155165.

[162] P. Docampo, J.M. Ball, M. Darwich, G.E. Eperon, H.J. Snaith, Efficient organometal trihalide perovskite planar-heterojunction solar cells on flexible polymer substrates, Nat. Commun. 4 (2013) 2761.

[163] O. Malinkiewicz, A. Yella, Y.H. Lee, G.M. Espallargas, M. Graetzel, M.K. Nazeeruddin, H.J. Bolink, Perovskite solar cells employing organic chargetransport layers, Nat. Photonics 8 (2014) 128132

[164] J.Y. Jeng, Y.F. Chiang, M.H. Lee, S.R. Peng, T.F. Guo, P. Chen, T.C. Wen, $\mathrm{CH}_{3} \mathrm{NH}_{3} \mathrm{PbI}_{3}$ Perovskite/Fullerene Planar-Heterojunction Hybrid Solar Cells, Adv. Mater. 25 (2013) 37273732.

[165] S. Sun, T. Salim, N. Mathews, M. Duchamp, C. Boothroyd, G. Xing T.C. Sum, Y.M. Lam, The origin of high efficiency in low-temperature solution-processable bilayer organometal halide hybrid solar cells, Energy Environ. Sci. 7 (2014) 399407.

[166] C.-C. Chen, Z. Hong, G. Li, Q. Chen, H. Zhou, Y. Yang, One-step, low-temperature deposited perovskite solar cell utilizing small molecule additive, J. Photonics Energy 5 (2015) 057405.

[167] P.W. Liang, C.Y. Liao, C.C. Chueh, F. Zuo, S.T. Williams, X.K. Xin, J. Lin, A.K.Y. Jen, Additive enhanced crystallization of solution-processed perovskite for highly efficient planar-heterojunction solar cells, Adv. Mater. 26 (2014) 37483754.

[168] C. Zuo, L. Ding, An 80.11\% FF record achieved for perovskite solar cells by using the $\mathrm{NH}_{4} \mathrm{Cl}$ additive, Nanoscale 6 (2014) 99359938.

[169] K.G. Lim, H.B. Kim, J. Jeong, H. Kim, J.Y. Kim, T.W. Lee, Boosting the Power Conversion Efficiency of Perovskite Solar Cells Using Self-Organized Polymeric Hole Extraction Layers with High Work Function, Adv. Mater. 26 (2014) 64616466.

[170] C.-W. Chen, H.-W. Kang, S.-Y. Hsiao, P.-F. Yang, K.-M. Chiang, H.-W. Lin, Efficient and Uniform Planar-Type Perovskite Solar Cells by Simple Sequential Vacuum Deposition, Adv. Mater. 26 (2014) 66476652.

[171] C.-H. Chiang, Z.-L. Tseng, C.-G. Wu, Planar heterojunction perovskite/ $\mathrm{PC}_{71} \mathrm{BM}$ solar cells with enhanced open-circuit voltage via a (2/1)-step spin-coating process, J. Mater. Chem. A 2 (2014) 1589715903

[172] W. Nie, H. Tsai, R. Asadpour, J.-C. Blancon, A.J. Neukirch, G. Gupta, J.J. Crochet, M. Chhowalla, S. Tretiak, M.A. Alam, H.-L. Wang, A.D. Mohite, High-efficiency solution-processed perovskite solar cells with millimeter-scale grains, Science 347 (2015) 522525.

[173] J. You, Y.M. Yang, Z. Hong, T.-B. Song, L. Meng, Y. Liu, C. Jiang, H. Zhou, W.H. Chang, G. Li, Y. Yang, Moisture assisted perovskite film growth for high performance solar cells, Appl. Phys. Lett. 105 (2014) 183902.

[174] M. Jørgensen, K. Norrman, F.C. Krebs, Stability/degradation of polymer solar 
cells, Sol. Energy Mater. Sol. Cells 92 (2008) 686714.

[175] K. Norrman, M.V. Madsen, S.A. Gevorgyan, F.C. Krebs, Degradation patterns in water and oxygen of an inverted polymer solar cell, J. Am. Chem. Soc. 132 (2010) 1688316892.

[176] Y. Zhang, X. Hu, L. Chen, Z. Huang, Q. Fu, Y. Liu, L. Zhang, Y. Chen, Flexible, hole transporting layer-free and stable $\mathrm{CH}_{3} \mathrm{NH}_{3} \mathrm{PbI}_{3} / \mathrm{PC}_{61} \mathrm{BM}$ planar heterojunction perovskite solar cells, Org. Electron. 30 (2016) 281288.

[177] S. Olthof, Research Update: the electronic structure of hybrid perovskite layers and their energetic alignment in devices, APL Mater. 4 (2016) 091502.

[178] P. Nagarjuna, K. Narayanaswamy, T. Swetha, G.H. Rao, S.P. Singh, G.D. Sharma, $\mathrm{CH}_{3} \mathrm{NH}_{3} \mathrm{PbI}_{3}$ Perovskite Sensitized Solar Cells Using a D-A Copolymer as Hole Transport Material, Electrochim. Acta 151 (2015) 2126.

[179] J.H. Heo, S.H. Im, $\mathrm{CH}_{3} \mathrm{NH}_{3} \mathrm{PbBr}_{3} \mathrm{CH}_{3} \mathrm{NH}_{3} \mathrm{PbI}_{3}$ perovskite perovskite tandem solar cells with exceeding $2.2 \mathrm{~V}$ open circuit voltage, Adv. Mater. 28 (2016) 51215125.

[180] Z. Li, P.P. Boix, G. Xing, K. Fu, S.A. Kulkarni, S.K. Batabyal, W. Xu, A. Cao, T.C. Sum, N. Mathews, L.H. Wong, Carbon nanotubes as an efficient hole collector for high voltage methylammonium lead bromide perovskite solar cells, Nanoscale 8 (2016) 63526360

[181] J. Dagar, M. Scarselli, M. De Crescenzi, T.M. Brown, Solar cells incorporating water/alcohol-soluble electron-extracting DNA nanolayers, ACS Energy Lett. 1 (2016) 510515.

[182] A.-R.M. Yusoff, J. Kim, J. Jang, M.K. Nazeeruddin, New horizons for perovskite solar cells employing DNA-CTMA as the hole-transporting material, ChemSusChem 9 (2016) 17361742.

[183] Y.-F. Chiang, J.-Y. Jeng, M.-H. Lee, S.-R. Peng, P. Chen, T.-F. Guo, T.-C. Wen, Y.J. Hsu, C.-M. Hsu, High voltage and efficient bilayer heterojunction solar cells based on an organic inorganic hybrid perovskite absorber with a low-cost flexible substrate, Phys. Chem. Chem. Phys. 16 (2014) 60336040.

[184] H. Choi, J. Jeong, H.-B. Kim, S. Kim, B. Walker, G.-H. Kim, J.Y. Kim, Cesiumdoped methylammonium lead iodide perovskite light absorber for hybrid solar cells, Nano Energy 7 (2014) 8085.

[185] C. Roldán-Carmona, O. Malinkiewicz, R. Betancur, G. Longo, C. Momblona, F. Jaramillo, L. Camacho, H.J. Bolink, High efficiency single-junction semitransparent perovskite solar cells, Energy Environ. Sci. 7 (2014) 29682973.

[186] J. You, Z. Hong, Y.M. Yang, Q. Chen, M. Cai, T.-B. Song, C.-C. Chen, S. Lu, Y. Liu, H. Zhou, Low-temperature solution-processed perovskite solar cells with high efficiency and flexibility, ACS Nano 8 (2014) 16741680.

[187] F. Hou, Z. Su, F. Jin, X. Yan, L. Wang, H. Zhao, J. Zhu, B. Chu, W. Li, Efficient and stable planar heterojunction perovskite solar cells with an $\mathrm{MoO}_{3}$ /PEDOT: pss hole transporting layer, Nanoscale 7 (2015) 94279432

[188] Q. Xue, Z. Hu, J. Liu, J. Lin, C. Sun, Z. Chen, C. Duan, J. Wang C. Liao, W.M. Lau, F. Huang, H.-L. Yip, Y. Cao, Highly efficient fullerene/perovskite planar heterojunction solar cells via cathode modification with an amino-functionalized polymer interlayer, J. Mater. Chem. A 2 (2014) 1959819603.

[189] Z. Xiao, C. Bi, Y. Shao, Q. Dong, Q. Wang, Y. Yuan, C. Wang, Y. Gao, J. Huang, Efficient, high yield perovskite photovoltaic devices grown by interdiffusion of solution-processed precursor stacking layers, Energy Environ. Sci. 7 (2014) 26192623.

[190] P. Qin, N. Tetreault, M.I. Dar, P. Gao, K.L. Mccall, S.R. Rutter, S.D. Ogier, N.D. Forrest, J.S. Bissett, M.J. Simms, A.J. Page, R. Fisher, M. Grätzel, M.K. Nazeeruddi, A novel oligomer as a hole transporting material for efficient perovskite solar cells, Adv. Energy Mater. 5 (2015) 1400980.

[191] J.A. Christians, P.V. Kamat, Trap and transfer. Two-step hole injection across the $\mathrm{Sb}_{2} \mathrm{~S}_{3} / \mathrm{CuSCN}$ interface in solid-state solar cells, ACS Nano 7 (2013) 79677974

[192] B. Li, L. Wang, B. Kang, P. Wang, Y. Qiu, Review of recent progress in solid-state dye-sensitized solar cells, Sol. Energy Mater. Sol. Cells 90 (2006) 549573.

[193] M. Rusop, T. Soga, T. Jimbo, M. Umeno, Copper Iodide thin films as a p-TYPE electrical conductivity in dye-sensitized p-CuI $\mid$ Dye $\mid n-\mathrm{TiO}_{2}$ heterojunction solid state solar cells, Surf. Rev. Lett. 11 (2004) 577.

[194] J.A. Chang, S.H. Im, Y.H. Lee, H.-j. Kim, C.-S. Lim, J.H. Heo, S.I. Seok, Panchromatic photon-harvesting by hole-conducting materials in inorganic organic heterojunction sensitized-solar cell through the formation of nanostructured electron channels, Nano Lett. 12 (2012) 18631867.

[195] S. Nezu, G. Larramona, C. Choné, A. Jacob, B. Delatouche, D. Péré, C. Moisan, Light soaking and gas effect on nanocrystalline $\mathrm{TiO} 2 / \mathrm{Sb}_{2} \mathrm{~S}_{3} / \mathrm{CuSCN}$ photovoltaic cells following extremely thin absorber concept, J. Phys. Chem. C 114 (2010) 68546859.

[196] J.A. Christians, R.C.M. Fung, P.V. Kamat, An inorganic hole conductor for organolead halide perovskite solar cells. Improved hole conductivity with copper iodide, J. Am. Chem. Soc. 136 (2014) 758764.

[197] V.P.S. Perera, K. Tennakone, Recombination processes in dye-sensitized solidstate solar cells with CuI as the hole collector, Sol. Energy Mater. Sol. Cells 79 (2003) 249255.

[198] S. Gharibzadeh, B.A. Nejand, A. Moshaii, N. Mohammadian, A.H. Alizadeh, R. Mohammadpour, V. Ahmadi, A. Alizadeh, Two-step physical deposition of a compact cui hole-transport layer and the formation of an interfacial species in perovskite solar cells, ChemSusChem 9 (2016) 19291937.

[199] B. O'regan, D.T. Schwartz, S.M. Zakeeruddin, M. Grätzel, Electrodeposited nanocomposite $\mathrm{n}$ p heterojunctions for solid-state dye-sensitized photovoltaics, Adv. Mater. 12 (2000) 12631267.

[200] P. Pattanasattayavong, G.O.N. Ndjawa, K. Zhao, K.W. Chou, N. Yaacobi-Gross, B.C. O'regan, A. Amassian, T.D. Anthopoulos, Electric field-induced hole transport in copper (I) thiocyanate (CuSCN) thin-films processed from solution at room temperature, Chem. Commun. 49 (2013) 41544156

[201] P. Pattanasattayavong, N. Yaacobi-Gross, K. Zhao, G.O.N. Ndjawa, J. Li, F. Yan,
B.C. O'regan, A. Amassian, T.D. Anthopoulos, Hole-transporting transistors and circuits based on the transparent inorganic semiconductor Copper (I) Thiocyanate (CuSCN) processed from solution at room temperature, Adv. Mater. 25 (2013) 15041509.

[202] S. Chavhan, O. Miguel, H.-J. Grande, V. Gonzalez-Pedro, R.S. Sánchez, E.M. Barea, I. Mora-Seró, R. Tena-Zaera, Organo-metal halide perovskite-based solar cells with CuSCN as the inorganic hole selective contact, J. Mater. Chem. A 2 (2014) 1275412760

[203] S. Ito, S. Tanaka, H. Vahlman, H. Nishino, K. Manabe, P. Lund, Carbon-doublebond-free printed solar cells from $\mathrm{TiO}_{2} / \mathrm{CH}_{3} \mathrm{NH}_{3} \mathrm{PbI}_{3} / \mathrm{CuSCN} / \mathrm{Au}$ : structural control and photoaging effects, ChemPhysChem 15 (2014) 11941200.

[204] S. Ito, S. Tanaka, K. Manabe, H. Nishino, Effects of surface blocking layer of $\mathrm{Sb}_{2} \mathrm{~S}_{3}$ on nanocrystalline $\mathrm{TiO}_{2}$ for $\mathrm{CH}_{3} \mathrm{NH}_{3} \mathrm{PbI}_{3}$ perovskite solar cells, J. Phys. Chem. C 118 (2014) 1699517000

[205] A. Fakharuddin, F. Di Giacomo, I. Ahmed, Q. Wali, T.M. Brown, R. Jose, Role of morphology and crystallinity of nanorod and planar electron transport layers on the performance and long term durability of perovskite solar cells, J. Power Sources 283 (2015) 6167.

[206] A. Fakharuddin, F. Di Giacomo, A.L. Palma, F. Matteocci, I. Ahmed, S. Razza, A. D’epifanio, S. Licoccia, J. Ismail, A. Di Carlo, T.M. Brown, R. Jose, Vertical $\mathrm{TiO}_{2}$ nanorods as a medium for stable and high-efficiency perovskite solar modules, ACS nano 9 (2015) 84208429.

[207] P. Qin, S. Tanaka, S. Ito, N. Tetreault, K. Manabe, H. Nishino, M. K. Nazeeruddin, M. Grätzel, Inorganic hole conductor-based lead halide perovskite solar cells with $12.4 \%$ conversion efficiency, Nat. Commun. 5 (2014) 3834.

[208] A.S. Subbiah, A. Halder, S. Ghosh, N. Mahuli, G. Hodes, S.K. Sarkar, Inorganic hole conducting layers for perovskite-based solar cells, J. Phys. Chem. Lett. 5 (2014) 17481753.

[209] M.D. Irwin, D.B. Buchholz, A.W. Hains, R.P. Chang, T.J. Marks, p-Type semiconducting nickel oxide as an efficiency-enhancing anode interfacial layer in polymer bulk-heterojunction solar cells, Proc. Natl. Acad. Sci. 105 (2008) 27832787.

[210] A. Garcia, G.C. Welch, E.L. Ratcliff, D.S. Ginley, G.C. Bazan, D.C. Olson, Improvement of Interfacial Contacts for New Small-Molecule BulkHeterojunction Organic Photovoltaics, Adv. Mater. 24 (2012) 53685373.

[211] E.A. Gibson, A.L. Smeigh, L. Le Pleux, J. Fortage, G. Boschloo, E. Blart, Y. Pellegrin, F. Odobel, A. Hagfeldt, L. Hammarström, A p-Type NiO-Based DyeSensitized Solar Cell with an Open-Circuit Voltage of 0.35 V, Angew. Chem. Int. Ed. 121 (2009) 44664469.

[212] J.R. Manders, S.-W. Tsang, M.J. Hartel, T.H. Lai, S. Chen, C.M. Amb, J.R. Reynolds, F. So, Solution-processed nickel oxide hole transport layers in high efficiency polymer photovoltaic cells, Adv. Funct. Mater. 23 (2013) 29933001.

[213] A. Nattestad, A.J. Mozer, M.K.R. Fischer, Y.-B. Cheng, A. Mishra, P. Bäuerle, U. Bach, Highly efficient photocathodes for dye-sensitized tandem solar cells, Nat. Mater. 9 (2010) 3135.

[214] E.L. Ratcliff, A. Garcia, S.A. Paniagua, S.R. Cowan, A.J. Giordano, D.S. Ginley, S.R. Marder, J.J. Berry, D.C. Olson, Investigating the influence of interfacial contact properties on open circuit voltages in organic photovoltaic performance: work function versus selectivity, Adv. Energy Mater. 3 (2013) 647656.

[215] H. Tian, B. Xu, H. Chen, E.M.J. Johansson, G. Boschloo, Solid-State PerovskiteSensitized p-Type Mesoporous Nickel Oxide Solar Cells, ChemSusChem 7 (2014) 21502153.

[216] Z. Zhu, Y. Bai, T. Zhang, Z. Liu, X. Long, Z. Wei, Z. Wang, L. Zhang, J. Wang, F. Yan, S. Yang, High-performance hole-extraction layer of Sol Gel-Processed $\mathrm{NiO}$ nanocrystals for inverted planar perovskite solar cells, Angew. Chem. Int. Ed. 53 (2014) 1257112575.

[217] L. Hu, J. Peng, W. Wang, Z. Xia, J. Yuan, J. Lu, X. Huang, W. Ma, H. Song, W. Chen, Y.-B. Cheng, J. Tang, Sequential deposition of $\mathrm{CH}_{3} \mathrm{NH}_{3} \mathrm{PbI}_{3}$ on planar $\mathrm{NiO}$ film for efficient planar perovskite solar cells, ACS Photonics 1 (2014) 547553.

[218] J. Cui, F. Meng, H. Zhang, K. Cao, H. Yuan, Y. Cheng, F. Huang, M. Wang, $\mathrm{CH}_{3} \mathrm{NH}_{3} \mathrm{PbI}_{3}$-based planar solar cells with magnetron-sputtered nickel oxide, ACS Appl. Mater. Interfaces 6 (2014) 2286222870.

[219] J.-Y. Jeng, K.-C. Chen, T.-Y. Chiang, P.-Y. Lin, T.-D. Tsai, Y.-C. Chang, T.-F. Guo, P. Chen, T.-C. Wen, Y.-J. Hsu, Nickel oxide electrode interlayer in $\mathrm{CH}_{3} \mathrm{NH}_{3} \mathrm{PbI}_{3}$ Perovskite/PCBM planar-heterojunction hybrid solar cells, Adv. Mater. 26 (2014) 41074113

[220] K.-C. Wang, P.-S. Shen, M.-H. Li, S. Chen, M.-W. Lin, P. Chen, T.-F. Guo, Lowtemperature sputtered nickel oxide compact thin film as effective electron blocking layer for mesoscopic $\mathrm{NiO} / \mathrm{CH}_{3} \mathrm{NH}_{3} \mathrm{PbI}_{3}$ perovskite heterojunction solar cells, ACS Appl. Mater. Interfaces 6 (2014) 1185111858.

[221] W. Chen, Y. Wu, J. Liu, C. Qin, X. Yang, A. Islam, Y.-B. Cheng, L. Han, Hybrid interfacial layer leads to solid performance improvement of inverted perovskite solar cells, Energy Environ. Sci. 8 (2015) 629640.

[222] A. Kay, M. Grätzel, Low cost photovoltaic modules based on dye sensitized nanocrystalline titanium dioxide and carbon powder, Sol. Energy Mater. Sol. Cells 44 (1996) 99117.

[223] H. Wang, G. Liu, X. Li, P. Xiang, Z. Ku, Y. Rong, M. Xu, L. Liu, M. Hu, Y. Yang, H. Han, Highly efficient poly (3-hexylthiophene) based monolithic dye-sensitized solar cells with carbon counter electrode, Energy Environ. Sci. 4 (2011) 20252029.

[224] X. Xu, Z. Liu, Z. Zuo, M. Zhang, Z. Zhao, Y. Shen, H. Zhou, Q. Chen, Y. Yang, $\mathrm{M}$. Wang, Hole selective $\mathrm{NiO}$ contact for efficient perovskite solar cells with carbon electrode, Nano Lett. 15 (2015) 24022408.

[225] K. Cao, Z. Zuo, J. Cui, Y. Shen, T. Moehl, S.M. Zakeeruddin, M. Grätzel, M. Wang Efficient screen printed perovskite solar cells based on mesoscopic $\mathrm{TiO}_{2} / \mathrm{Al}_{2} \mathrm{O}_{3}$ / 
NiO/carbon architecture, Nano Energy 17 (2015) 171179.

[226] M.I. Hossain, F.H. Alharbi, Recent advances in alternative material photovoltaics, Mater. Technol. 28 (2013) 8897.

[227] Y.S. Lee, J. Heo, M.T. Winkler, S.C. Siah, S.B. Kim, R.G. Gordon, T. Buonassisi, Nitrogen-doped cuprous oxide as a p-type hole-transporting layer in thin-film solar cells, J. Mater. Chem. A 1 (2013) 1541615422.

[228] Y. Wang, Z. Xia, J. Liang, X. Wang, Y. Liu, C. Liu, S. Zhang, H. Zhou, Towards printed perovskite solar cells with cuprous oxide hole transporting layers: a theoretical design, Semicond. Sci. Technol. 30 (2015) 054004.

[229] S. Chatterjee, A.J. Pal, Introducing $\mathrm{Cu}_{2} \mathrm{O}$ thin films as a hole-transport layer in Efficient Planar perovskite Solar Cell Structures, J. Phys. Chem. C. 120 (2016) 14281437.

[230] B.A. Nejand, V. Ahmadi, S. Gharibzadeh, H.R. Shahverdi, Cuprous oxide as a potential low-cost hole-transport material for stable perovskite solar cells, ChemSusChem 9 (2016) 302313.

[231] W. Yu, F. Li, H. Wang, E. Alarousu, Y. Chen, B. Lin, L. Wang, M.N. Hedhili, Y. Li, K. Wu, X. Wang, O.F. Mohammed, T. Wu, Ultrathin $\mathrm{Cu}_{2} \mathrm{O}$ as an efficient inorganic hole transporting material for perovskite solar cells, Nanoscale 8 (2016) 61736179

[232] W. Sun, Y. Li, S. Ye, H. Rao, W. Yan, H. Peng, Y. Li, Z. Liu, S. Wang, Z. Chen, L. Xiao, Z. Bian, C. Huang, High-performance inverted planar heterojunction perovskite solar cells based on a solution-processed $\mathrm{CuO}_{\mathrm{x}}$ hole transport layer, Nanoscale 8 (2016) 1080610813.

[233] S. Chen, X. Yu, M. Zhang, J. Cao, Y. Li, L. Ding, G. Shi, A graphene oxide/oxygen deficient molybdenum oxide nanosheet bilayer as a hole transport layer for efficient polymer solar cells, J. Mater. Chem. A 3 (2015) 1838018383.

[234] G.A. Ali, S.A. Makhlouf, M.M. Yusoff, K.F. Chong, Structural and electrochemical characteristics of graphene nanosheets as supercapacitor electrodes, Rev. Adv. Mater. Sci. 41 (2015) 3543.

[235] M.C. Lemme, T.J. Echtermeyer, M. Baus, H. Kurz, A. Graphene Field-Effect, Device, IEEE Electron Device Lett. 28 (2007) 282284.

[236] S.V. Morozov, K.S. Novoselov, M.I. Katsnelson, F. Schedin, D.C. Elias, J.A. Jaszczak, A.K. Geim, Giant intrinsic carrier mobilities in graphene and its bilayer, Phys. Rev. Lett. 100 (2008) 016602.

[237] A.A. Balandin, S. Ghosh, W. Bao, I. Calizo, D. Teweldebrhan, F. Miao, C.N. Lau, Superior thermal conductivity of single-layer graphene, Nano Lett. 8 (2008) 902907.

[238] J.H. Seol, I. Jo, A.L. Moore, L. Lindsay, Z.H. Aitken, M.T. Pettes, X. Li, Z. Yao, R. Huang, D. Broido, Two-dimensional phonon transport in supported graphene, Science 328 (2010) 213216.

[239] R.R. Nair, P. Blake, A.N. Grigorenko, K.S. Novoselov, T.J. Booth, T. Stauber, N.M. Peres, A.K. Geim, Fine structure constant defines visual transparency of graphene, Science 320 (2008) (1308-1308).

[240] J.T.-W. Wang, J.M. Ball, E.M. Barea, A. Abate, J.A. Alexander-Webber, J. Huang, M. Saliba, I. Mora-Sero, J. Bisquert, H.J. Snaith, R.J. Nicholas, Low-temperature processed electron collection layers of graphene $/ \mathrm{TiO}_{2}$ nanocomposites in thin film perovskite solar cells, Nano Lett. 14 (2014) 724730.

[241] Z. Zhu, J. Ma, Z. Wang, C. Mu, Z. Fan, L. Du, Y. Bai, L. Fan, H. Yan, D.L. Phillips, S. Yang, Efficiency enhancement of perovskite solar cells through fast electron extraction: the role of graphene quantum dots, J. Am. Chem. Soc. 136 (2014) 37603763.

[242] Z. Wu, S. Bai, J. Xiang, Z. Yuan, Y. Yang, W. Cui, X. Gao, Z. Liu, Y. Jin, B. Sun, Efficient planar heterojunction perovskite solar cells employing graphene oxide as hole conductor, Nanoscale 6 (2014) 1050510510.

[243] B. Dasgupta, W.P. Goh, Z.E. Ooi, L.M. Wong, C.Y. Jiang, Y. Ren, E.S. Tok, J. Pan, J. Zhang, S.Y. Chiam, Enhanced extraction rates through gap states of molybdenum oxide anode buffer, J. Phys. Chem. C. 117 (2013) 92069211.

[244] N.K. Elumalai, A. Saha, C. Vijila, R. Jose, Z. Jie, S. Ramakrishna, Enhancing the stability of polymer solar cells by improving the conductivity of the nanostructured $\mathrm{MoO}_{3}$ hole-transport layer, Phys. Chem. Chem. Phys. 15 (2013) 68316841.

[245] D. Kabra, L.P. Lu, M.H. Song, H.J. Snaith, R.H. Friend, Efficient single-layer polymer light-emitting diodes, Adv. Mater. 22 (2010) 31943198.

[246] B.-S. Kim, T.-M. Kim, M.-S. Choi, H.-S. Shim, J.-J. Kim, Fully vacuum processed perovskite solar cells with high open circuit voltage using $\mathrm{MoO}_{3} / \mathrm{NPB}$ as hole extraction layers, Org. Electron. 17 (2015) 102106.

[247] E. Della Gaspera, Y. Peng, Q. Hou, L. Spiccia, U. Bach, J.J. Jasieniak, Y.-B. Cheng, Ultra-thin high efficiency semitransparent perovskite solar cells, Nano Energy 13 (2015) 249257.

[248] J. Kim, G. Kim, T.K. Kim, S. Kwon, H. Back, J. Lee, S.H. Lee, H. Kang, K. Lee, Efficient planar-heterojunction perovskite solar cells achieved via interfacial modification of a sol gel ZnO electron collection layer, J. Mater. Chem. A 2 (2014) 1729117296.

[249] E.M. Sanehira, B.J. Tremolet De Villers, P. Schulz, M.O. Reese, S. Ferrere, K. Zhu, L.Y. Lin, J.J. Berry, J.M. Luther, Influence of electrode interfaces on the stability of perovskite solar cells: reduced degradation using $\mathrm{MoO}_{\mathrm{X}} / \mathrm{Al}$ for hole collection, ACS Energy Lett. 1 (2016) 3845.

[250] Y. Zhao, A.M. Nardes, K. Zhu, Effective hole extraction using $\mathrm{MoO}_{\mathrm{x}}-\mathrm{Al}$ contact in perovskite $\mathrm{CH}_{3} \mathrm{NH}_{3} \mathrm{PbI}_{3}$ solar cells, Appl. Phys. Lett. 104 (2014) 213906.

[251] H. Peng, W. Sun, Y. Li, S. Ye, H. Rao, W. Yan, H. Zhou, Z. Bian, C. Huang, Solution processed inorganic $\mathrm{V}_{2} \mathrm{O}_{\mathrm{x}}$ as interfacial function materials for inverted planarheterojunction perovskite solar cells with enhanced efficiency, Nano Res. 9 (2016) 29602971.

[252] H. Sun, X. Hou, Q. Wei, H. Liu, K. Yang, W. Wang, Q. An, Y. Rong, Lowtemperature solution-processed p-type vanadium oxide for perovskite solar cells, Chem. Commun. 52 (2016) 80998102.

[253] Z. Li, Stable perovskite solar cells based on $\mathrm{WO}_{3}$ nanocrystals as hole transport layer, Chem. Lett. 44 (2015) 11401141.

[254] Z.-L. Tseng, L.-C. Chen, C.-H. Chiang, S.-H. Chang, C.-C. Chen, C.-G. Wu, Efficient inverted-type perovskite solar cells using UV-ozone treated $\mathrm{MoO}_{\mathrm{X}}$ and $\mathrm{WO}_{\mathrm{X}}$ as hole transporting layers, Sol. Energy 139 (2016) 484488.

[255] B. Tell, J.L. Shay, H.M. Kasper, Electrical properties, optical properties, and band structure of $\mathrm{CuGaS}_{2}$ and CuInS 2 , Phys. Rev. B 4 (1971) 24632471.

[256] Y. Hou, H. Azimi, N. Gasparini, M. Salvador, W. Chen, L.S. Khanzada, M. Brandl, R. Hock, C.J. Brabec, Low-temperature solution-processed kesterite solar cell based on in situ deposition of ultrathin absorber layer, ACS Appl. Mater. Interfaces 7 (2015) 2110021106.

[257] L. Li, N. Coates, D. Moses, Solution-processed inorganic solar cell based on in situ synthesis and film deposition of $\mathrm{CuInS}_{2}$ nanocrystals, J. Am. Chem. Soc. 132 (2010) 2223.

[258] C. Chen, C. Li, F. Li, F. Wu, F. Tan, Y. Zhai, W. Zhang, Efficient perovskite solar cells based on low-temperature solution-processed $\left(\mathrm{CH}_{3} \mathrm{NH}_{3}\right) \mathrm{PbI}_{3}$ perovskite/ $\mathrm{CuInS}_{2}$ planar heterojunctions, Nanoscale Res. Lett. 9 (2014) 457.

[259] L.S. Khanzada, I. Levchuk, Y. Hou, H. Azimi, A. Osvet, R. Ahmad, M. Brandl, P. Herre, M. Distaso, R. Hock, W. Peukert, M. Batentschuk, C.J. Brabec, Effective ligand engineering of the $\mathrm{Cu}_{2} \mathrm{ZnSnS}_{4}$ nanocrystal surface for increasing hole transport efficiency in perovskite solar cells, Adv. Funct. Mater. 26 (2016) 83008306.

[260] T. Zhao, E.D. Goodwin, J. Guo, H. Wang, B.T. Diroll, C.B. Murray, C.R. Kagan, Advanced architecture for colloidal PbS quantum dot solar cells exploiting a CdSe quantum dot buffer layer, ACS Nano 10 (2016) 92679273.

[261] M. Navaneethan, K. Nisha, S. Ponnusamy, C. Muthamizhchelvan, Optical, structural and surface morphological studies of $n$-methylaniline capped lead sulphide nanoparticles, Rev. Adv. Mater. Sci. 21 (2009) 217224.

[262] H. Zhao, H. Liang Fo Vidal, F. Rosei, A. Vomiero, D. Ma, Size dependence of temperature-related optical properties of $\mathrm{PbS}$ and $\mathrm{PbS} / \mathrm{CdS}$ core/shell quantum dots, J. Phys. Chem. C 118 (2014) 2058520593.

[263] L. Etgar, P. Gao, P. Qin, M. Graetzel, M.K. Nazeeruddin, A hybrid lead iodide perovskite and lead sulfide QD heterojunction solar cell to obtain a panchromatic response, J. Mater. Chem. A 2 (2014) 1158611590.

[264] G. Seo, J. Seo, S. Ryu, W. Yin, T.K. Ahn, S.I. Seok, Enhancing the performance of sensitized solar cells with $\mathrm{PbS} / \mathrm{CH}_{3} \mathrm{NH}_{3} \mathrm{PbI}_{3}$ core/shell quantum dots, J. Phys. Chem. Lett. 5 (2014) 20152020.

[265] L. Hu, W. Wang, H. Liu, J. Peng, H. Cao, G. Shao, Z. Xia, W. Ma, J. Tang, Pbs colloidal quantum dots as an effective hole transporter for planar heterojunction perovskite solar cells, J. Mater. Chem. A 3 (2015) 515518.

[266] M. Lv, J. Zhu, Y. Huang, Y. Li, Z. Shao, Y. Xu, S. Dai, Colloidal CuInS 2 Quantum Dots as Inorganic Hole-Transporting Material in Perovskite Solar Cells, ACS Appl. Mater. Interfaces 7 (2015) 1748217488.

[267] A. Fakharuddin, R. Jose, T.M. Brown, F. Fabregat-Santiago, J. Bisquert, A perspective on the production of dye-sensitized solar modules, Energy Environ. Sci. 7 (2014) 39523981.

[268] M. Jørgensen, K. Norrman, S.A. Gevorgyan, T. Tromholt, B. Andreasen, F.C. Krebs, Stability of Polymer Solar Cells, Adv. Mater. 24 (2012) 580612

[269] M.O. Reese, S.A. Gevorgyan, M. Jørgensen, E. Bundgaard, S.R. Kurtz, D.S. Ginley, D.C. Olson, M.T. Lloyd, P. Morvillo, E.A. Katz, A. Elschner, O. Haillant, T.R. Currier, V. Shrotriya, M. Hermenau, M. Riede, K.R. Kirov, G. Trimmel, T. Rath, O. Inganäs, F. Zhang, M. Andersson, K. Tvingstedt, M. Lira-Cantu, D. Laird, C. Mcguiness, S. Gowrisanker, M. Pannone, M. Xiao, J. Hauch, R. Steim, D.M. Delongchamp, R. Rösch, H. Hoppe, N. Espinosa, A. Urbina, G. YamanUzunoglu, J.-B. Bonekamp, A.J.J.M. Van Breemen, C. Girotto, E. Voroshazi, F.C. Krebs, Consensus stability testing protocols for organic photovoltaic materials and devices, Sol. Energy Mater. Sol. Cells 95 (2011) 12531267.

[270] R. Roesch, T. Faber, E. Von Hauff, T.M. Brown, M. Lira-Cantu, H. Hoppe, Procedures and practices for evaluating thin-film solar cell stability, Adv. Energy Mater. 5 (2015) 1501407.

[271] S.N. Habisreutinger, D.P. Mcmeekin, H.J. Snaith, R.J. Nicholas, Research Update: strategies for improving the stability of perovskite solar cells, APL Mater. 4 (2016) 091503.

[272] S. Ito, Research Update: overview of progress about efficiency and stability on perovskite solar cells, APL Mater. 4 (2016) 091504

[273] T. Leijtens, G.E. Eperon, N.K. Noel, S.N. Habisreutinger, A. Petrozza, H.J. Snaith, Stability of metal halide perovskite solar cells, Adv. Energy Mater. 5 (2015) 1500963.

[274] V. Turkovic, S. Engmann, D.A.M. Egbe, M. Himmerlich, S. Krischok, G. Gobsch, $\mathrm{H}$. Hoppe, Multiple stress degradation analysis of the active layer in organic photovoltaics, Sol. Energy Mater. Solar Cells 120 (Part B) (2014) 654668.

[275] B. Conings, J. Drijkoningen, N. Gauquelin, A. Babayigit, J. D'haen, L. D'olieslaeger, A. Ethirajan, J. Verbeeck, J. Manca, E. Mosconi, F. De Angelis, H.-G. Boyen, Intrinsic thermal instability of methylammonium lead trihalide perovskite, Adv. Energy Mater. 5 (2015) 1500477.

[276] J. Yang, B.D. Siempelkamp, E. Mosconi, F. De Angelis, T.L. Kelly, Origin of the thermal instability in $\mathrm{CH}_{3} \mathrm{NH}_{3} \mathrm{PbI}_{3}$ thin films deposited on $\mathrm{ZnO}$, Chem. Mater. 27 (2015) 42294236.

[277] J.H. Noh, S.H. Im, J.H. Heo, T.N. Mandal, S.I. Seok, Chemical management for colorful, efficient, and stable inorganic-organic hybrid nanostructured solar cells, Nano Lett. 13 (2013) 17641769.

[278] J. Yang, B.D. Siempelkamp, D. Liu, T.L. Kelly, Investigation of $\mathrm{CH}_{3} \mathrm{NH}_{3} \mathrm{PbI}_{3}$ degradation rates and mechanisms in controlled humidity environments using in situ techniques, ACS Nano 9 (2015) 19551963.

[279] N. Aristidou, I. Sanchez-Molina, T. Chotchuangchutchaval, M. Brown, L. Martinez, T. Rath, S.A. Haque, The role of oxygen in the degradation of methylammonium lead trihalide perovskite photoactive layers, Angew. Chem. Int. 
Ed. 54 (2015) 82088212.

[280] T. Leijtens, G.E. Eperon, S. Pathak, A. Abate, M.M. Lee, H.J. Snaith, Overcoming ultraviolet light instability of sensitized $\mathrm{TiO}_{2}$ with meso-superstructured organometal tri-halide perovskite solar cells, Nat. Commun. 4 (2013) 2885.

[281] N.A. Manshor, Q. Wali, K.K. Wong, S.K. Muzakir, A. Fakharuddin, L. SchmidtMende, R. Jose, Humidity versus photo-stability of metal halide perovskite films in a polymer matrix, Phys. Chem. Chem. Phys. 18 (2016) 2162921639.

[282] G. Murugadoss, S. Tanaka, G. Mizuta, S. Kanaya, H. Nishino, T. Umeyama, H. Imahori, S. Ito, Light stability tests of methylammonium and formamidinium Pb-halide perovskites for solar cell applications, Jpn. J. Appl. Phys. 54 (2015) 08KF08.

[283] O. Almora, I. Zarazua, E. Mas-Marza, I. Mora-Sero, J. Bisquert, G. GarciaBelmonte, Capacitive dark currents, hysteresis, and electrode polarization in lead halide perovskite solar cells, J. Phys. Chem. Lett. 6 (2015) 16451652.

[284] J.M. Frost, K.T. Butler, A. Walsh, Molecular ferroelectric contributions to anomalous hysteresis in hybrid perovskite solar cells, APL Mater. 2 (2014) 081506.

[285] R.S. Sanchez, V. Gonzalez-Pedro, J.-W. Lee, N.-G. Park, Y.S. Kang, I. Mora-Sero, J. Bisquert, Slow dynamic processes in lead halide perovskite solar cells. Characteristic times and hysteresis, J. Phys. Chem. Lett. 5 (2014) 23572363.

[286] H.J. Snaith, A. Abate, J.M. Ball, G.E. Eperon, T. Leijtens, N.K. Noel, S.D. Stranks, J.T.W. Wang, K. Wojciechowski, W. Zhang, Anomalous hysteresis in perovskite solar cells, J. Phys. Chem. Lett. 5 (2014) 15111515.

[287] E.L. Unger, E.T. Hoke, C.D. Bailie, W.H. Nguyen, A.R. Bowring, T. Heumüller, M.G. Christoforo, M.D. Mcgehee, Hysteresis and transient behavior in currentvoltage measurements of hybrid-perovskite absorber solar cells, Energy Environ. Sci. 7 (2014) 36903698.

[288] M.A. Green, A. Ho-Baillie, H.J. Snaith, The emergence of perovskite solar cells, Nat. Photonics 8 (2014) 506514.

[289] T. Baikie, Y. Fang, J.M. Kadro, M. Schreyer, F. Wei, S.G. Mhaisalkar, M. Graetzel, T.J. White, Synthesis and crystal chemistry of the hybrid perovskite $\left(\mathrm{CH}_{3} \mathrm{NH}_{3}\right)$ $\mathrm{PbI}_{3}$ for solid-state sensitised solar cell applications, J. Mater. Chem. A 1 (2013) 56285641.

[290] I.P. Swainson, M.G. Tucker, D.J. Wilson, B. Winkler, V. Milman, Pressure response of an organic inorganic perovskite: methylammonium lead bromide, Chem. Mater. 19 (2007) 24012405.

[291] G. Niu, X. Guo, L. Wang, Review of recent progress in chemical stability of perovskite solar cells, J. Mater. Chem. A 3 (2015) 89708980.

[292] G. Niu, W. Li, F. Meng, L. Wang, H. Dong, Y. Qiu, Study on the stability of $\mathrm{CH}_{3} \mathrm{NH}_{3} \mathrm{PbI}_{3}$ films and the effect of post-modification by aluminum oxide in allsolid-state hybrid solar cells, J. Mater. Chem. A 2 (2014) 705710.

[293] J.M. Frost, K.T. Butler, F. Brivio, C.H. Hendon, M. Van Schilfgaarde, A. Walsh, Atomistic origins of high-performance in hybrid halide perovskite solar cells, Nano Lett. 14 (2014) 25842590.

[294] W. Li, W. Zhang, S. Van Reenen, R.J. Sutton, J. Fan, A.A. Haghighirad, M.B. Johnston, L. Wang, H.J. Snaith, Enhanced UV-light stability of planar heterojunction perovskite solar cells with caesium bromide interface modification, Energy Environ. Sci. 9 (2016) 490498

[295] D. Wei, T. Wang, J. Ji, M. Li, P. Cui, Y. Li, G. Li, J.M. Mbengue, D. Song, Photoinduced degradation of lead halide perovskite solar cells caused by the hole transport layer/metal electrode interface, J. Mater. Chem. A 4 (2016) 19911998.

[296] I. Ahmed, A. Fakharuddin, Q. Wali, A.R.B. Zainun, J. Ismail, R. Jose, Mesoporous titania-vertical nanorod films with interfacial engineering for high performance dye-sensitized solar cells, Nanotechnology 26 (2015) 105401.

[297] A. Fakharuddin, A.L. Palma, F. Di Giacomo, S. Casaluci, F. Matteocci, Q. Wali, M. Rauf, A. Di Carlo, T.M. Brown, R. Jose, Solid state perovskite solar modules by vacuum-vapor assisted sequential deposition on $\mathrm{Nd}$ : $\mathrm{YVO}_{4}$ laser patterned rutile nanorods, Nanotechnology 26 (2015) 494002.

[298] X. Dong, X. Fang, M. Lv, B. Lin, S. Zhang, J. Ding, N. Yuan, Improvement of the humidity stability of organic-inorganic perovskite solar cells using ultrathin $\mathrm{Al}_{2} \mathrm{O}_{3}$ layers prepared by atomic layer deposition, J. Mater. Chem. A 3 (2015) 53605367.

[299] A. Emly, E. Kioupakis, A. Van Der Ven, Phase stability and transport mechanisms in Antiperovskite $\mathrm{Li}_{3} \mathrm{OCl}$ and $\mathrm{Li}_{3} \mathrm{OBr}$ superionic conductors, Chem. Mater. 25 (2013) 46634670

[300] S. Guarnera, A. Abate, W. Zhang, J.M. Foster, G. Richardson, A. Petrozza, H.J. Snaith, Improving the long-term stability of perovskite solar cells with a porous $\mathrm{Al}_{2} \mathrm{O}_{3}$ buffer layer, J. Phys. Chem. Lett. 6 (2015) 432437.

[301] I. Hwang, I. Jeong, J. Lee, M.J. Ko, K. Yong, Enhancing stability of perovskite solar cells to moisture by the facile hydrophobic passivation, ACS Appl. Mater. Interfaces 7 (2015) 1733017336

[302] X. Li, M.I. Dar, C. Yi, J. Luo, M. Tschumi, S.M. Zakeeruddin, M.K. Nazeeruddin, H. Han, M. Grätzel, Improved performance and stability of perovskite solar cells by crystal crosslinking with alkylphosphonic acid $\omega$-ammonium chlorides, Nat. Chem. 7 (2015) 703711.

[303] S.S. Reddy, K. Gunasekar, J.H. Heo, S.H. Im, C.S. Kim, D.H. Kim, J.H. Moon, J.Y. Lee, M. Song, S.-H. Jin, Highly efficient organic hole transporting materials for perovskite and organic solar cells with long-term stability, Adv. Mater. 28 (2016) 686693

[304] I.C. Smith, E.T. Hoke, D. Solis-Ibarra, M.D. Mcgehee, H.I. Karunadasa, A layered hybrid perovskite solar-cell absorber with enhanced moisture stability, Angew. Chem. Int. Ed. 126 (2014) 1141411417.

[305] L. Zheng, Y.-H. Chung, Y. Ma, L. Zhang, L. Xiao, Z. Chen, S. Wang, B. Qu, Q. Gong, A hydrophobic hole transporting oligothiophene for planar perovskite solar cells with improved stability, Chem. Commun. 50 (2014) 1119611199.

[306] W. Chen, X. Bao, Q. Zhu, D. Zhu, M. Qiu, M. Sun, R. Yang, Simple planar perovskite solar cells with a dopant-free benzodithiophene conjugated polymer as hole transporting material, J. Mater. Chem. C 3 (2015) 1007010073.

[307] M. Franckevičius, A. Mishra, F. Kreuzer, J. Luo, S.M. Zakeeruddin, M. Grätzel, A dopant-free spirobi[cyclopenta[2,1-b:3,4-b'] dithiophene] based hole-transport material for efficient perovskite solar cells, Mater. Horiz. 2 (2015) 613618.

[308] S. Kazim, F.J. Ramos, P. Gao, M.K. Nazeeruddin, M. Grätzel, S. Ahmad, A dopant free linear acene derivative as a hole transport material for perovskite pigmented solar cells, Energy Environ. Sci. 8 (2015) 18161823.

[309] Q. Luo, Y. Zhang, C. Liu, J. Li, N. Wang, H. Lin, Iodide-reduced graphene oxide with dopant-free spiroOMeTAD for ambient stable and high-efficiency perovskite solar cells, J. Mater. Chem. A 3 (2015) 1599616004.

[310] C. Steck, M. Franckevičius, S.M. Zakeeruddin, A. Mishra, P. Bäuerle, M. Grätzel, A-D-A-type S,N-heteropentacene-based hole transport materials for dopant-free perovskite solar cells, J. Mater. Chem. A 3 (2015) 1773817746.

[311] M.I. Hossain, F.H. Alharbi, N. Tabet, Copper oxide as inorganic hole transport material for lead halide perovskite based solar cells, Sol. Energy 120 (2015) 370380.

[312] B.A. Nejand, V. Ahmadi, H.R. Shahverdi, New physical deposition approach for low cost inorganic hole transport layer in normal architecture of durable perovskite solar cells, ACS Appl. Mater. Interfaces 7 (2015) 2180721818.

[313] K. Zhao, R. Munir, B. Yan, Y. Yang, T. Kim, A. Amassian, Solution-processed inorganic copper(i) thiocyanate (CuSCN) hole transporting layers for efficient p-in perovskite solar cells, J. Mater. Chem. A 3 (2015) 2055420559.

[314] J.H. Yun, I. Lee, T.-S. Kim, M.J. Ko, J.Y. Kim, H.J. Son, Synergistic enhancement and mechanism study of mechanical and moisture stability of perovskite solar cells introducing polyethylene-imine into the $\mathrm{CH}_{3} \mathrm{NH}_{3} \mathrm{PbI}_{3} / \mathrm{HTM}$ interface, $\mathrm{J}$. Mater. Chem. A 3 (2015) 2217622182

[315] J. Cao, J. Yin, S. Yuan, Y. Zhao, J. Li, N. Zheng, Thiols as interfacial modifiers to enhance the performance and stability of perovskite solar cells, Nanoscale 7 (2015) 94439447

[316] M. Kaltenbrunner, G. Adam, E.D. Glowacki, M. Drack, R. Schwodiauer, L. Leonat, D.H. Apaydin, H. Groiss, M.C. Scharber, M.S. White, N.S. Sariciftci, S. Bauer, Flexible high power-per-weight perovskite solar cells with chromium oxide-metal contacts for improved stability in air, Nat. Mater. 14 (2015) 10321039.

[317] H.C. Weerasinghe, Y. Dkhissi, A.D. Scully, R.A. Caruso, Y.-B. Cheng, Encapsulation for improving the lifetime of flexible perovskite solar cells, Nano Energy 18 (2015) 118125.

[318] A. Abate, T. Leijtens, S. Pathak, J. Teuscher, R. Avolio, M.E. Errico, J. Kirkpatrik, J.M. Ball, P. Docampo, I. Mcpherson, H.J. Snaith, Lithium salts as "redox active" p-type dopants for organic semiconductors and their impact in solid-state dyesensitized solar cells, Phys. Chem. Chem. Phys. 15 (2013) 25722579.

[319] H. Bi, Y. Zhang, Influence of the additives in poly(3-hexylthiophene) hole transport layer on the performance of perovskite solar cells, Mater. Lett. 161 (2015) 767769 .

[320] H. Zhang, Y. Shi, F. Yan, L. Wang, K. Wang, Y. Xing, Q. Dong, T. Ma, A dual functional additive for the HTM layer in perovskite solar cells, Chem. Commun. 50 (2014) 50205022

[321] C.-C. Chueh, C.-Z. Li, A.K.-Y. Jen, Recent progress and perspective in solutionprocessed Interfacial materials for efficient and stable polymer and organometal perovskite solar cells, Energy Environ. Sci. 8 (2015) 11601189.

[322] M. Shahbazi, H. Wang, Progress in research on the stability of organometal perovskite solar cells, Sol. Energy 123 (2016) 7487.

[323] J. Cao, Y.-M. Liu, X. Jing, J. Yin, J. Li, B. Xu, Y.-Z. Tan, N. Zheng, Well-defined thiolated nanographene as hole-transporting material for efficient and stable perovskite solar cells, J. Am. Chem. Soc. 137 (2015) 1091410917.

[324] T. Leijtens, T. Giovenzana, S.N. Habisreutinger, J.S. Tinkham, N.K. Noel, B.A. Kamino, G. Sadoughi, A. Sellinger, H.J. Snaith, Hydrophobic organic hole transporters for improved moisture resistance in metal halide perovskite solar cells, ACS Appl. Mater. Interfaces 8 (2016) 59815989.

[325] J. Carrillo, A. Guerrero, S. Rahimnejad, O. Almora, I. Zarazua, E. Mas-Marza, J. Bisquert, G. Garcia-Belmonte, Ionic reactivity at contacts and aging of methylammonium lead triiodide perovskite solar cells, Adv. Energy Mater. 6 (2016) 1502246.

[326] W. Li, H. Dong, L. Wang, N. Li, X. Guo, J. Li, Y. Qiu, Montmorillonite as bifunctional buffer layer material for hybrid perovskite solar cells with protection from corrosion and retarding recombination, J. Mater. Chem. A 2 (2014) 1358713592.

[327] K. Domanski, J.-P. Correa-Baena, N. Mine, M.K. Nazeeruddin, A. Abate, M. Saliba, W. Tress, A. Hagfeldt, M. Grätzel, Not all that glitters is gold: metalmigration-induced degradation in perovskite solar cells, ACS Nano 10 (2016) 63066314.

[328] W. Chen, Y. Wu, Y. Yue, J. Liu, W. Zhang, X. Yang, H. Chen, E. Bi, I. Ashraful, M. Grätzel, L. Han, Efficient and stable large-area perovskite solar cells with inorganic charge extraction layers, Science 350 (2015) 944948.

[329] Y.-K. Wang, Z.-C. Yuan, G.-Z. Shi, Y.-X. Li, Q. Li, F. Hui, B.-Q. Sun, Z.-Q. Jiang, L.-S. Liao, Dopant-free spiro-triphenylamine/fluorene as hole-transporting material for perovskite solar cells with enhanced efficiency and stability, Adv. Funct. Mater. 26 (2016) 13751381.

[330] D.-Y. Lee, S.-I. Na, S.-S. Kim, Graphene oxide/PEDOT: pss composite hole transport layer for efficient and stable planar heterojunction perovskite solar cells, Nanoscale 8 (2016) 15131522.

[331] A.L. Palma, L. Cinà, S. Pescetelli, A. Agresti, M. Raggio, R. Paolesse, F. Bonaccorso, A. Di Carlo, Reduced graphene oxide as efficient and stable hole transporting material in mesoscopic perovskite solar cells, Nano Energy 22 (2016) 349360.

[332] S. Bai, N. Cheng, Z. Yu, P. Liu, C. Wang, X.-Z. Zhao, Cubic: column composite 
structure $\left(\mathrm{NH}_{2} \mathrm{CH}=\mathrm{NH}_{2}\right)_{x}\left(\mathrm{CH}_{3} \mathrm{NH}_{3}\right)_{1}{ }_{x} \mathrm{PbI}_{3}$ for efficient hole-transport materialfree and insulation layer free perovskite solar cells with high stability, Electrochim. Acta 190 (2016) 775779.

[333] Z. Liu, T. Shi, Z. Tang, B. Sun, G. Liao, Using a low-temperature carbon electrode for preparing hole-conductor-free perovskite heterojunction solar cells under high relative humidity, Nanoscale 8 (2016) 70177023.

[334] Z. Su, F. Hou, F. Jin, L. Wang, Y. Li, J. Zhu, B. Chu, W. Li, Hole transporting material-free and annealing-free thermal evaporated planar perovskite solar cells with an ultra-thin $\mathrm{CH}_{3} \mathrm{NH}_{3} \mathrm{PbI}_{3} \mathrm{Cl}_{\mathrm{X}}$ layer, Org. Electron. 26 (2015) 104108.

[335] K. Cao, J. Cui, H. Zhang, H. Li, J. Song, Y. Shen, Y. Cheng, M. Wang, Efficient mesoscopic perovskite solar cells based on the $\mathrm{CH}_{3} \mathrm{NH}_{3} \mathrm{PbI}_{2} \mathrm{Br}$ light absorber, J. Mater. Chem. A 3 (2015) 91169122.

[336] Z. Yu, F. Qi, P. Liu, S. You, K.K. Kondamareddy, C. Wang, N. Cheng, S. Bai, W. Liu, S. Guo, X.-Z. Zhao, A composite nanostructured electron-transport layer for stable hole-conductor free perovskite solar cells: design and characterization, Nanoscale 8 (2016) 58475851.

[337] J.H. Heo, H.J. Han, M. Lee, M. Song, D.H. Kim, S.H. Im, Stable semi-transparent $\mathrm{CH}_{3} \mathrm{NH}_{3} \mathrm{PbI}_{3}$ planar sandwich solar cells, Energy Environ. Sci. 8 (2015) 29222927.

[338] X. Yin, M. Que, Y. Xing, W. Que, High efficiency hysteresis-less inverted planar heterojunction perovskite solar cells with a solution-derived $\mathrm{NiO}_{\mathrm{X}}$ hole contact layer, J. Mater. Chem. A 3 (2015) 2449524503.

[339] G.-W. Kim, G. Kang, J. Kim, G.-Y. Lee, H.I. Kim, L. Pyeon, J. Lee, T. Park, Dopant-free polymeric hole transport materials for highly efficient and stable perovskite solar cells, Energy Environ. Sci. 9 (2016) 23262333.

[340] F. Zhang, X. Liu, C. Yi, D. Bi, J. Luo, S. Wang, X. Li, Y. Xiao, S.M. Zakeeruddin, M. Grätzel, Dopant-free donor (D) $\pi$ D $\pi$ D conjugated hole-transport materials for efficient and stable perovskite solar cells, ChemSusChem 9 (2016) 25782585.

[341] T. Matsui, I. Petrikyte, T. Malinauskas, K. Domanski, M. Daskeviciene, M. Steponaitis, P. Gratia, W. Tress, J.-P. Correa-Baena, A. Abate, A. Hagfeldt, M. Grätzel, M.K. Nazeeruddin, V. Getautis, M. Saliba, Additive-free transparent triarylamine-based polymeric hole-transport materials for stable perovskite solar cells, ChemSusChem 9 (2016) 25672571.

[342] F. Zhang, X. Zhao, C. Yi, D. Bi, X. Bi, P. Wei, X. Liu, S. Wang, X. Li, S.M. Zakeeruddin, M. Grätzel, Dopant-free star-shaped hole-transport materials for efficient and stable perovskite solar cells, Dyes Pigm. 136 (2017) 273277.

[343] B. Koo, H. Jung, M. Park, J.-Y. Kim, H.J. Son, J. Cho, M.J. Ko, Pyrite-based Bifunctional layer for long-term stability and high-performance of organo-lead halide perovskite solar cells, Adv. Funct. Mater. 26 (2016) 54005407.

[344] H.-C. Liao, T.L.D. Tam, P. Guo, Y. Wu, E.F. Manley, W. Huang, N. Zhou, C.M.M. Soe, B. Wang, M.R. Wasielewski, L.X. Chen, M.G. Kanatzidis, A. Facchetti, R.P.H. Chang, T.J. Marks, Dopant-free hole transporting polymers for high efficiency, environmentally stable perovskite solar cells, Adv. Energy Mater. 6 (2016) 1600502.

[345] G. Gong, N. Zhao, J. Li, F. Li, J. Chen, Y. Shen, M. Wang, G. Tu, F4TCNQ-doped DEPT-SC as hole transporting material for stable perovskite solar cells, Org. Electron. 35 (2016) $171 \quad 175$

[346] J. Zhang, B. Xu, M.B. Johansson, N. Vlachopoulos, G. Boschloo, L. Sun, E.M.J. Johansson, A. Hagfeldt, Strategy to boost the efficiency of mixed-ion perovskite solar cells: changing geometry of the hole transporting material, ACS Nano 10 (2016) 68166825.

[347] P.-L. Qin, H.-W. Lei, X.-L. Zheng, Q. Liu, H. Tao, G. Yang, W.-J. Ke, L.-B. Xiong, M.-C. Qin, X.-Z. Zhao, G.-J. Fang, Copper-doped chromium oxide hole-transporting layer for perovskite solar cells: interface engineering and performance improvement, Adv. Mater. Interfaces 3 (2016) 1500799.

[348] F. Wang, M. Endo, S. Mouri, Y. Miyauchi, Y. Ohno, A. Wakamiya, Y. Murata, K. Matsuda, Highly stable perovskite solar cells with an all-carbon hole transport layer, Nanoscale 8 (2016) 1188211888.

[349] C.-Y. Chen, J.-H. Chang, K.-M. Chiang, H.-L. Lin, S.-Y. Hsiao, H.-W. Lin, Perovskite Photovoltaics for Dim-Light Applications, Adv. Funct. Mater. 25 (2015) 70647070

[350] F. Di Giacomo, V. Zardetto, G. Lucarelli, L. Cinà, A. Di Carlo, M. Creatore T.M. Brown, Mesoporous perovskite solar cells and the role of nanoscale compact layers for remarkable all-round high efficiency under both indoor and outdoor illumination, Nano Energy 30 (2016) 460469. 